Sandro Luis Vatanabe

\title{
Estudo de Viabilidade de Atuadores Piezelétricos Bilaminares para Bombeamento de Líquidos
}


Sandro Luis Vatanabe

\section{Estudo de Viabilidade de Atuadores Piezelétricos Bilaminares para Bombeamento de Líquidos}

Dissertação apresentada à Escola Politécnica da Universidade de São Paulo para obtenção do Título de Mestre em Engenharia Mecânica. 
Sandro Luis Vatanabe

\section{Estudo de Viabilidade de Atuadores Piezelétricos Bilaminares para Bombeamento de Líquidos}

Dissertação apresentada à Escola Politécnica da Universidade de São Paulo para obtenção do Título de Mestre em Engenharia Mecânica.

Área de concentração:

Engenharia de Controle e Automação Mecânica

Orientador:

Prof. Dr. Emílio Carlos Nelli Silva 
Este exemplar foi revisado e alterado em relação à versão original, sob responsabilidade única do autor e com a anuência de seu orientador.

São Paulo, de dezembro de 2008.

Assinatura do autor

Assinatura do orientador

\section{FICHA CATALOGRÁFICA}

\section{Vatanabe, Sandro Luis}

Estudo de viabilidade de atuadores piezelétricos bilaminares para bombeamento de líquidos / S.L. Vatanabe. -- ed.rev. -- São Paulo, 2008.

84 p.

Dissertação (Mestrado) - Escola Politécnica da Universidade de São Paulo. Departamento de Engenharia Mecatrônica e de Sistemas Mecânicos.

1.Dinâmica dos fluídos 2.Método dos elementos finitos 3.Atuadores piezelétricos I.Universidade de São Paulo. Escola Politécnica. Departamento de Engenharia Mecatrônica e de Sistemas Mecânicos II.t. 
Dedico este trabalho aos meus pais, Luiz Carlos e Fujika, exemplos admiráveis da divina virtude do trabalho, por me apoiar, acreditar em meu potencial e incentivar-me na busca de novas realizações. 


\section{Agradecimentos}

Ao meu orientador, Prof. Dr. Emílio Carlos Nelli Silva, pela atenção dispensada, discussões estimuladas e sugestões dadas durante todo o período de elaboração desta dissertação. Os anos de convívio me proporcionaram enorme amadurecimento acadêmico, pessoal e profissional.

Minha sincera gratidão à minha mãe Fujika Nagano Vatanabe, ao meu pai Luiz Carlos Vatanabe e à minha irmã Francina Vatanabe, pela educação que vocês me deram, pela formação que vocês me proporcionaram e pelo apoio incondicional em todos os meus sonhos.

À minha namorada Priscila Hiromi Shiroma, agradeço pelo amor, carinho, colaboração e paciência durante todo o período deste trabalho.

Ao grande amigo Andres Choi, pelo enorme auxílio prestado na realização deste trabalho, além da amizade e apoio nas horas difíceis.

Ao amigo Claudinei Gil Feitosa, pela usinagem dos protótipos utilizados neste trabalho e pela amizade fortificada durante este período.

Aos amigos da pós-graduação Erick Wakamoto Takarabe, Ronny Calixto Carbonari, Marco Aurélio Brizzotti Andrade, Cícero Ribeiro de Lima, Cesar Yukishigue Kiyono, Fausto Kenzo Chinen, Rodrigo Bellizia Polastro, Vitor Pereira Faria, Adriano Akio Koga, Ramon Vieira Canales e Luiz Augusto Motta Mello pelas discussões acadêmicas e pela amizade e companheirismo.

À FAPESP (Fundação de Amparo à Pesquisa do Estado de São Paulo) pela concessão de bolsa de mestrado. 


\section{Resumo}

As bombas de fluxo, além das aplicações clássicas em Engenharia, são instrumentos importantes em áreas como a Bioengenharia, seja para o bombeamento de sangue ou dosagem de reagentes e medicamentos, e na área de refrigeração de equipamentos eletrônicos. Muitos dos novos princípios aplicados no desenvolvimento desse tipo de bomba de fluxo baseiam-se no uso de atuadores piezelétricos. Esses atuadores apresentam certas vantagens em relação a outros tipos tradicionalmente utilizados, como maior potencial de miniaturização, menor geração de ruídos e número reduzido de partes móveis. Entre os vários tipos de bombas de fluxo piezelétricas destacam-se as baseadas nos movimentos ondulatórios e oscilatórios, como o nadar dos peixes. É bem conhecido que os peixes ao nadarem não provocam a morte de micro-organismos ao seu redor, o que torna esse princípio bem promissor para as aplicações em Biotecnologia, por exemplo. Assim, o presente trabalho de mestrado dedica-se ao estudo de novas configurações de atuadores piezelétricos bilaminares associados em paralelo e série para bombeamento de líquidos através do princípio oscilatório, a fim de se obter maiores vazões ou pressões. O escopo deste projeto abrange, computacionalmente, análises estruturais de atuadores piezelétricos bilaminares e simulações do escoamento de fluido e, experimentalmente, construções de protótipos para validação de resultados. Inicialmente é investigado o comportamento de um único atuador piezelétrico bilaminar em fluido viscoso (água), a fim de se dominar o princípio de funcionamento proposto neste trabalho. Esse estudo serviu de referência para as configurações de atuadores em série e paralelo propostas. Espera-se que a configuração dos atuadores em paralelo apresente um ganho na vazão de saída, enquanto que a configuração dos atuadores em série apresente um ganho na pressão de saída. Ao longo desta dissertação são apresentadas a metodologia empregada e as discussões dos resultados obtidos, de forma a analisar o princípio proposto e os fenômenos físicos em questão. 


\section{Abstract}

Flow pumps, in addition to traditional applications in Engineering, are important tools in areas such as Bioengineering, applied to blood pumping, dosage of medicine and chemical reagents, and in the field of thermal management solutions for electronic devices. Many of the new principles in flow pumps development are based on the use of piezoelectric actuators. These actuators present some advantages in relation to other applied types, for example, miniaturization potential, lower noise generation and fewer numbers of moving parts. Flow pumps based on undulatory and oscillatory movements, such as fish swimming, stand out among the various types of piezoelectric flow pumps. It is well known that fish swimming does not cause the death of microorganisms, what makes this principle applicable in Biotechnology, for example. Thus, the objective of this work is to study parallel-cascade configurations of bimorph piezoelectric actuators for liquid pumping based on the oscillatory principle, in order to obtain higher flow rates and pressure. The scope of this work includes structural and analyses of bimorph piezoelectric actuators and fluid flow simulations, and construction of prototypes for result validation. First, it is investigated the behavior of a single bimorph piezoelectric actuator oscillating in viscous fluid (water) to better understand the working principle used in this work. The study of a single piezoelectric actuator was used as a reference for the other proposed parallel-cascade configurations of actuators. It is expected that parallel actuators achieve higher flow rates, while the series actuators achieve higher pressures. The methods employed are presented and the obtained results are discussed, analyzing the principle and the related physical phenomena. 


\section{Conteúdo}

\section{Lista de Figuras}

\section{Lista de Tabelas}

\section{Lista de Abreviaturas}

1 INTRODUÇÃO

1.1 Princípio de Bombeamento de Líquidos . . . . . . . . . . . . . . . . . . . . 2

1.2 Princípio de Bombeamento de Líquidos Utilizando Atuadores Piezelétricos 3

1.2.1 Princípio Bomba de Fluxo Piezelétrica de Diafragma ou Pistão . . . 4

1.2.2 Princípios Oscilatório e Ondulatório . . . . . . . . . . 5

1.3 Motivação . . . . . . . . . . . . . . . . . . . . . . . . . . . . . . 9

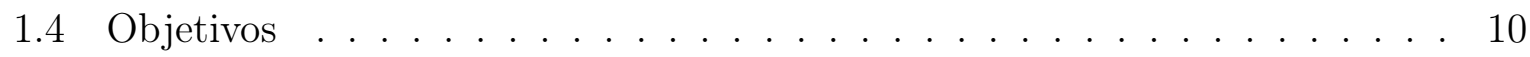

2 FUNDAMENTAÇÃO TEÓRICA 11

2.1 Cerâmicas Piezelétricas . . . . . . . . . . . . . . . . . . . . 11

2.2 Atuadores Piezelétricos Bilaminares . . . . . . . . . . . . . . . . 13

2.3 Modelagem Numérica . . . . . . . . . . . . . . . . . . . . . . . . . 14

2.3.1 MEF Piezelétrico . . . . . . . . . . . . . . . . . 15

2.3.2 Modelagem de Dinâmica dos Fluidos . . . . . . . . . . . . . . . . . 19

3 MODELAGEM COMPUTACIONAL 20

3.1 Descrição dos Elementos Utilizados no ANSYS . . . . . . . . . . . . . . 20 
3.2 Condições de Contorno Móveis . . . . . . . . . . . . . . . . . . . . . . . . . 22

3.3 Linguagem APDL . . . . . . . . . . . . . . . . . . . . . . 23

4 BOMBA DE FLUXO PIEZELÉTRICA COM UM ÚNICO ATUADOR 24

4.1 Simulação Acústica . . . . . . . . . . . . . . . . . . . 25

4.2 Simulação do Escoamento de Fluido . . . . . . . . . . . . . . . . . . . . . 29

4.3 Verificação Experimental . . . . . . . . . . . . . . . . . . . . 33

5 BOMBA DE FLUXO PIEZELÉTRICA COM DOIS ATUADORES EM PARALELO

5.1 Configuração dos Atuadores em Paralelo . . . . . . . . . . . . . . . . . 41

5.2 Simulação Acústica . . . . . . . . . . . . . . . . . . . . . . . . . . 42

5.3 Simulação de Escoamento de Fluido . . . . . . . . . . . . . . . . . 45

5.4 Verificação Experimental . . . . . . . . . . . . . . . . . . 49

6 BOMBA DE FLUXO PIEZELÉTRICA COM DOIS ATUADORES EM SÉRIE

6.1 Configuração dos Atuadores em Série . . . . . . . . . . . . . . 55

6.2 Simulação Acústica . . . . . . . . . . . . . . . . . . . . . 55

6.3 Simulação do Escoamento de Fluido . . . . . . . . . . . . . . . . 58

6.4 Verificação Experimental . . . . . . . . . . . . . . . . 61

7 CONCLUSÕES $\quad 66$

7.1 Sugestões de Trabalhos Futuros . . . . . . . . . . . . . . . . 68

$\begin{array}{ll}\text { Referências } & 69\end{array}$

Apêndice A - Programas em APDL $\quad 73$

A.1 Simulação acústica de um único atuador . . . . . . . . . . . . . . . . 73 
A.2 Simulação acústica de dois atuadores em paralelo . . . . . . . . . . . 76

A.3 Simulação acústica de dois atuadores em série . . . . . . . . . . . . . . . 80 


\section{Lista de Figuras}

1.1 Classificação de bombas e microbombas (LASER; SANTIAGO, 2004). . . . . 3

1.2 Bomba piezelétrica de diafragma. . . . . . . . . . . . . . . . 4

1.3 Bomba piezelétrica de diafragma sem válvulas. . . . . . . . . . . . . . 5

1.4 Princípio de funcionamento da bomba de fluxo oscilatória proposta. . . . . 5

1.5 Modos de nadar dos peixes. As áreas hachuradas contribuem para a locomoção . . . . . . . . . . . . . . . . . . . 6

1.6 (a) Esteira de Karman para um cilindro; (b) rastro deixado pelo nadar de um peixe. ......................... 7

1.7 Vista superior da formação em um cardume. . . . . . . . . . . . . . . . . . 7

1.8 (a) Geração de vórtices por um atuador bilaminar; (b) Esquema de um atuador piezelétrico bilaminar. . . . . . . . . . . . . . . . . . 8

1.9 Exemplo de uma bomba de fluxo ondulatória ultra-sônica. . . . . . . . . . 8

2.1 Efeitos (a) longitudinais e (b) transversais das cerâmicas piezelétricas. . . . 12

2.2 Atuador piezelétrico bilaminar. . . . . . . . . . . . . . . . . . . 14

3.1 Abordagem utilizada nas simulações. . . . . . . . . . . . . . . . . . . 21

3.2 Exemplo de malha de elementos em tempos diferentes utilizando ALE. . . 22

4.1 Desenho esquemático e dimensões do modelo acústico adotado. . . . . . . . 26

4.2 Condições de contorno aplicadas no modelo acústico. . . . . . . . . . . . . 27

4.3 Segundo modo de vibrar do atuador piezelétrico na água: (a) $1^{\circ}$ modo (20

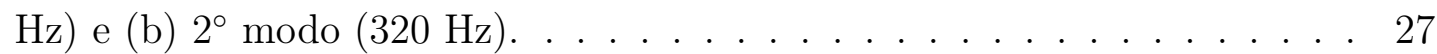


4.4 (a)Curvas de impedância elétrica do atuador imerso em água para o segundo modo de vibrar; (b) Curva de amplitude pico-a-pico da extremidade livre do atuador piezelétrico. . . . . . . . . . . . . . . 28

4.5 Gráfico da equação polinomial obtida da análise acústica para o segundo modo de vibrar. . . . . . . . . . . . . . . . . . . . . . . 29

4.6 Desenho esquemático e dimensões do modelo fluídico adotado. . . . . . . . 30

4.7 Malha de elementos finitos do modelo fluídico e condições de contorno utilizadas. . . . . . . . . . . . . . . . . . . . 30

4.8 Distribuição dos vetores de velocidade no instante 1,52 s. . . . . . . . . . 31

4.9 Gráfico da vazão média em função do tempo obtido computacionalmente para a freqüência de $320 \mathrm{~Hz} \ldots$. . . . . . . . . . . . . . . . 32

4.10 Gráfico de vazões médias em função da freqüência, computacional e experimental. . . . . . . . . . . . . . . . . . . 32

4.11 Distribuição de pressão ao longo do canal obtida computacionalmente para o instante $1,75 \mathrm{~s} . \ldots \ldots \ldots . \ldots \ldots . \ldots \ldots$

4.12 Detalhe da distribuição de pressão na ponta do atuador e vetores de

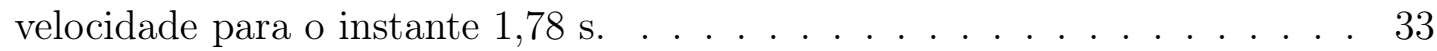

4.13 Gráfico de pressões médias máximas em função da freqüência, computacional e experimental. . . . . . . . . . . . . . . . . 34

4.14 Desenho de montagem do protótipo fabricado. . . . . . . . . . . . . 34

4.15 Desenho esquemático da conexão elétrica para aplicação da tensão no atuador. 35

4.16 Esquema de medição experimental da vazão. . . . . . . . . . . . . . . . . 36

4.17 Desenho esquemático das ondas geradas nas superfícies do atuador piezelétrico. . . . . . . . . . . . . . . . . . . . 37

4.18 Imagens dos testes experimentais de medição de vazão realizados utilizando o protótipo fabricado. . . . . . . . . . . . . . . . . . . 38

4.19 Imagem do teste experimental para medição de coluna d'água gerada pelo protótipo. . . . . . . . . . . . . . . . . . 39

5.1 Atuadores em paralelo excitados em: (a) fase; (b) defasados de $180^{\circ} \ldots$. . . 42 
5.2 Desenho esquemático e dimensões do modelo acústico adotado. . . . . . . . 42

5.3 Condições de contorno aplicadas no modelo acústico. . . . . . . . . . . . . 44

5.4 Segundo modo de vibrar $(325 \mathrm{~Hz})$ dos atuadores piezelétricos em paralelo, imersos na água, excitados em: (a) fase e (b) defasados de $180^{\circ}$. . . . . . 44

5.5 (a)Curva de impedância elétrica dos atuadores em paralelo, imersos em água, quando excitados em fase (segundo modo de vibrar); (b) Curva de amplitude pico-a-pico das extremidades livres dos atuadores piezelétricos. . 45

5.6 Desenho esquemático e dimensões do modelo fluídico adotado para a configuração de dois atuadores em paralelo. . . . . . . . . . . . . . . . . 46

5.7 Malha de elementos finitos do modelo fluídico de dois atuadores em paralelo. 46

5.8 Distribuição dos vetores de velocidade no instante 2,09 s. . . . . . . . . . . 47

5.9 Distribuição dos vetores de velocidade na região dos engastes, no instante 2,09 s. . . . . . . . . . . . . . . . . . . . . . . . . . 48

5.10 Distribuição da pressão e dos vetores de velocidade na região das extremidades dos atuadores, no instante 2,09 s. . . . . . . . . . . . . 49

5.11 Gráfico da vazão média em função do tempo utilizando dois atuadores em paralelo para freqüência de $335 \mathrm{~Hz}$. . . . . . . . . . . . . . . . . . . . . . 49

5.12 Gráfico da vazão média variando a distância entre os atuadores $\left(H_{\text {gap }}\right)$. . . 50

5.13 Gráfico da vazão média em função da freqüência utilizando dois atuadores em paralelo. . . . . . . . . . . . . . . . . . . . 50 50

5.14 Curva de pressão média máxima em função da freqüência. . . . . . . . . . . 51

5.15 Imagem do protótipo de dois atuadores em paralelo. . . . . . . . . . . . 51

5.16 Imagens dos testes experimentais para medição de vazão realizados utilizando o protótipo de atuadores em série. . . . . . . . . . . . . . . 52

5.17 Imagem do teste experimental para medição de coluna d'água gerada pelo protótipo de atuadores em paralelo. . . . . . . . . . . . . . . . . 53

5.18 Comparação das vazões geradas pelo (a) dois modelos de um único atuador em paralelo e pelo (b) modelo de dois atuadores em paralelo. . . . . . . . . 54 
6.1 Desenho esquemático e dimensões do modelo acústico adotado. . . . . . . . 56

6.2 Condições de contorno aplicadas no modelo acústico. . . . . . . . . . . . 56

6.3 (a)Curva de impedância elétrica dos atuadores em série, imersos em água, no segundo modo de vibrar; (b) Curva de amplitude pico-a-pico das extremidades livres dos atuadores piezelétricos. . . . . . . . . . . . 57

6.4 Desenho esquemático e dimensões do modelo fluídico adotado para a configuração de dois atuadores em série. . . . . . . . . . . . . . 58

6.5 Malha de elementos finitos do modelo fluídico de dois atuadores em série. . 59

6.6 Gráfico da vazão média em função do tempo utilizando dois atuadores em paralelo. . . . . . . . . . . . . . . . . . . 6 6 60

6.7 Gráfico da vazão média variando a distância entre os atuadores $\left(L_{\text {gap }}\right)$. . 60

6.8 Gráfico da pressão média na saída variando a distância entre os atuadores

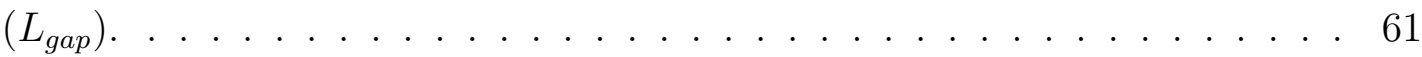

6.9 Gráfico da vazão média em função da freqüência utilizando dois atuadores em série. . . . . . . . . . . . . . . . . . . . . . 61

6.10 Curva de pressão média máxima em função da freqüência. . . . . . . . . . 62

6.11 Imagem do protótipo de dois atuadores em série. . . . . . . . . . . . . . 63

6.12 Imagens dos testes experimentais para medição de vazão realizados utilizando o protótipo de atuadores em série. . . . . . . . . . . . . . . 63

6.13 Imagem do teste experimental para medição de coluna d'água gerada pelo protótipo de atuadores em série. . . . . . . . . . . . . . . . . . . . 64

6.14 Comparação das vazões geradas pelo (a) dois modelos de um único atuador em série e pelo (b) modelo de dois atuadores em série. . . . . . . . . . . . . 65

7.1 Sugestão de estudo: atuadores piezelétricos em forma de cardume. . . . . . 68 


\section{Lista de Tabelas}

4.1 Propriedades dos materiais utilizados nas simulações acústicas. . . . . . . . 26

4.2 Resultados computacionais e experimentais. . . . . . . . . . . . . . 39

5.1 Resultados computacionais e experimentais da configuração em paralelo. . 53

6.1 Resultados computacionais e experimentais da configuração em série. . . . 65 


\section{Lista de Abreviaturas}

2D Duas Dimensões

3D Três Dimensões

ALE Arbitrary Lagrangian-Eulerian

APDL ANSYS Parametric Design Language

CAD Computer-Aided Design

CFD Computational Fluid Dynamics

FSI Fluid-Structure Interaction

MEF Método de Elementos Finitos

PZT Titanato Zircanato de Chumbo

PZT5A Titanato Zircanato de Chumbo 


\section{INTRODUÇÃO}

Bombas de fluxo de precisão têm sido estudadas no mundo inteiro em diversas áreas ao longo das últimas duas décadas. Elas constituem uma categoria de bombas de pequena potência (em geral, também de pequenas dimensões, da ordem de milímetros) para deslocamento de pequenos volumes de fluido, podendo ser aplicadas como componente essencial de diversos sistemas, tais como sistemas de resfriamento de componentes eletrônicos (YOO; HONG; CAO, 2000), dosadores de reagentes e medicamentos (TEYMOORI; ABBASPOUR-SANI, 2005) e sistemas de bombeamento de fluidos biológicos (ANDRADE et al., 1996).

A Bioengenharia é uma das áreas que tem demonstrado grande interesse nessa tecnologia, pois as atuais técnicas de bombeamento (peristáltica e centrífuga) apresentam elevadas taxas de hemólise (morte das hemáceas), sendo prejudicial ao paciente (YANO et al., 2003). Para tentar minimizar esse problema uma das abordagens é o estudo de novos princípios de bombeamento. No Brasil, por exemplo, existe a proposta da Bomba Espiral de Andrade et al. (ANDRADE et al., 1996) desenvolvida para utilização em circulação extra-corpórea e que combina o princípio de duas bombas já conhecidas: a axial e a radial. Nesta linha investiga-se também a utilização de bombas de fluxo piezelétricas como um método de bombeamento de fluido menos turbulento em relação aos métodos tradicionais, que pode contornar os problemas presentes nas atuais técnicas de bombeamento de fluidos biológicos, como a morte de micro-organismos ou células contidas no fluido devido à pressão a que o fluido é submetido ou mesmo à turbulência no escoamento.

Bombas de fluxo piezelétricas também podem ser utilizadas para dosagem de reagentes e medicamentos, como por exemplo, injeção contínua de insulina em pacientes diabéticos, dentre outras possíveis aplicações (TEYMOORI; ABBASPOUR-SANI, 2005; KAR et al., 1998).

Outra potencial aplicação prática para esta categoria de bombas de fluxo reside na indústria eletrônica, como componentes essenciais em sistemas de resfriamento de 
equipamentos eletrônicos (GARIMELLA; SINGHAL; LIU, 2006).

Sistemas de refrigeração a água de processadores em microcomputadores de alto desempenho vêm sendo desenvolvidos nos últimos anos como alternativa aos métodos convencionalmente utilizados que consistem no uso de ventilação a ar, compostos por um dissipador de calor e um pequeno ventilador. Muitas vezes estes sistemas tradicionais não são dimensionados adequadamente, o que torna o equipamento eletrônico instável, podendo, conseqüentemente, ocasionar a sua falha. Frente a esses e outros problemas da atual técnica de resfriamento por meio de ventilação, os sistemas de resfriamento a água oferecem como diferenciais, maior capacidade de dissipação térmica, redução na emissão de ruídos, potencial de miniaturização, menor vibração mecânica, além de um número reduzido de peças e partes móveis. No Brasil os sistemas de refrigeração a água de processadores ainda não são utilizados amplamente pelos fabricantes de microcomputadores de alto desempenho e notebooks. Isso ocorre devido ao desconhecimento da nova tecnologia, ao alto custo da mesma por representar ainda uma novidade e poucas empresas a dominarem, e ainda pelo fato dos métodos tradicionais de refrigeração a ar conseguirem dissipar o calor emitido pela maioria dos processadores, embora com os diversos problemas citados anteriormente. No entanto, os processadores estão mais potentes e, conseqüentemente, dissipando mais calor, o que culmina com a crescente complexidade dos sistemas de refrigeração, e esses, por sua vez, ocasionam maior emissão de ruídos nos computadores.

Além disso, há ainda uma crescente demanda por tecnologias que se adeqüem à tendência de compactação e miniaturização dos computadores pessoais. Frente a esse cenário, novas tecnologias de refrigeração que apresentem essas características, como a baseada em bombas piezelétricas, estão sendo pesquisadas e desenvolvidas por centros de pesquisa e empresas do setor em todo o mundo.

\subsection{Princípio de Bombeamento de Líquidos}

As bombas de fluxo de precisão podem ser classificadas de acordo com o princípio de bombeamento utilizado para gerar vazão e pressão, conforme descrito na Fig. 1.1. Os princípios de diafragma e de corrente acústica são baseados no uso de atuadores piezelétricos (LASER; SANTIAGO, 2004; GARIMELLA; SINGHAL; LIU, 2006), por exemplo. 


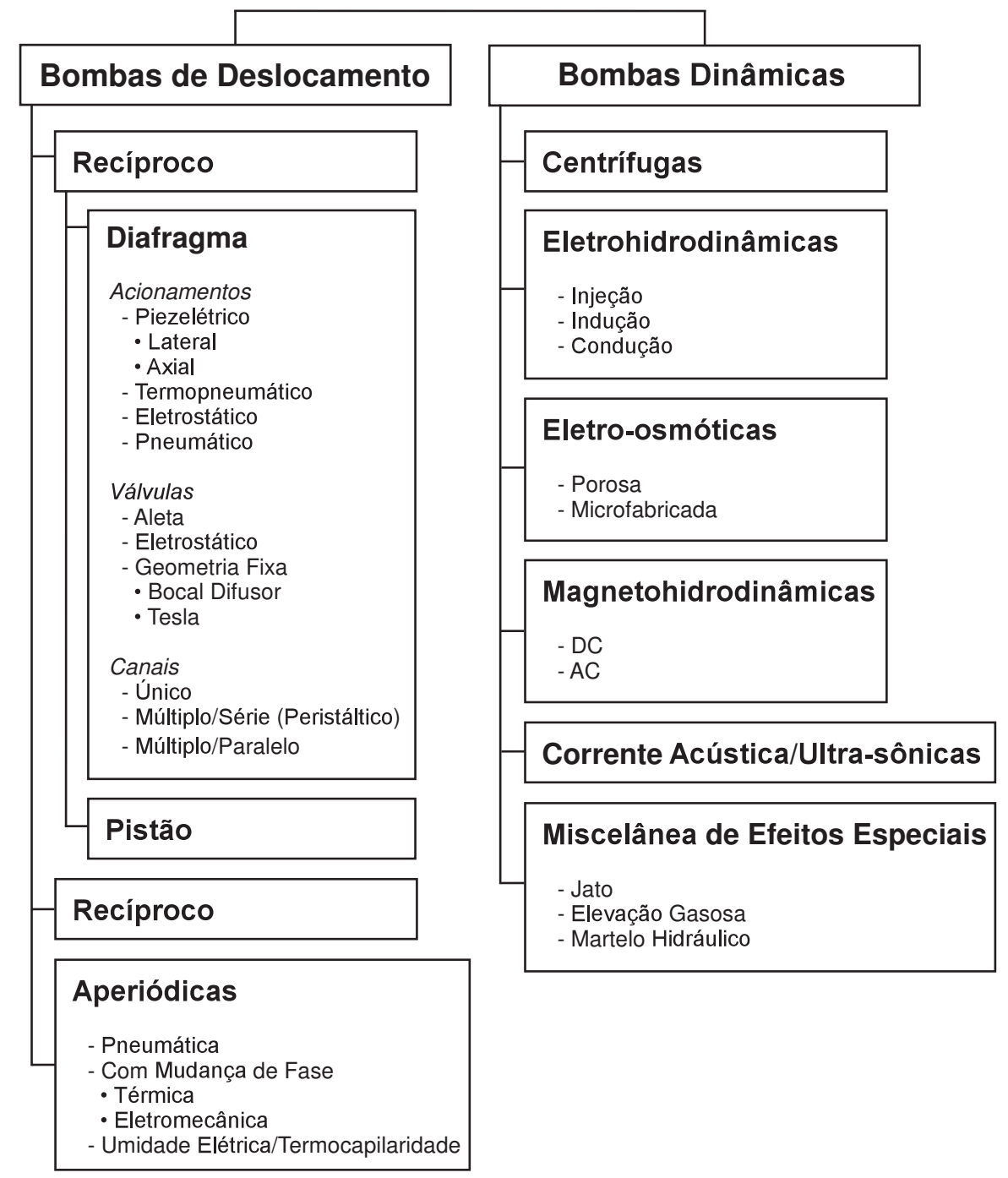

Figura 1.1: Classificação de bombas e microbombas (LASER; SANTIAGO, 2004).

\subsection{Princípio de Bombeamento de Líquidos Utilizando Atuadores Piezelétricos}

Materiais piezelétricos têm a propriedade de converter a energia elétrica (potencial e carga elétricas) em energia mecânica (tensão e deformação mecânicas) e vice-versa (IKEDA, 1996). Em geral, os materiais piezelétricos utilizados em atuadores são cerâmicas como o PZT. Esses atuadores apresentam certas vantagens em relação a outros tipos tradicionalmente utilizados, como por exemplo, maior potencial de miniaturização, menor geração de ruídos e número reduzido de partes móveis.

Bombas de fluxo piezelétricas têm sido amplamente estudadas, sendo que os principais princípios de funcionamento são de diafragma ou pistão (KOCH et al., 1997; 
ULLMANN; FONO; TAITEL, 2001; NGUYEN; TRUONG, 2004), ondulatório (MIYAZAKI; KAWAI; ARARAGI, 1991), oscilatório (ACIKALIN; RAMAN; GARIMELLA, 2003; ACIKALIN et al., 2004; NAKASONE et al., 2005; NAKASONE, 2006; PIRES et al., 2006) e de correnteza acústica (KINSLER et al., 1982).

A seguir, são brevemente descritos os principais tipos de bombas de fluxo piezelétricas.

\subsubsection{Princípio Bomba de Fluxo Piezelétrica de Diafragma ou Pistão}

A bomba piezelétrica com diafragma utiliza o material piezelétrico como atuador para mover uma membrana (diafragma). A direção do fluxo é garantida por válvulas que permitem o fluxo em um único sentido.

A Fig. 1.2 apresenta a cerâmica piezelétrica agindo como um pistão: movendo o diafragma para cima, a válvula de saída se fecha e a válvula de entrada se abre permitindo a entrada de líquido, na situação contrária, com o diafragma descendo, a válvula de entrada se fecha enquanto a de saída se abre, fazendo com que o fluido interno seja expulso. Assim, obtém-se fluxo num único sentido.

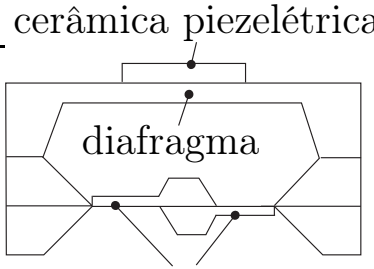

válvulas

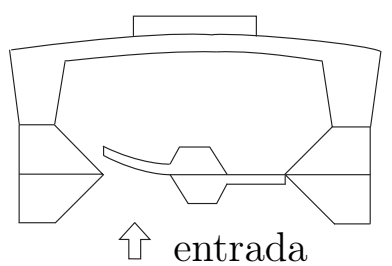

仓 entrada

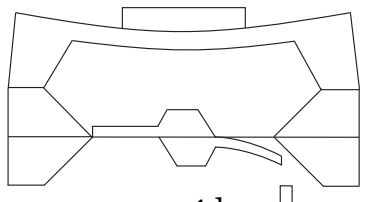

saída

Figura 1.2: Bomba piezelétrica de diafragma.

Esse princípio é estudado por vários pesquisadores, como Koch et al. (KOCH et al., 1997), Ullman et al. (ULLMANN; FOnO; TAITEL, 2001), Nguyen e Truong (NGUYEN; TRUONG, 2004), Mu et al. (MU; HUNG; NGOI, 1999) e Kar et al. (KAR et al., 1998).

Já na Fig. 1.3, vê-se o esquema de uma bomba piezelétrica sem válvulas (valveless), de Ullmann et al. (ULLMANN; FONO; TAITEL, 2001). Seu funcionamento é bastante similar ao caso anterior, onde a cerâmica piezelétrica age como um pistão. A diferença aqui é a ausência de válvulas. A direção do fluxo é conseguida através da geometria difusora nas regiões de entrada e saída do fluido, uma vez que a resistência ao fluxo da esquerda para a direita é menor do que da direita para a esquerda, ocasionando num fluxo resultante no sentido desejado. 

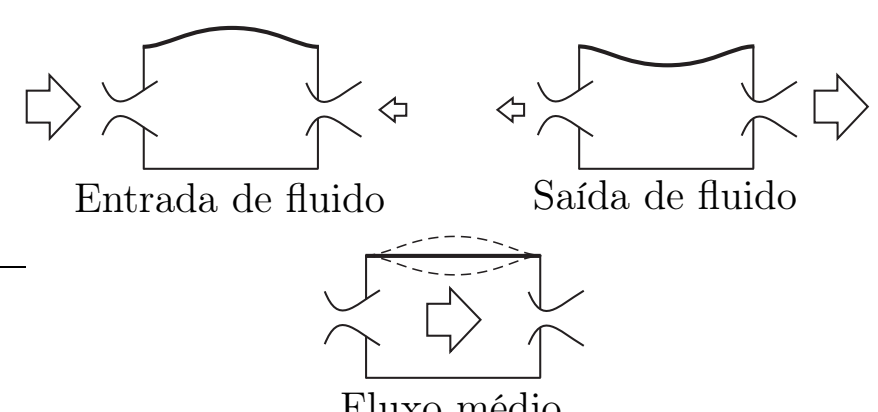

Figura 1.3: Bomba piezelétrica de diafragma sem válvulas.

Uma revisão bibliográfica detalhada sobre princípios de bombas piezelétricas pode ser encontrada em Laser e Santiago (LASER; SANTIAGO, 2004) e Garimella et al.(GARIMELLA; SINGHAL; LIU, 2006).

\subsubsection{Princípios Oscilatório e Ondulatório}

Um princípio que pode minimizar a morte de microorganismos é o princípio de bombeamento baseado em movimentos ondulatórios e oscilatórios, como o nadar de peixes. Para nadar, os peixes realizam movimentos oscilatórios ou ondulatórios, balançando seu corpo ou cauda de forma a se deslocar para frente (ver Fig. 1.4a). Mas o que aconteceria ao mantermos o peixe fixo enquanto ele tenta nadar? Provavelmente teríamos o fluido se movimentando em sentido contrário, ou seja, ele estaria desempenhando o papel de uma bomba de fluxo como descrito na Fig. 1.4b.
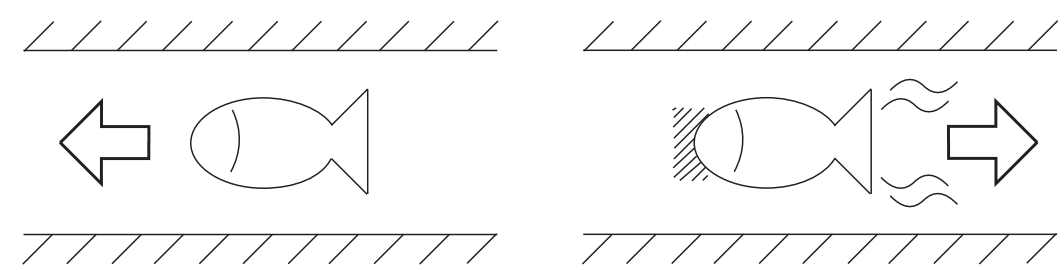

Figura 1.4: Princípio de funcionamento da bomba de fluxo oscilatória proposta.

O princípio de nadar dos peixes é estudado por autores como Videler et al. (VIDELER; MULLER; STAMHUIS, 1999), Tryantafyllou et al. (TRIANTAFYLLOU; TRIANTAFYLlOU; Grosenbaugh, 1993) e Sfakiotakis et al. (SFAKIOTAKIS; LANE; DAVIES, 1999). Como mostrado na Fig. 1.5, o nadar de diferentes espécies de peixe varia entre o princípio ondulatório (por exemplo, enguia, raia) e o princípio oscilatório (peixe de aquário, peixes em geral). Esses princípios também podem estar combinados (por exemplo, tubarão). É bem conhecido que os peixes ao nadarem não provocam a morte de micro-organismos ao 
seu redor, o que torna esse princípio bem promissor para as aplicações em Biotecnologia, por exemplo.

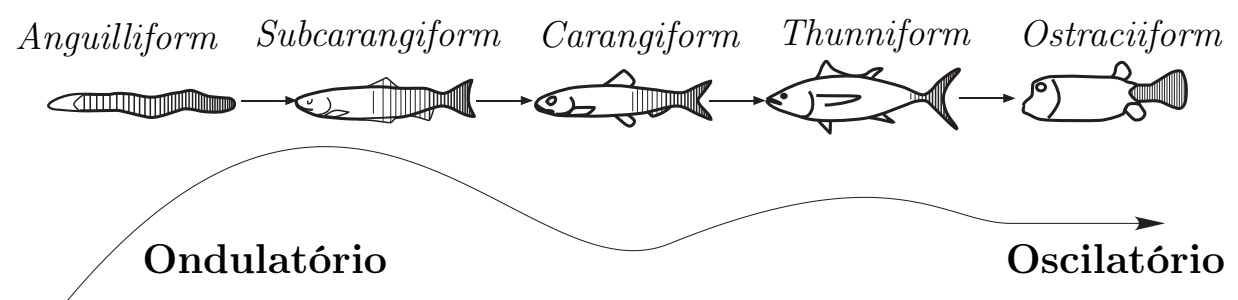

(a) Locomoção por meio de movimentos ao longo do corpo e/ou de nadadeira caudal.

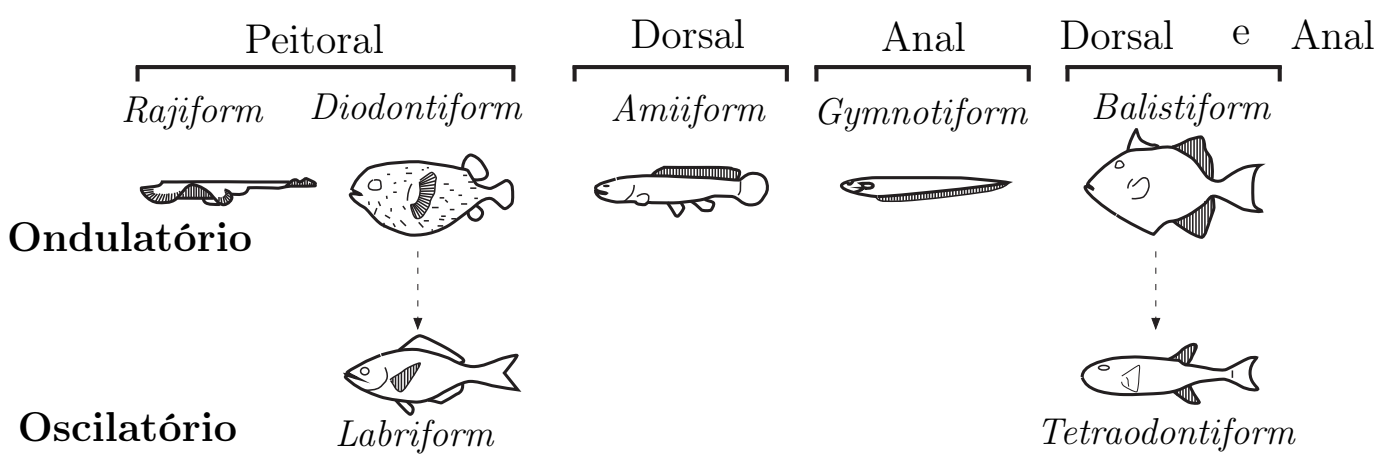

(b) Locomoção por meio de nadadeira mediana e/ou em pares.

Figura 1.5: Modos de nadar dos peixes. As áreas hachuradas contribuem para a locomoção

O rastro deixado pelos peixes que nadam devido a movimentos ondulatórios e/ou oscilatórios de seu corpo e cauda consiste numa esteira de vórtices discretos de sinal alternado, gerados devido ao movimento da cauda (SFAKIOTAKIS; LANE; DAVIES, 1999). Esta esteira de vórtices possui orientação contrária à esteira de vórtices de Karman, a qual produz arrasto (TRIANTAFYLLOU; TRIANTAFYLLOU; GROSENBAUGH, 1993; SFAKIOTAKIS; LANE; DAVIES, 1999), em torno de corpos colocados numa corrente livre (ver Fig. 1.6a e Fig. 1.6b). Na Fig. 1.6c pode-se observar o fluxo gerado entre os vórtices na direção contrária.

A importância deste fato é que cada vórtice gerado impulsiona o que foi gerado anteriormente e o resultado desta interação é a movimentação dos peixes, segundo o princípio da ação e reação.

De acordo com Sfakiotakis et al. (SFAKIOTAKIS; LANE; DAVIES, 1999), é bastante comum em um cardume a formação dos peixes em forma de diamante (ver fig. 1.7). Essa formação é eficiente devido ao impulso gerado pelos vórtices dos peixes frontais aos peixes traseiros. 


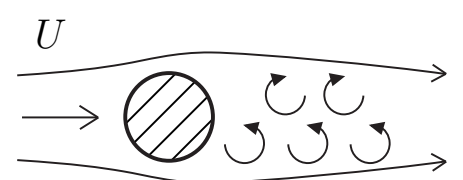

(a)

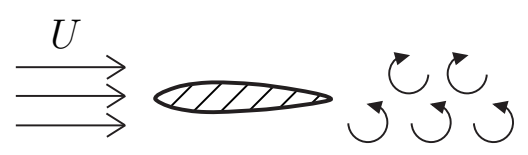

(b)

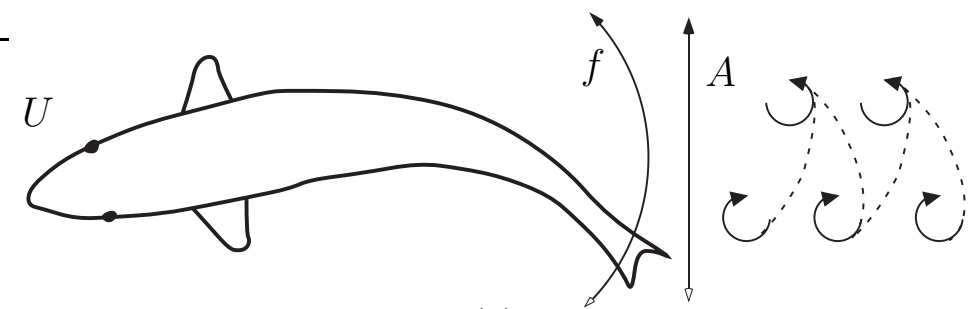

(c)

Figura 1.6: (a) Esteira de Karman para um cilindro; (b) rastro deixado pelo nadar de um peixe.

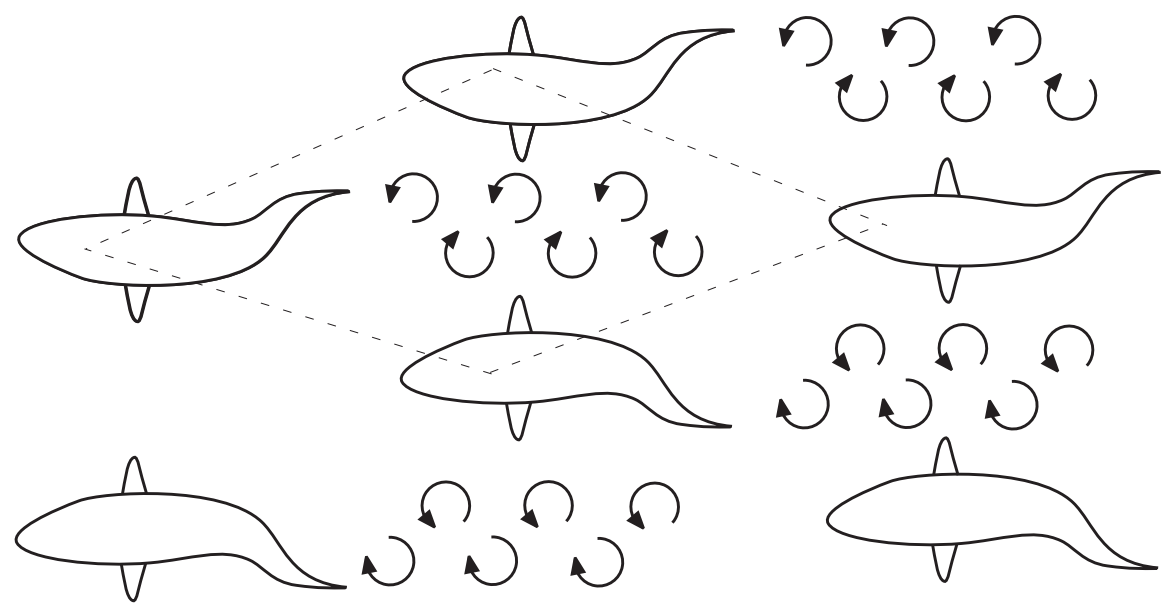

Figura 1.7: Vista superior da formação em um cardume.

Esta mesma formação cíclica de vórtices com sentidos alternados pode ser obtida através de um atuador do tipo bilaminar (ou bimorph), que consiste numa placa engastada que oscila por atuação piezelétrica como descrito na Fig. 1.8a. Esse movimento gera vórtices em sentidos opostos (ver Fig. 1.8b) que provocam a movimentação do fluido no sentido horizontal (IHARA; WATANABE, 1994; KIM; WERELEY; CHUN, 2004)(ver Fig. 1.8c).

Já o movimento ondulatório pode ser obtido através da propagação de uma onda numa placa em contato com o líquido. Essas ondas são geradas por atuadores piezelétricos fixos na placa, como por exemplo na montagem mostrada na fig. Fig. 1.9. A distância entre as cerâmicas é ajustada de maneira que ocorram interferências construtiva em um sentido e destrutiva no outro das ondas geradas pelas cerâmicas piezelétricas, além de haver uma defasagem no tempo entre os sinais gerados nas duas piezocerâmicas. Nas montagens em 


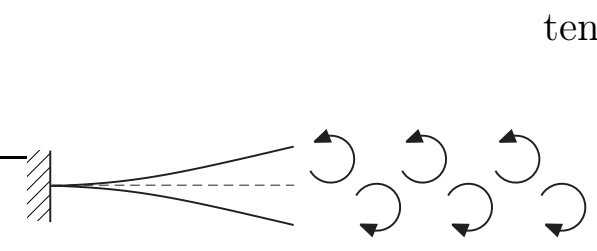

(a) tensão aplicada fluxo

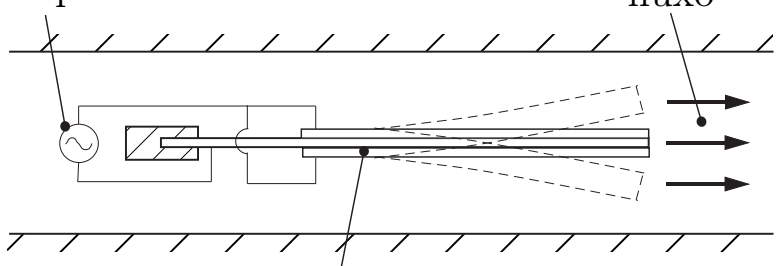

atuador piezelétrico bilaminar

(b)

Figura 1.8: (a) Geração de vórtices por um atuador bilaminar; (b) Esquema de um atuador piezelétrico bilaminar.

geral, são utilizados mais do que um par de cerâmicas para excitar a placa.

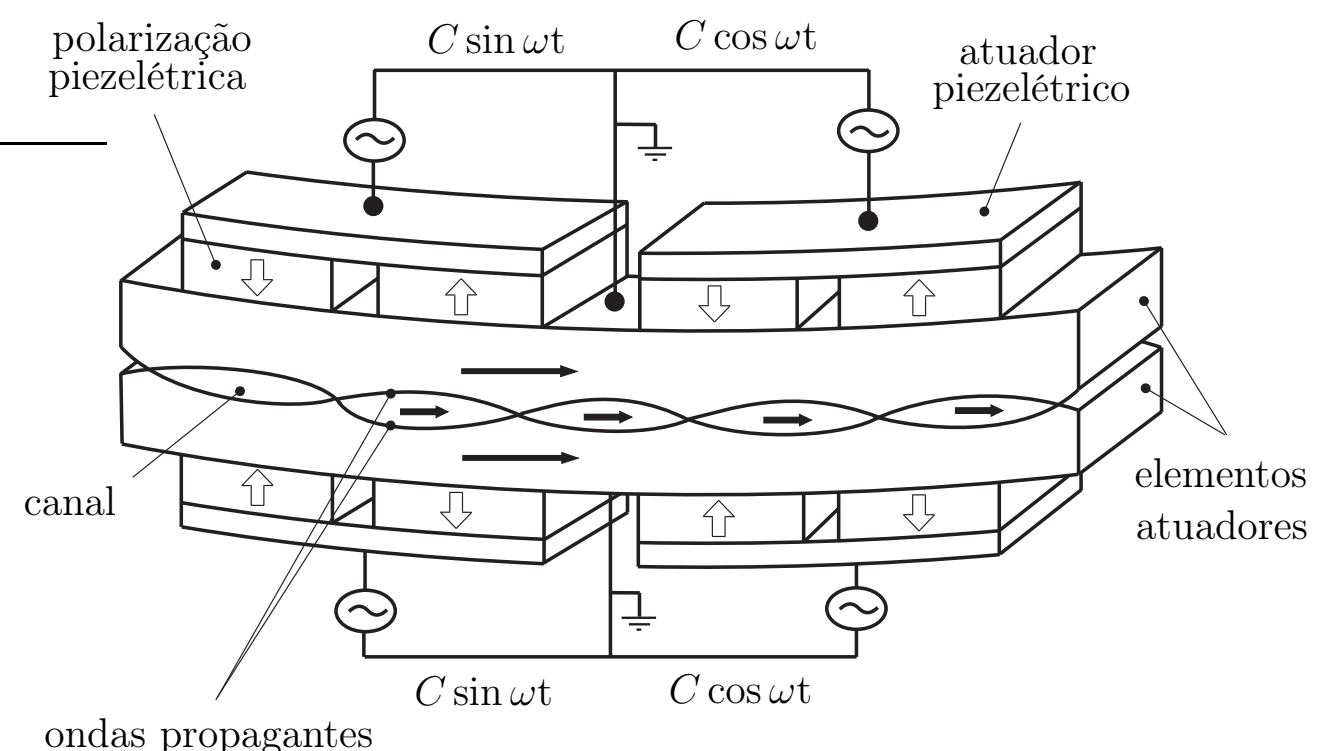

(flecha mostrando a direção da onda)

Figura 1.9: Exemplo de uma bomba de fluxo ondulatória ultra-sônica.

O princípio de bombeamento consiste em, devido ao movimento das ondas propagantes ao longo de um corpo elástico (placa), transmitir ao fluido através da viscosidade o movimento elíptico dos pontos na superfície da placa. Gerando-se a propagação de onda em ambas as paredes de um canal, o movimento do líquido ocorre de forma análoga ao esôfago ou intestino humano como mostrado na Fig. 1.9, porém com amplitudes menores, e numa alta freqüência (MIYAZAKI; KAWAI; ARARAGI, 1991).

Um dos exemplos de bomba de fluxo piezelétrica baseadas nesse princípio é a bomba ultra-sônica de Bar-Cohen e Chang (BAR-COHEN; CHANG, 2001), mostrada na Fig. 1.9 que utiliza estatores circulares. Esse princípio da bomba ultra-sônica piezelétrica também é explorado no conhecido motor ultra-sônico piezelétrico (SASHIDA; KENJO, 1993). O 
efeito de onda propagante também foi explorado por Miyazaki et al. (MIYAZAKI; KAWAI; ARARAGI, 1991), Nguyen e White (NGUYEN; WHITE, 1999) e Henmi et al. (HENMI N.AND OHYAMA et al., 2005).

Outro efeito importante utilizado para o bombeamento de líquidos, e também pouco estudado, é o princípio da correnteza acústica (ou acoustic streaming). De acordo com a teoria acústica linear, durante a propagação de uma onda mecânica em um fluido, as partículas do meio se movem para trás e para frente em torno da posição de equilíbrio (KINSLER et al., 1982). Isso é comprovado através de resultados experimentais para ondas acústicas de baixa intensidade. No entanto, a medida que é aumentada a amplitude da onda, as partículas deixam de apresentar somente comportamento ondulatório e começa a ocorrer escoamento do fluido. O escoamento de um fluido gerado pela passagem de uma onda acústica é chamado de correnteza acústica (acoustic streaming) (NYBORG, 1965).

Todos esses princípios dão origem a bombas de fluxo dinâmicas que produzem vazão com baixíssimas pressões. O princípio baseado no fenômeno oscilatório já vem sendo investigado pelo grupo (NAKASONE; PIRES; SILVA, 2004; PIRES et al., 2005; NAKASONE et al., 2005) como descrito na Fig. 1.8a e tem se mostrado bastante promissor. Um princípio similar, também baseado num atuador bilaminar, tem sido estudado por Bürmann et al. (BURMANN; RAMAN; GARIMELlA, 2002) e Açikalin et al. (ACIKALIN; RAMAN; GARIMELLA, 2003; ACIKALIN et al., 2004), visando aplicações no resfriamento de componentes eletrônicos utilizando ar como fluido refrigerante.

\subsection{Motivação}

Pelo exposto anteriormente, o desenvolvimento de bombas de fluxo de precisão, ou seja, bombas de pequena potência para deslocamento de pequenos volumes de fluido, vem ocorrendo em diversas áreas, como a Bioengenharia e sistemas de refrigeração para equipamentos eletrônicos.

Existem vários princípios de funcionamento de bombas piezelétricas estudados. No entanto, um princípio pouco estudado e que deve minimizar a morte de micro-organismos, como já comentado, é o princípio baseado no nadar de peixes (TRIANTAFYLLOU; TRIANTAFYLLOU; GROSENBAUGH, 1993; SFAKIOTAKIS; LANE; DAVIES, 1999) que varia entre o princípio ondulatório e o princípio oscilatório (ver Fig. 1.5) que podem ser perfeitamente obtidos através de excitação piezelétrica. Na literatura encontram-se alguns 
trabalhos sobre bombas piezelétricas baseados no princípio ondulatório, mas não no princípio oscilatório ou numa combinação de ambos.

Atualmente a utilização de bombas de fluxo piezelétricas em aplicações de microfluídica, sistemas de refrigeração de componentes eletrônicos e na condução de pequenas vazões de líquidos é consenso comum. Assim, o estudo de novos princípios baseado em movimentos oscilatórios trará grandes contribuições nestas áreas.

Trata-se de um tema atual que vem demonstrando grande interesse na comunidade científica em conferências nacionais e internacionais e que ainda é inexplorado no Brasil.

\subsection{Objetivos}

O presente trabalho de mestrado tem como objetivo aplicar a modelagem através do método de elementos finitos para análise de novas configurações de bombas de fluxo piezelétricas baseadas no princípio oscilatório, realizar análises de sensibilidade, bem como construir modelos e protótipo para verificação de seu funcionamento.

Os objetivos específicos deste projeto são:

- Dar continuidade ao trabalho de mestrado de Nakasone (NAKASONE, 2006) no estudo de viabilidade de uma bomba de fluxo baseada em princípios oscilatórios para bombeamento de líquidos utilizando um único atuador piezelétrico bilaminar, considerando água como fluido viscoso na simulações computacionais e realizando novos testes experimentais mais detalhados;

- Estudar a viabilidade de duas novas configurações de bombas de fluxo piezelétricas utilizando dois atuadores piezelétricos bilaminares em paralelo e em série através de simulação computacional;

- Realizar análises de sensibilidade do posicionamento dos atuadores piezelétricos para ambos os casos (paralelo e série) a fim de obter maiores valores de vazão e pressão;

- Validar os resultados obtidos computacionalmente através da construção de protótipos (dimensões da ordem de centímetros) e realização de testes experimentais, utilizando um único atuador, dois atuadores em paralelo e dois atuadores em série. 


\section{FUNDAMENTAÇÃO TEÓRICA}

Abaixo estão descritos os principais conceitos abordados neste trabalho de forma resumida para uma melhor compreensão do trabalho realizado.

\subsection{Cerâmicas Piezelétricas}

Os materiais piezelétricos são materiais específicos que se contraem e se expandem de acordo com a tensão elétrica aplicada em seus terminais e vice-versa, gerando deformação no sentido longitudinal e transversal de acordo com a excitação aplicada, como mostra a Fig. 2.1.

Devido a essa característica, os materiais piezelétricos são geralmente usados em acelerômetros, sensores de pressão e força, transdutores de ultra-som, atuadores, nanoposicionadores, giroscópios, entre outros dispositivos de mecânica de precisão.

As equações constitutivas do efeito piezelétrico são (IKEDA, 1996):

$$
\begin{gathered}
T=\mathbf{c}^{\mathrm{E}} \mathbf{S}-\mathbf{e}^{\mathrm{t}} \mathbf{E} \\
\mathrm{D}=\varepsilon^{\mathrm{S}} \mathbf{E}+\mathbf{e S}
\end{gathered}
$$

onde:

$\mathbf{T}=$ tensor de tensão mecânica;

D = vetor deslocamento elétrico;

$\boldsymbol{c}^{\boldsymbol{E}}=$ tensor de rigidez elástica obtido com campo elétrico constante;

$\mathbf{S}=$ tensor de deformação mecânica;

e = tensor de coeficientes piezelétricos de tensão mecânica;

$\varepsilon^{S}=$ tensor dielétrico medido com deformação constante;

$\mathbf{E}=$ vetor campo elétrico. 


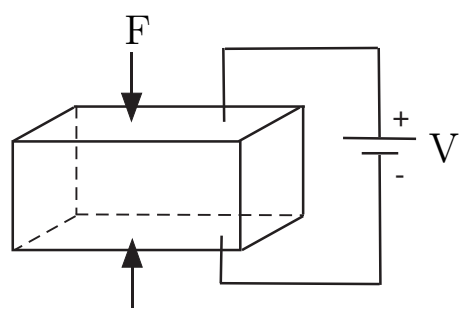

F

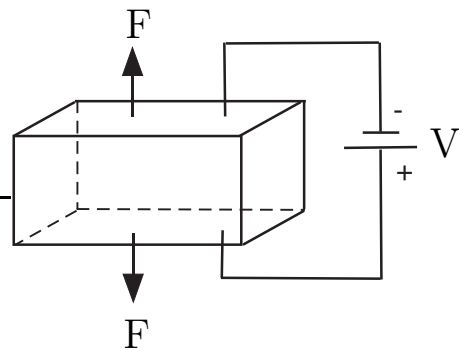

(c)
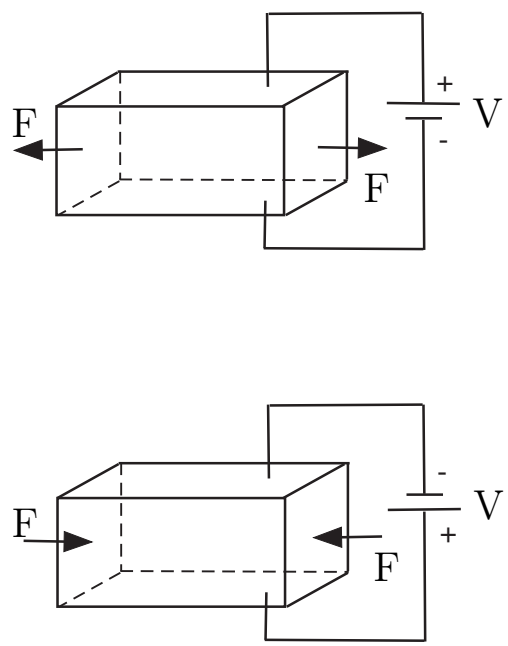

(d)

Figura 2.1: Efeitos (a) longitudinais e (b) transversais das cerâmicas piezelétricas.

Os materiais utilizados neste trabalho são cerâmicas de classe de simetria hexagonal da família 6mm, como os diversos tipos de PZT. De acordo com as normas do IEEE standards (IEEE, 1996), a direção de polarização é a direção do eixo cartesiano z. Para os materiais das classes hexagonais com anisotropia na direção $z$ são mostrados a seguir o tensor piezelétrico $(\mathbf{e})$, o tensor dielétrico $\left(\boldsymbol{\varepsilon}^{\boldsymbol{S}}\right)$ e o tensor de rigidez elástica $\left(\boldsymbol{c}^{\boldsymbol{E}}\right)$ na forma matricial (IKEDA, 1996): 


$$
\begin{aligned}
& \mathbf{e}=\left[\begin{array}{cccccc}
0 & 0 & 0 & 0 & e_{15} & 0 \\
0 & 0 & 0 & e_{15} & 0 & 0 \\
e_{31} & e_{31} & e_{33} & 0 & 0 & 0
\end{array}\right] \\
& \boldsymbol{\varepsilon}_{\boldsymbol{D}}^{\boldsymbol{S}}=\left[\begin{array}{ccc}
\varepsilon_{D_{11}} & 0 & 0 \\
0 & \varepsilon_{D_{11}} & 0 \\
0 & 0 & \varepsilon_{D_{33}}
\end{array}\right] \\
& \mathbf{c}^{E}=\left[\begin{array}{cccccc}
c_{11} & c_{12} & c_{13} & 0 & 0 & 0 \\
c_{12} & c_{22} & c_{13} & 0 & 0 & 0 \\
c_{13} & c_{13} & c_{33} & 0 & 0 & 0 \\
0 & 0 & 0 & c_{44} & 0 & 0 \\
0 & 0 & 0 & 0 & c_{55} & 0 \\
0 & 0 & 0 & 0 & 0 & c_{66}
\end{array}\right] \\
& S_{\mathbf{i j}}=\frac{1}{2}\left(\frac{\partial u_{i}}{\partial x_{j}}+\frac{\partial u_{j}}{\partial x_{i}}\right) \\
& \mathbf{E}=-\nabla \phi \text {, onde } \phi \text { é o potencial elétrico. }
\end{aligned}
$$

\section{$2.2 \quad$ Atuadores Piezelétricos Bilaminares}

Um atuador piezelétrico bilaminar é um dispositivo eletromecânico com alto grau de flexão, também conhecido por cantiléver bilaminar, porque normalmente são montados como uma viga em balanço. Neste atuador uma tira de fibra de carbono é alocada entre duas placas piezocerâmicas, normalmente um tipo de PZT (UCHINO; GINIEWICZ, 2003). A fibra de carbono, por ter uma densidade relativamente baixa em relação aos metais, tem a vantagem de proporcionar um melhor acoplamento com as cerâmicas piezelétricas, aumentando assim o desempenho do atuador bilaminar.

Quando é aplicada uma tensão elétrica nas piezocerâmicas, a tira de fibra de carbono inclina-se com um movimento proporcional à tensão elétrica aplicada. Um atuador piezelétrico bilaminar pode apresentar deslocamentos em torno de $1 \mathrm{~mm}$, no entanto produz forças muito pequenas.

Conforme é realizada a varredura da freqüência do sinal elétrico senoidal aplicado no atuador, a corrente elétrica aumenta, assim como a potência elétrica, até que, para uma determinada freqüência, a amplitude pico-a-pico na extremidade livre do atuador 
atinja seu valor máximo. Esta freqüência é denominada de ressonância. Aumentando a freqüência do sinal, a corrente elétrica diminui e, conseqüentemente, a potência elétrica também, até que o valor da impedância atinja um máximo local. Neste ponto é definida a freqüência de anti-ressonância (SHERRIT et al., 2000).

Um atuador piezelétrico bilaminar de dimensões $40 \times 20 \mathrm{~mm}$ e espessura de $0,6 \mathrm{~mm}$ possui uma resposta típica de deslocamento na ordem de $10 \mu \mathrm{m} / \mathrm{V}$ em regime de excitação estático. Na freqüência de ressonância, que é da ordem de $80 \mathrm{~Hz}$, o deslocamento pode atingir até $50 \mu \mathrm{m} / \mathrm{V}$.

A Fig. 2.2 mostra a combinação de um bilaminar (PZT/fibra de carbono/PZT) que possibilita esses deslocamentos devido ao fato das cerâmicas piezelétricas operarem em modos opostos (podendo ser ligadas em série ou em paralelo), ou seja, enquanto uma das cerâmicas é expandida a outra é contraída, produzindo uma inclinação do cantiléver bilaminar.

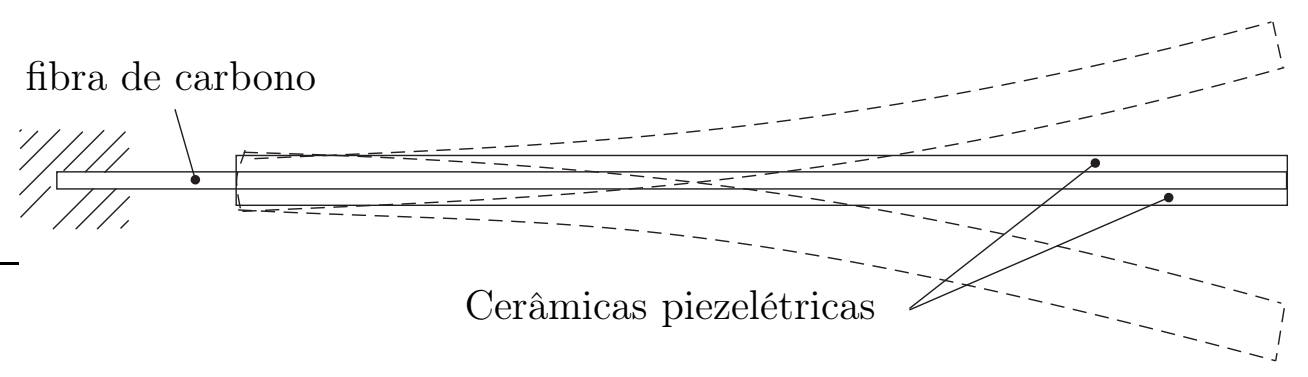

Figura 2.2: Atuador piezelétrico bilaminar.

\subsection{Modelagem Numérica}

A utilização do método de elementos finitos é justificada em situações nas quais a solução analítica de um dado problema é complexa ou mesmo quando não há uma formulação analítica disponível.

Uma formulação analítica do problema da bomba seria bastante complexa, inviabilizando a sua solução e exigindo a adoção de restrições e hipóteses que acabariam por comprometer os resultados. Além disso, um item importante refere-se à caracterização do equipamento, feita de maneira bem mais simples através de simulação computacional, havendo assim, uma diminuição do número de protótipos a serem construídos e ensaiados, além da possibilidade de determinação de parâmetros ótimos de funcionamento e curvas de resposta. 
Um exemplo bastante prático da utilização de simulações é a análise de sensibilidade. Para mapear o comportamento do sistema para um determinado parâmetro (geométrico, por exemplo) em 10 ou 20 pontos dentro de um domínio, basta alterar a variável desejada e rodar novamente a simulação. A situação análoga quando se pensa na construção de protótipos seria a construção de 10 ou 20 protótipos, o que de imediato é inviável.

A simulação computacional para problemas envolvendo fluidos é comumente denominada CFD ("Computational Fluid Dynamics"), sendo uma área bastante ampla. A simulação de bombas de fluxo dos mais diversos tipos é feita a partir de ferramentas de CFD, promovendo um aumento no desempenho das mesmas e como auxílio em seus projetos, como pode ser visto em (VOORDE; VIERENDEELS; DICK, 2004), (BURGREEN et al., 2001) e (GULICH, 1999).

Neste trabalho de mestrado o MEF é utilizado como ferramenta para a simulação e análise do problema da bomba de fluxo e optou-se pela utilização do software comercial ANSYS para a condução das simulações, ao invés da implementação de um software próprio. Este software permite um maior aprofundamento no estudo do dispositivo bombeador de fluido, possibilitando a realização de um número maior de simulações e, portanto, análises de sensibilidade.

Para um melhor entendimento do trabalho realizado, a seguir são descritos uma breve introdução à teoria do MEF, tanto o MEF piezelétrico quanto o MEF para fluidos, e os principais conceitos utilizados no software ANSYS.

\subsubsection{MEF Piezelétrico}

Para realizar as simulações computacionais de atuadores piezelétricos é utilizado o MEF. A seguir, é discutida sua aplicação para elementos piezelétricos e o desenvolvimento de suas equações.

A formulação do MEF piezelétrico pode ser escrita em termos do deslocamento $\mathbf{U}$ e do potencial elétrico $\Phi$ para cada nó, sendo que os esforços mecânicos são expressos em termos de $\mathbf{F}$ e as cargas elétricas em termos de $\mathbf{Q}$, resultando nas equações abaixo (LERCH, 1990): 


$$
\begin{array}{r}
{\left[\mathbf{M}_{\mathbf{u u}}\right]\{\ddot{\mathbf{U}}\}+\left[\mathbf{C}_{\mathbf{u u}}\right]\{\dot{\mathbf{U}}\}+\left[\mathbf{K}_{\mathbf{u u}}\right]\{\mathbf{U}\}+\left[\mathbf{K}_{\mathbf{u} \phi}\right]\{\boldsymbol{\Phi}\}=\{\mathbf{F}\}} \\
{\left[\mathbf{K}_{\mathbf{u} \phi}\right]^{T}\{\mathbf{U}\}+\left[\mathbf{K}_{\phi \phi}\right]\{\boldsymbol{\Phi}\}=\{\mathbf{Q}\}}
\end{array}
$$

Essa mesma expressão pode também ser expressa na seguinte forma matricial (LERCH, 1990):

$$
\begin{gathered}
{\left[\begin{array}{cc}
{\left[\mathbf{M}_{\mathbf{u u}}\right]} & \mathbf{0} \\
\mathbf{0} & \mathbf{0}
\end{array}\right]\left\{\begin{array}{c}
\ddot{\mathbf{U}} \\
\ddot{\mathbf{\Phi}}
\end{array}\right\}+\left[\begin{array}{cc}
{\left[\mathbf{C}_{\mathbf{u u}}\right]} & \mathbf{0} \\
\mathbf{0} & \mathbf{0}
\end{array}\right]\left\{\begin{array}{c}
\dot{\mathbf{U}} \\
\dot{\boldsymbol{\Phi}}
\end{array}\right\}+} \\
+\left[\begin{array}{ll}
{\left[\mathbf{K}_{\mathbf{u u}}\right]} & {\left[\mathbf{K}_{\mathbf{u} \phi}\right]} \\
{\left[\mathbf{K}_{\mathbf{u} \phi}\right]} & {\left[\mathbf{K}_{\phi \phi}\right]}
\end{array}\right]\left\{\begin{array}{l}
\mathbf{U} \\
\mathbf{\Phi}
\end{array}\right\}=\left\{\begin{array}{l}
\mathbf{F} \\
\mathbf{Q}
\end{array}\right\}
\end{gathered}
$$

onde para cada elemento finito $e$ (LERCH, 1990):

Matriz de rigidez mecânica: $\left[\mathbf{K}_{\mathbf{u u}}\right]_{e}=\iiint_{\Omega e}\left[\mathbf{B}_{\mathbf{u}}\right]^{T}[\mathbf{c}]\left[\mathbf{B}_{\mathbf{u}}\right] d V_{e}$

Matriz de acoplamento piezelétrico: $\left[\mathbf{K}_{\mathbf{u} \phi}\right]_{e}=\iiint_{\Omega e}\left[\mathbf{B}_{\mathbf{u}}\right]^{T}[\mathbf{e}]\left[\mathbf{B}_{\phi}\right] d V_{e}$

Matriz de rigidez elétrica: $\left[\mathbf{K}_{\phi \phi}\right]_{e}=\iiint_{\Omega e}\left[\mathbf{B}_{\phi}\right]^{T}[\varepsilon]\left[\mathbf{B}_{\phi}\right] d V_{e}$

Matriz de massa: $\left[\mathbf{M}_{\mathbf{u u}}\right]_{e}=\rho \iiint_{\Omega e}\left[\mathbf{N}_{\mathbf{u}}\right]^{T}\left[\mathbf{N}_{\mathbf{u}}\right] d V_{e}$

Matriz de amortecimento: $\left[\mathbf{C}_{\mathbf{u u}}\right]_{e}=\alpha\left[\mathbf{M}_{\mathbf{u u}}\right]_{e}+\beta\left[\mathbf{K}_{\mathbf{u u}}\right]_{e}$

$\mathrm{e}$

$\beta$ : constante de amortecimento multiplicadora da matriz de rigidez e

$\alpha$ : constante de amortecimento multiplicadora da matriz de massa (LERCH, 1990).

\section{Análise Modal}

Para análise de atuadores piezelétricos é necessário determinar suas freqüências naturais (ressonância e anti-ressonância). Para isso utiliza-se a análise modal, que consiste 
na solução das eq. 2.8 e 2.9 na forma de um problema de autovalores e auto-vetores. Assim, reduzindo as eq. 2.8 e 2.9, tem-se (LERCH, 1990):

$$
\left[\begin{array}{cc}
\mathbf{M}_{\mathbf{u u}} & \mathbf{0} \\
\mathbf{0} & \mathbf{0}
\end{array}\right]\left\{\begin{array}{c}
\ddot{\mathbf{U}} \\
\ddot{\boldsymbol{\Phi}}
\end{array}\right\}+\left[\begin{array}{ll}
\mathbf{K}_{\mathbf{u u}} & \mathbf{K}_{\mathbf{u} \phi} \\
\mathbf{K}_{\mathbf{u} \phi}^{T} & \mathbf{K}_{\phi \phi}
\end{array}\right]\left\{\begin{array}{c}
\mathbf{U} \\
\boldsymbol{\Phi}
\end{array}\right\}=\left\{\begin{array}{l}
\mathbf{0} \\
\mathbf{Q}
\end{array}\right\}
$$

Para $\mathbf{Q}=\mathbf{0}$ na equação acima, obtém-se um problema de autovalor e auto-vetor que permite calcular a freqüência de anti-ressonância. Para a obtenção da freqüência de ressonância, basta fechar o curto-circuito dos eletrodos e após considerar o sistema de eqs. 2.16, eliminando-se as equações que envolvem os nós dos eletrodos, obtém-se o problema de autovalor e autovetor correspondente (WU et al., 2003).

\section{Análise Harmônica}

As cerâmicas piezelétricas dos atuadores são excitadas com ondas de tensão elétricas senoidais (harmônicas), o que faz necessário realizar uma simula harmônica, permitindo investigar a estrutura piezelétrica sob a influência de força, cargas elétricas, deslocamentos e/ou voltagens harmônicas. Forças e cargas elétricas podem ser expressas da seguinte forma:

$$
\{\mathbf{F}(t)\}=\{\mathbf{F}\} e^{j \omega t} ; \quad\{\mathbf{Q}(t)\}=\{\mathbf{Q}\} e^{j \omega t}
$$

Dessa forma, os deslocamentos e o potencial elétrico são dados por:

$$
\{\mathbf{U}(t)\}=\{\mathbf{U}\} e^{j \omega t} ; \quad\{\boldsymbol{\Phi}(t)\}=\{\boldsymbol{\Phi}\} e^{j \omega t}
$$

onde $\omega$ é a freqüência de excitação.

Vale lembrar que esses valores de $\{\mathbf{U}\},\{\boldsymbol{\Phi}\},\{\mathbf{F}\}$ e $\{\mathbf{Q}\}$ apresentam números reais quando não há amortecimento e, números complexos quando há amortecimento no sistema, o que significa a adição de um deslocamento de fase. Substituindo as eq. 2.17 e 2.18 nas equações de equilíbrio piezelétricas eq. 2.8 e 2.9, obtém-se (LERCH, 1990):

$$
\left[\begin{array}{cc}
\mathbf{K}_{\mathbf{u u}}+j \omega \mathbf{C}_{\mathbf{u u}}-\omega^{2} \mathbf{M}_{\mathbf{u u}} & \mathbf{K}_{\mathbf{u} \phi} \\
\mathbf{K}_{\mathbf{u} \phi}^{T} & \mathbf{K}_{\phi \phi}
\end{array}\right]\left\{\begin{array}{c}
\widehat{\mathbf{U}} \\
\widehat{\mathbf{\Phi}}
\end{array}\right\}=\left\{\begin{array}{c}
\widehat{\mathbf{F}} \\
\frac{1}{j \omega} \widehat{\mathbf{I}}
\end{array}\right\}
$$


Sendo que $\frown$ representa matrizes complexas. A análise harmônica permite determinar a resposta em freqüência das características da estrutura piezelétrica (OSTERGAARD; PAWLAK, 1987; LERCH, 1990), como deslocamento e impedância elétrica.

O elemento que representa a cerâmica piezelétrica fornece o valor da carga elétrica na forma complexa $(Q)$ de cada elemento quando utilizado como material piezelétrico. Utilizando este valor é possível calcular a impedância elétrica $(Z)$ do elemento da seguinte forma (NADER, 2002):

$$
Z=\frac{V}{I}=\frac{V}{i \omega Q}
$$

onde:

$$
\begin{aligned}
& \mathrm{V}=\text { diferença de potencial elétrico; } \\
& \mathrm{I}=\text { corrente elétrica; } \\
& \omega \quad=\text { freqüência de excitação; } \\
& \mathrm{Q}=\text { carga elétrica. }
\end{aligned}
$$

A partir desta equação é possível calcular a curva de impedância elétrica em função da freqüência de excitação, como pode ser visto na fig. 4.4, por exemplo.

\section{Análise Transiente}

Essa análise consiste em se resolver as eq. 2.8 e 2.9 em que $F(t)$ e $Q(t)$ são funções quaisquer no tempo. Deve-se, então, definir a função de excitação, especificando-se o valor da função para diferentes incrementos de tempo. A função é dividida nos chamados passos de carga, cada um contendo um ou mais incrementos de tempo. Para a solução do problema transiente o ANSYS utiliza o método numérico de Newmark (OSTERGAARD; PAWLAK, 1987). Trata-se de um método de integração direta implícito, em que as eqs. 2.8 e 2.9 são resolvidas entre um instante de tempo e o próximo. O que o método faz é interpretar $\left[\mathbf{M}_{\mathbf{u u}}\right]\{\ddot{\mathbf{U}}\}$ e $\left[\mathbf{C}_{\mathbf{u u}}\right]\{\dot{\mathbf{U}}\}$ como forças de inércia e viscosa respectivamente, e impor o equilíbrio estático em cada instante de tempo seguinte. 


\subsubsection{Modelagem de Dinâmica dos Fluidos}

Para realizar as simulações computacionais de atuadores piezelétricos imersos em fluidos também é utilizado o MEF. A seguir, as equações do problema de escoamento de fluidos são brevemente apresentadas.

O problema de escoamento de fluidos é governado pelas equações de Navier-Stokes, conservação de massa e conservação da quantidade de movimento. As equações de conservação da quantidade de movimento linear e da continuidade são dadas por (FOX; MCDONALD, 2006):

$$
\begin{aligned}
\frac{\partial \rho}{\partial t}+\rho \nabla \cdot \vec{V} & =0 \\
\frac{\partial \vec{V}}{\partial t}+(\vec{V} \cdot \vec{\nabla}) \vec{V} & =-\frac{1}{\rho} \vec{\nabla} P+\mu \nabla^{2} \vec{V}
\end{aligned}
$$

onde:

$$
\begin{array}{ll}
\rho \text { : densidade } & \vec{V} \text { : vetor de velocidade } \\
\text { P: pressão } & \vec{g} \text { : vetor de gravidade }
\end{array}
$$

Para um fluido incompressível, tem-se que:

$$
\vec{\nabla} \cdot \vec{V}=0
$$




\section{MODELAGEM COMPUTACIONAL}

Neste capítulo são descritos os elementos utilizados no ANSYS, a condição de contornos móveis (ALE) e a linguagem APDL utilizada nas simulações da bomba de fluxo piezelétrica.

\subsection{Descrição dos Elementos Utilizados no ANSYS}

Para a simulação da bomba de fluxo piezelétrica é utilizado o software de elementos finitos ANSYS (ANSYS, INC., 2007). O software conta com uma vasta biblioteca de elementos para a simulação dos mais diversos tipos de sistemas, incluindo sistemas multidisciplinares, através do pacote Multiphysics, e simulações de escoamento de fluidos, através do módulo CFX (que utiliza o método dos volumes finitos). As simulações computacionais geradas neste trabalho podem ser divididas em dois grupos, que são: simulações do atuador piezelétrico e simulações de escoamentos (ver Fig. 3.1). A primeira etapa consiste na simulação do atuador piezelétrico propriamente dito, onde são obtidos os modos e as freqüências de ressonância e amplitudes de oscilação. A segunda etapa consiste na simulação do comportamento do líquido a ser bombeado no interior do canal da bomba de fluxo, onde é possível visualizar a formação dos vórtices gerados pelos atuadores, obter curvas de vazão e pressão e realizar estudos de sensibilidade dos parâmetros geométricos da bomba de fluxo.

Para simular o comportamento do atuador bilaminar é necessário criar um modelo acústico do canal interno da bomba de fluxo (ANSYS, INC., 2007) a fim de reproduzir o efeito de massa e rigidez da água no atuador piezelétrico. Isso é realizado utilizando-se o elemento "FLUID29" com as propriedades da água (peso específico e velocidade de propagação do som) e em seu interior modela-se o atuador piezelétrico bilaminar, 


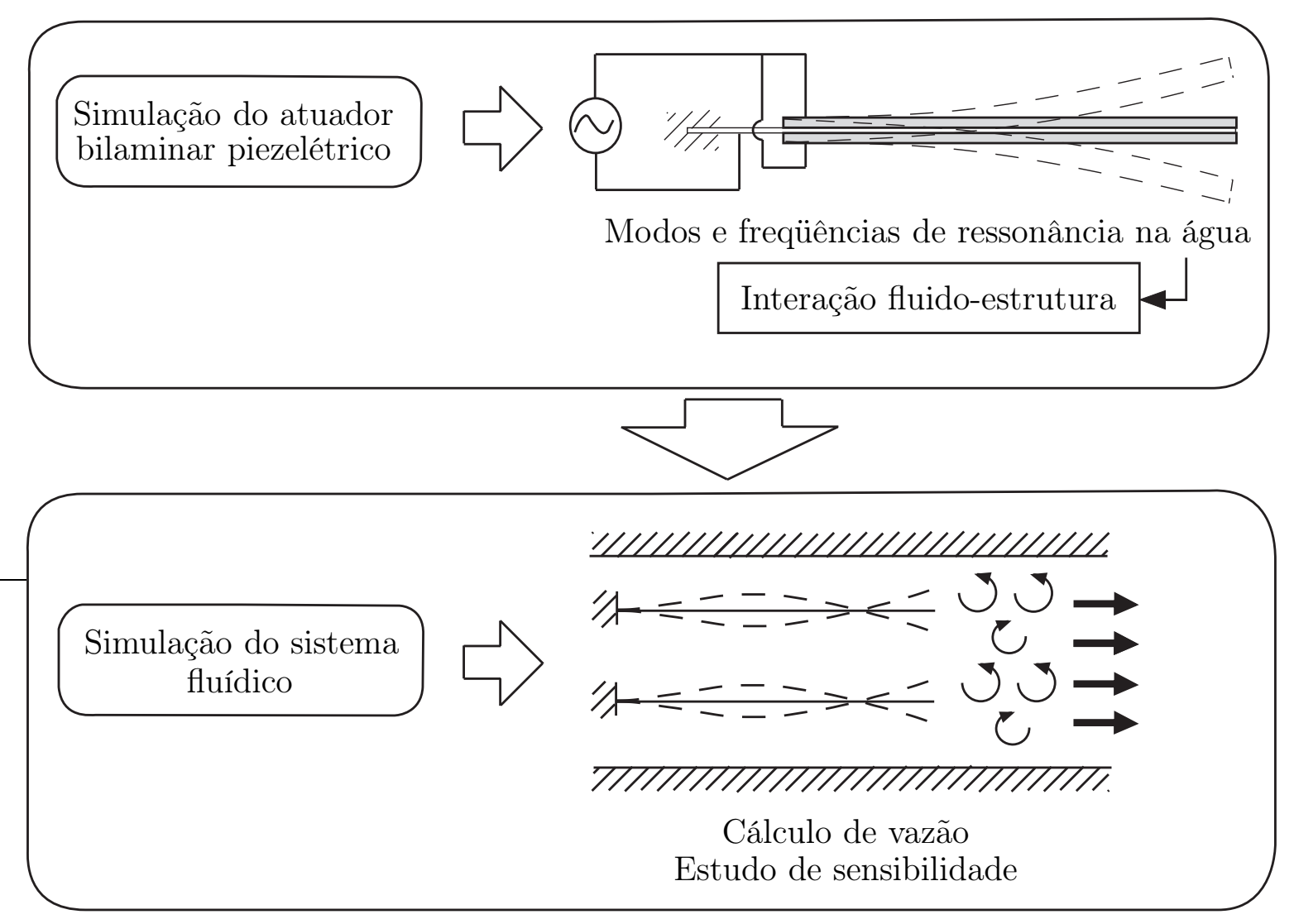

Figura 3.1: Abordagem utilizada nas simulações.

utilizando-se o elemento "PLANE13", que é capaz de simular no plano bi-dimensional materiais estruturais, como o cobre, e também materiais piezelétricos. Os graus de liberdade do "FLUID29" são os deslocamentos em 'x' e ' $y$ '; do "PLANE13" são: deslocamentos em 'x' e 'y' e voltagem ' $\phi$ '.

Nas simulações de escoamentos do fluido é utilizado o elemento "FLUID142", que é capaz de simular regimes permanentes ou transientes e escoamentos laminares ou turbulentos. Os graus de liberdade deste elemento são: velocidades em 'x' e 'y', pressão e energia cinética.

As simulações no ANSYS são realizadas com o software operando em modo 'batch', ou seja, utilizando um arquivo de texto em linguagem APDL (ANSYS Parametric Design Language) (ANSYS, INC., 2007), descrita posteriormente. 


\subsection{Condições de Contorno Móveis}

A descrição Lagrangeana expressa o movimento de um meio contínuo em termos da configuração inicial e do tempo (referência fixa) e é tradicionalmente utilizada na mecânica dos sólidos, onde o propósito das análises em geral é determinar os deslocamentos dos pontos de um corpo a partir de sua forma inicial. A descrição Euleriana, por outro lado, é definida em termos da configuração deformada e do tempo, sendo muito aplicada à mecânica dos fluidos, onde as variáveis geralmente são velocidades e não deslocamentos. Sendo o fluido modelado por uma formulação Euleriana e o sólido por uma formulação Lagrangeana (método particionado), surgem dificuldades para se analisar ambos simultaneamente. A solução para o acoplamento entre o fluido e a estrutura é descrever o fluido através da formulação Lagrangeana-Euleriana Arbitrária (ALE Arbitrary Lagrangian-Eulerian) (DONEA et al., 2004).

No caso estudado neste trabalho, o atuador dentro do duto tem um movimento oscilatório e, portanto, o domínio em estudo se altera com o decorrer do tempo. Assim, a malha de elementos finitos deve ser alterada de forma a satisfazer esta condição. Para tanto é utilizada a formulação ALE implementada no ANSYS. Esta formulação ALE permite realocar a malha de elementos finitos de forma a satisfazer às condições de contorno impostas a cada instante.

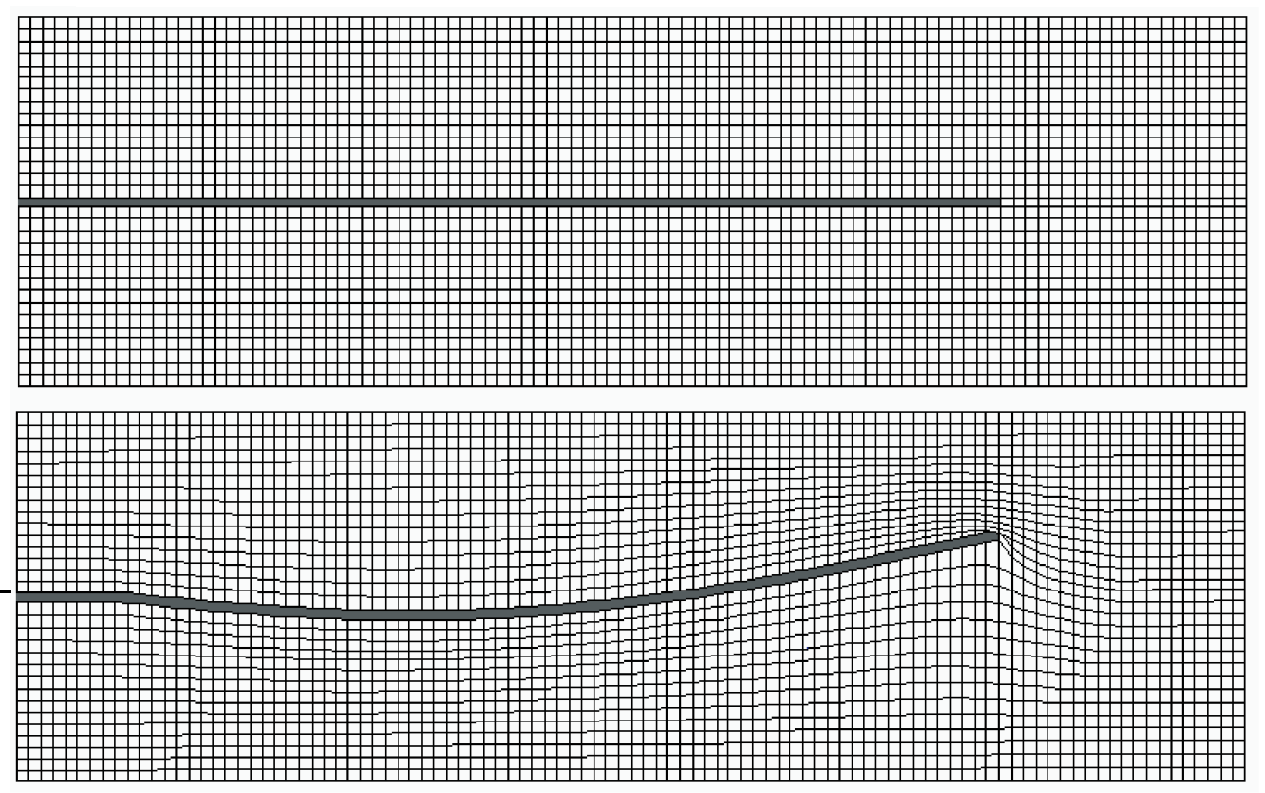

Figura 3.2: Exemplo de malha de elementos em tempos diferentes utilizando ALE.

A Fig. 3.2 é um exemplo da aplicação dessa formulação, mostrando como a malha é 
realocada durante a simulação. Através de uma simulação como esta podemos obter pressão e velocidade, que são as variáveis do problema no caso da bomba de fluxo piezelétrica.

\subsection{Linguagem APDL}

Nas simulações da bomba de fluxo piezelétrica é empregada a linguagem de programação APDL (ANSYS Parametric Design Language). Esta linguagem de programação é utilizada para automatizar funções comuns ou mesmo para a construção de um modelo a partir de seus parâmetros ou variáveis. O APDL possibilita ainda a realização de uma série de outras funcionalidades, tais como: repetição de comandos, macros, condições "if-then-else", loops, além de operações com vetores e matrizes.

Esta linguagem é utilizada neste trabalho para dinamizar a criação de modelos computacionais para a bomba piezelétrica, uma vez que para alterar um determinado parâmetro, basta editar o arquivo do código-fonte e refazer a simulação, ao invés de realizar novamente toda a montagem do modelo utilizando a interface gráfica do programa. No Apêndice A estão listados alguns programas como exemplo utilizados durante este trabalho. 


\section{BOMBA DE FLUXO PIEZELÉTRICA COM UM ÚNICO ATUADOR}

O princípio de funcionamento utilizado neste trabalho é inspirado no modo de nadar dos peixes, conforme mostrado na seção 1.2.2.

Em trabalhos anteriores (NAKASONE et al., 2005; NAKASONE, 2006; PIRES et al., 2006) foi investigada a utilização de um atuador piezelétrico bilaminar para bombeamento de líquidos, engastado no interior de um canal retangular. O procedimento utilizado envolveu simulações computacionais 2D, divididas em duas etapas: simulações acústicas, para obtenção dos modos de vibrar, freqüências de ressonância e amplitudes de oscilação; e simulações do escoamento, para obtenção de vazão e pressão na saída da bomba de fluxo.

Nos trabalhos citados no parágrafo anterior foi observado que nas simulações do escoamento de fluido foi simulado o escoamento potencial, ou seja, o fluido foi considerado como um fluido não viscoso. Outro fato observado foi que as maiores vazões de água obtidas, tanto computacional quanto experimentalmente, são geradas quando o atuador piezelétrico é excitado por uma freqüência próxima à do segundo modo de vibrar. Uma hipótese levantada para este fato é que, para um atuador piezelétrico bilaminar, tem-se que a vazão gerada é proporcional à amplitude de oscilação (e conseqüentemente, à tensão aplicada nas cerâmicas) e à freqüência de excitação (NAKASONE, 2006). Entretanto, quanto maior for a ordem do modo de vibrar do atuador bilaminar (semelhante a uma viga engastada), menor será a amplitude de oscilação e maior será a freqüência de ressonância. Como é observado que o segundo modo de vibrar gera maiores vazões, tanto computacional quanto experimentalmente, conclui-se que há uma solução de compromisso entre a amplitude de oscilação e a freqüência de ressonância do atuador bilaminar.

Em vista disso, no presente trabalho decidiu-se investigar o comportamento do 
atuador piezelétrico bilaminar em um fluido viscoso (no caso, água) nas simulações computacionais. Além disso, os testes experimentais descritos posteriormente são conduzidos de forma minuciosa, a fim de se obter repetibilidade nos resultados obtidos e dominar o princípio de funcionamento proposto neste trabalho. O estudo desta configuração de bomba de fluxo piezelétrica de um atuador também serve de referência para as outras configurações de atuadores propostas no próximo capítulo.

\subsection{Simulação Acústica}

No estudo do atuador piezelétrico bilaminar a primeira etapa a ser realizada é simular a estrutura do atuador piezelétrico a fim de verificar seus modos de vibrar, freqüências de ressonância e amplitude de oscilação.

Modelos computacionais de bombas de fluxo piezelétricas podem abranger o fluido ou não. Caso o interesse seja analisar o comportamento do atuador piezelétrico no ar, não é necessário modelar o ambiente ao redor do atuador, pois a influência do meio no atuador será desprezível (ANSYS, INC., 2007). Isto significa que o modelo computacional terá um menor número de elementos e, conseqüentemente, um custo computacional menor. Porém, neste trabalho é proposto o estudo do atuador piezelétrico bilaminar imerso em água e, portanto, torna-se necessário a modelagem do meio também.

A simulação computacional de um atuador piezelétrico bilaminar em meio aquático envolve três campos acoplados (elétrico, estrutural e fluido) e, conforme descrito na seção 3.1, pode-se utilizar os elementos PLANE13 e FLUID29 na modelagem das partes estruturais e do fluido, respectivamente. No modelo acústico da bomba de fluxo piezelétrica é necessário modelar uma camada de elementos FLUID29 com estrutura na região de interface entre o fluido e a estrutura, para que a condição de contorno de interação fluido-estrutura (FSI - fluid-structure interaction) seja aplicada. As dimensões do modelo acústico podem ser vistas na fig. 4.1. Estas dimensões foram adotadas devido à escolha do atuador N. ${ }^{o} 40-1040$ da APC International, cujas dimensões são $20 \times 40 \times$ $0,6 \mathrm{~mm}$.

A fim de facilitar a modelagem computacional, ao invés de fibra de carbono adota-se o material cobre para a camada intermediária, entre as cerâmicas piezelétricas. Além disso, em catálogos de fabricantes de atuadores piezelétricos há informações que para atuadores bilaminares as cerâmicas piezelétricas mais utilizadas são PZT-5A, PZT-5H, 
PZT-4 e PZT-8. Entretanto, no catálogo de produtos da APC International não é mencionado qual o tipo de cerâmica piezelétrica é utilizado na fabricação do modelo citado no parágrafo anterior. Através de testes de correlação entre testes experimentais e simulações computacionais, verifica-se que o PZT-5A e o cobre apresentam bons resultados de correlação. Assim, nos modelos acústicos utilizados neste trabalho considera-se que as cerâmicas piezelétricas deste atuador sejam PZT-5A.

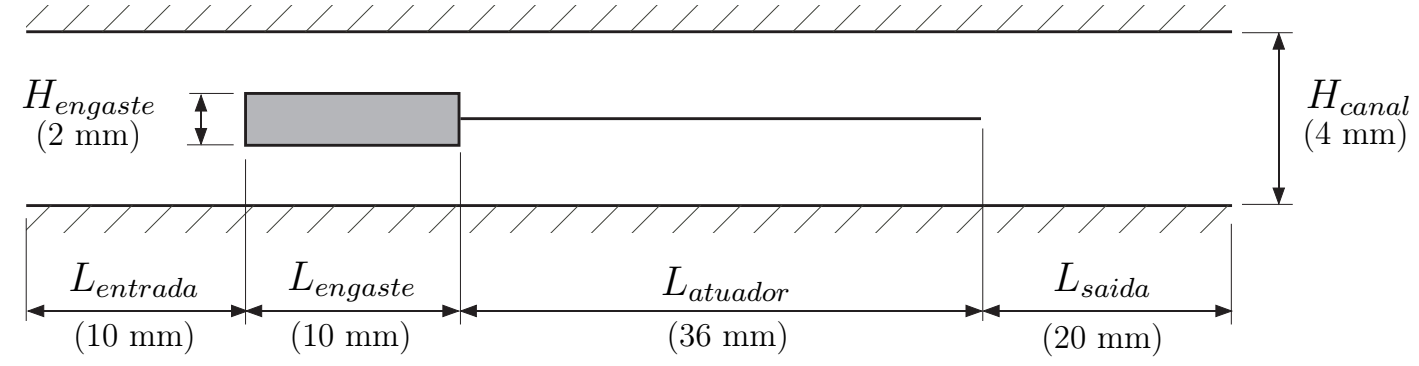

Figura 4.1: Desenho esquemático e dimensões do modelo acústico adotado.

Os materiais empregados no modelo acústico são água, cobre e PZT-5A, cujas propriedades estão listadas na tabela 4.1 .

Tabela 4.1: Propriedades dos materiais utilizados nas simulações acústicas.

\begin{tabular}{|c|c|c|c|c|}
\hline Água & $\begin{array}{l}\text { Massa específica } \\
\text { Viscosidade dinâmica } \\
\text { Velocidade de propagação do som }\end{array}$ & $\begin{array}{c}\rho_{\mathrm{H}_{2} \mathrm{O}} \\
\mu \\
v_{s}\end{array}$ & $\begin{array}{c}998 \\
0,001003 \\
1500\end{array}$ & $\begin{array}{l}\mathrm{kg} / \mathrm{m}^{3} \\
\mathrm{Pa.s} \\
\mathrm{m} / \mathrm{s}\end{array}$ \\
\hline Cobre & $\begin{array}{l}\text { Massa específica } \\
\text { Módulo de Elasticidade } \\
\text { Coeficiente de Poisson }\end{array}$ & $\begin{array}{c}\rho_{\text {metal }} \\
\mathrm{E} \\
\nu\end{array}$ & $\begin{array}{c}8970 \\
110 \\
0,34\end{array}$ & $\begin{array}{c}\mathrm{kg} / \mathrm{m}^{3} \\
G P a\end{array}$ \\
\hline PZT-5A & $\begin{array}{l}\text { Constantes piezelétricas } \\
\text { Constantes dielétricas } \\
\left(\epsilon_{0}=8,85 \times 10^{-12} F . m^{-1}\right) \\
\text { Massa específica }\end{array}$ & $\begin{array}{c}c_{11}^{E} \\
c_{12}^{E} \\
c_{13}^{E} \\
c_{33}^{E} \\
c_{44}^{E} \\
e_{31} \\
e_{33} \\
e_{15} \\
\epsilon_{11}^{S} / \epsilon_{0} \\
\epsilon_{33}^{S} / \epsilon_{0} \\
\rho_{P Z T}\end{array}$ & $\begin{array}{c}12,10 \\
7,54 \\
7,52 \\
11,10 \\
2,11 \\
-5,35 \\
15,8 \\
12,3 \\
916 \\
830 \\
7750\end{array}$ & $\begin{aligned} \times & 10^{10} N . m^{-2} \\
\times & 10^{10} N . m^{-2} \\
\times & 10^{10} \text { N.m } m^{-2} \\
\times & 10^{10} \text { N.m } m^{-2} \\
\times & 10^{10} N \cdot m^{-2} \\
& \text { C. } m^{-2} \\
& \text { C. } m^{-2} \\
& \text { C. } m^{-2}\end{aligned}$ \\
\hline
\end{tabular}

A malha de elementos do atuador no líquido pode ser vista na fig. 4.2. Esta malha apresenta um total de 26.272 elementos e 26.948 nós. As cores indicam os diferentes materiais utilizados e também é possível ver as condições de contorno aplicadas no modelo. 
O objetivo da análise acústica é observar o comportamento do atuador bilaminar imerso em um fluido viscoso, ou seja, qual a influência da massa adicional do fluido ao redor do atuador. Porém, na análise acústica é possível definir se ocorre reflexão ou absorção das ondas geradas pela vibração do atuador nas regiões de fronteira do modelo (no caso, nas paredes do canal e ao redor do engaste). Assim, através de testes de correlação das freqüências de ressonância obtidas computacional e experimentalmente, verifica-se que a condição de contorno de absorção nas paredes é a que melhor representa o comportamento do atuador fisicamente. Portanto, as paredes do canal e do engaste são consideradas como superfícies absorvedoras de ondas.

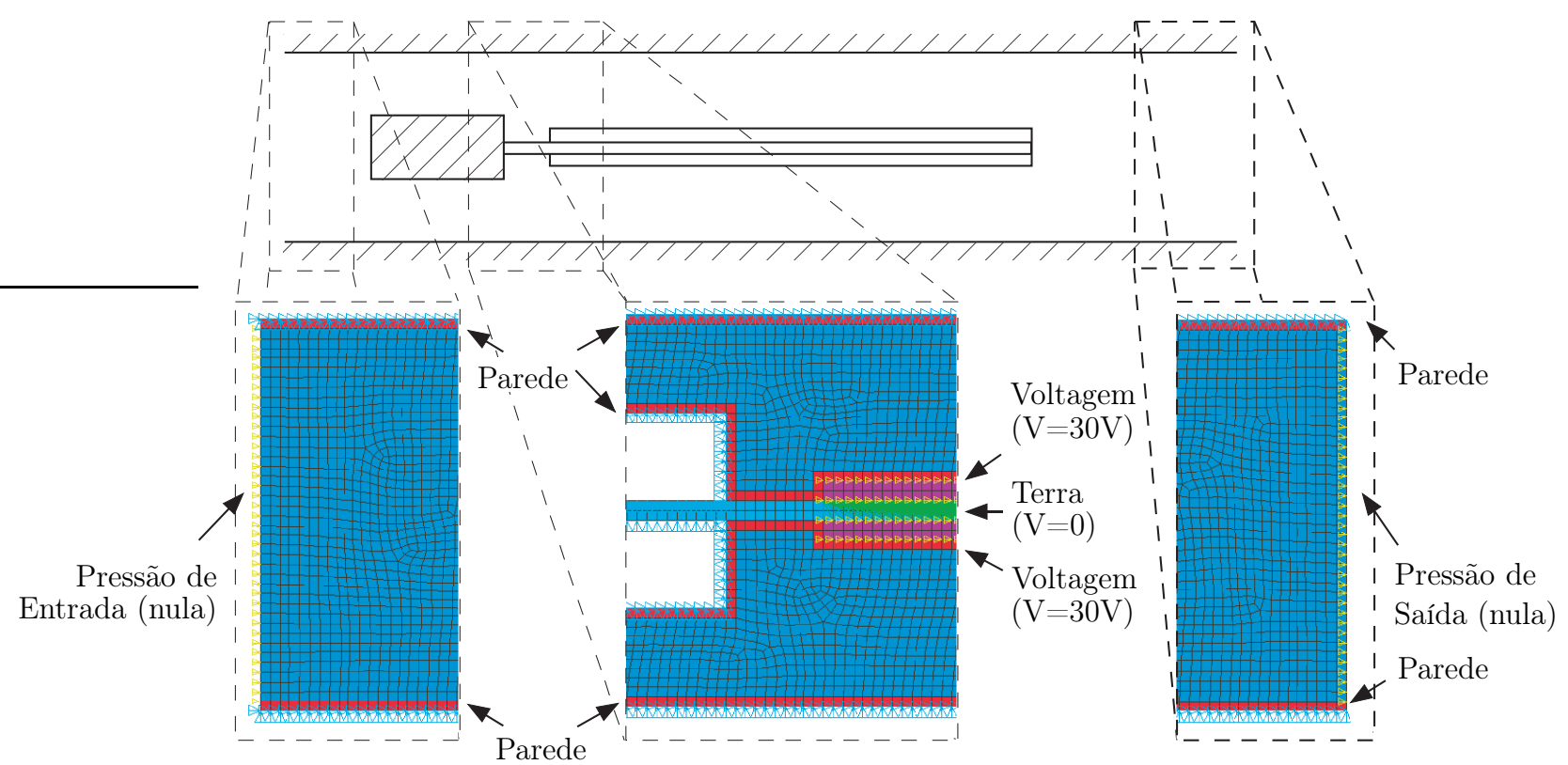

Figura 4.2: Condições de contorno aplicadas no modelo acústico.

Definido o modelo acústico, é simulada uma análise harmônica a fim de se obter a curva de impedância elétrica e as freqüências de ressonância do atuador. Os modos de vibrar do primeiro e segundo modo, com o atuador imerso em água, podem ser vistos na fig. 4.3.
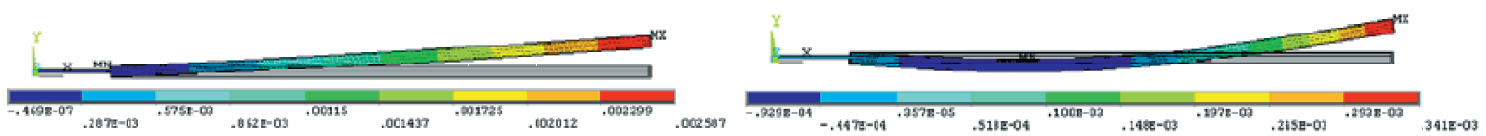

Figura 4.3: Segundo modo de vibrar do atuador piezelétrico na água: (a) $1^{\circ}$ modo (20 $\mathrm{Hz})$ e (b) $2^{\circ}$ modo $(320 \mathrm{~Hz})$.

A curva de impedância elétrica do atuador no fluido é obtida em função da freqüência do sinal elétrico aplicado ao atuador $\left(60 \mathrm{~V}_{\text {pico-a-pico }}\right)$. Na fig. 4.4a é mostrada a 
curva de impedância obtida computacionalmente no intervalo do segundo modo de vibrar do atuador bilaminar imerso em água, onde é possível ver os pontos de ressonância e anti-ressonância, em $315 \mathrm{~Hz}$ e $355 \mathrm{~Hz}$, respectivamente. A curva de impedância elétrica experimental será descrita posteriormente na seção 4.3. A fig. 4.4b mostra a curva da amplitude pico-a-pico da extremidade livre do atuador piezelétrico em função da freqüência. Da análise harmônica também se obtém os deslocamentos verticais dos nós da linha de centro do atuador quando excitado na segunda freqüência de ressonância.
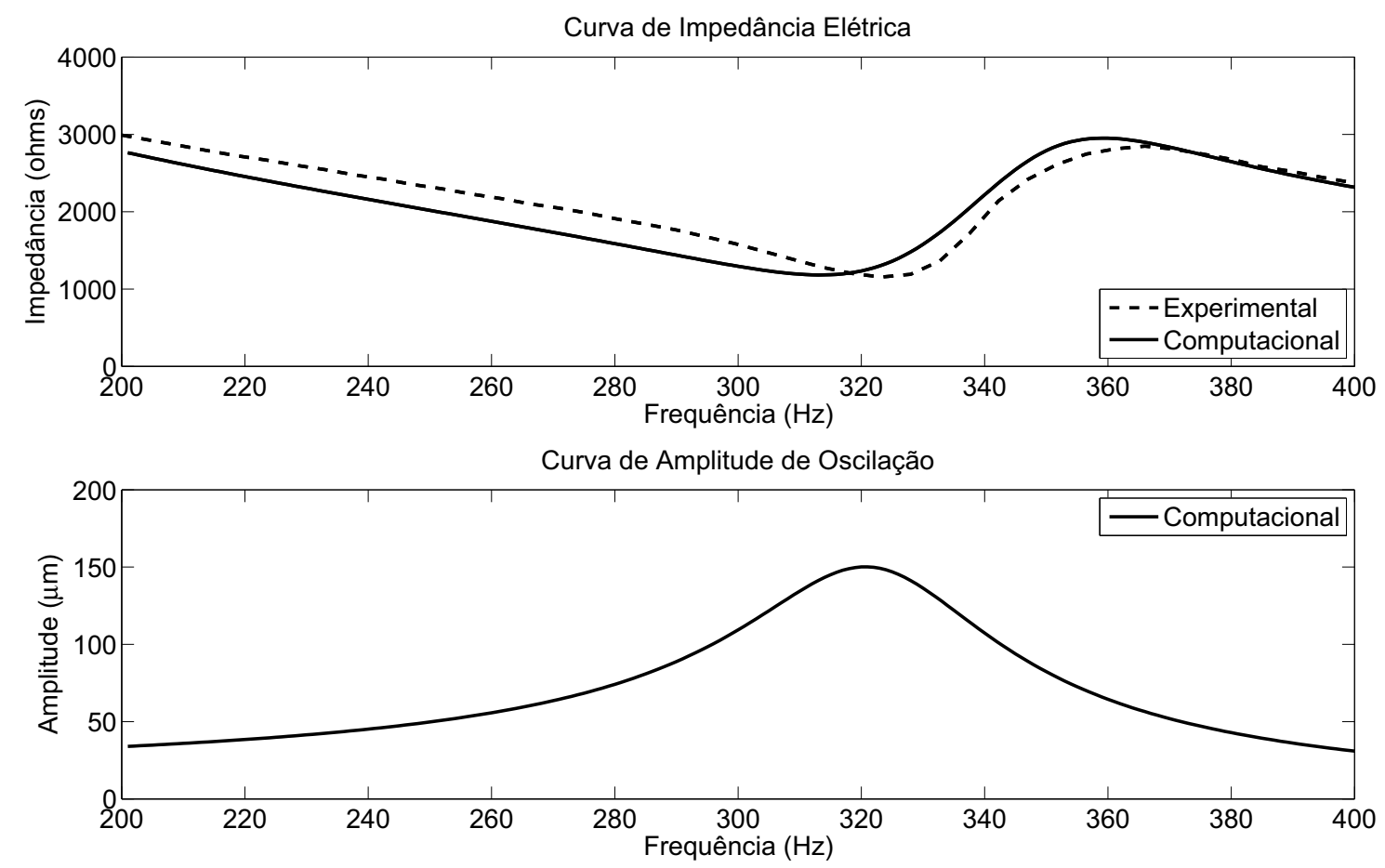

Figura 4.4: (a)Curvas de impedância elétrica do atuador imerso em água para o segundo modo de vibrar; (b) Curva de amplitude pico-a-pico da extremidade livre do atuador piezelétrico.

A partir dos gráficos da fig. 4.4, observa-se o deslocamento máximo (local) de 150 $\mu \mathrm{m}$ em $320 \mathrm{~Hz}$ e o valor da impedância mínima local de $1300 \Omega$ em $315 \mathrm{~Hz}$. A diferença nos valores das freqüências significa que, do ponto de vista elétrico, a corrente elétrica conduzida é máxima (local) em $315 \mathrm{~Hz}$, ou seja, nesta freqüência a potência elétrica é maxima (local). Já do ponto de vista estrutural, a freqüência de ressonância é de $320 \mathrm{~Hz}$.

No caso da bomba de fluxo piezelétrica oscilatória estudada neste trabalho, é desejável operar o atuador piezelétrico com o maior deslocamento possível, pois deslocamentos maiores geram maiores vazões (NAKASONE, 2006). Portanto, a partir do resultado para a freqüência de ressonância de $320 \mathrm{~Hz}$, é possível obter uma equação polinomial que 
represente a forma do segundo modo de vibrar do atuador piezelétrico (ver fig. 4.5). Quando multiplicamos este polinômio por $\operatorname{sen}(\omega t)$, onde $\omega$ é a velocidade angular e $t$ é o tempo, obtemos uma representação do movimento oscilatório do atuador ao longo do tempo. Derivando esta nova equação, obtém-se a equação da velocidade do atuador. Com estas duas equações (deslocamento e velocidade) pode-se prescrever o comportamento do atuador piezelétrico no fluido como um modo de aproximação para reproduzir o comportamento do sistema de bombeamento. Isto elimina a necessidade de utilizar um sistema acoplado de simulação considerando os efeitos piezelétricos e do escoamento do sistema, o que geraria um alto custo computacional.

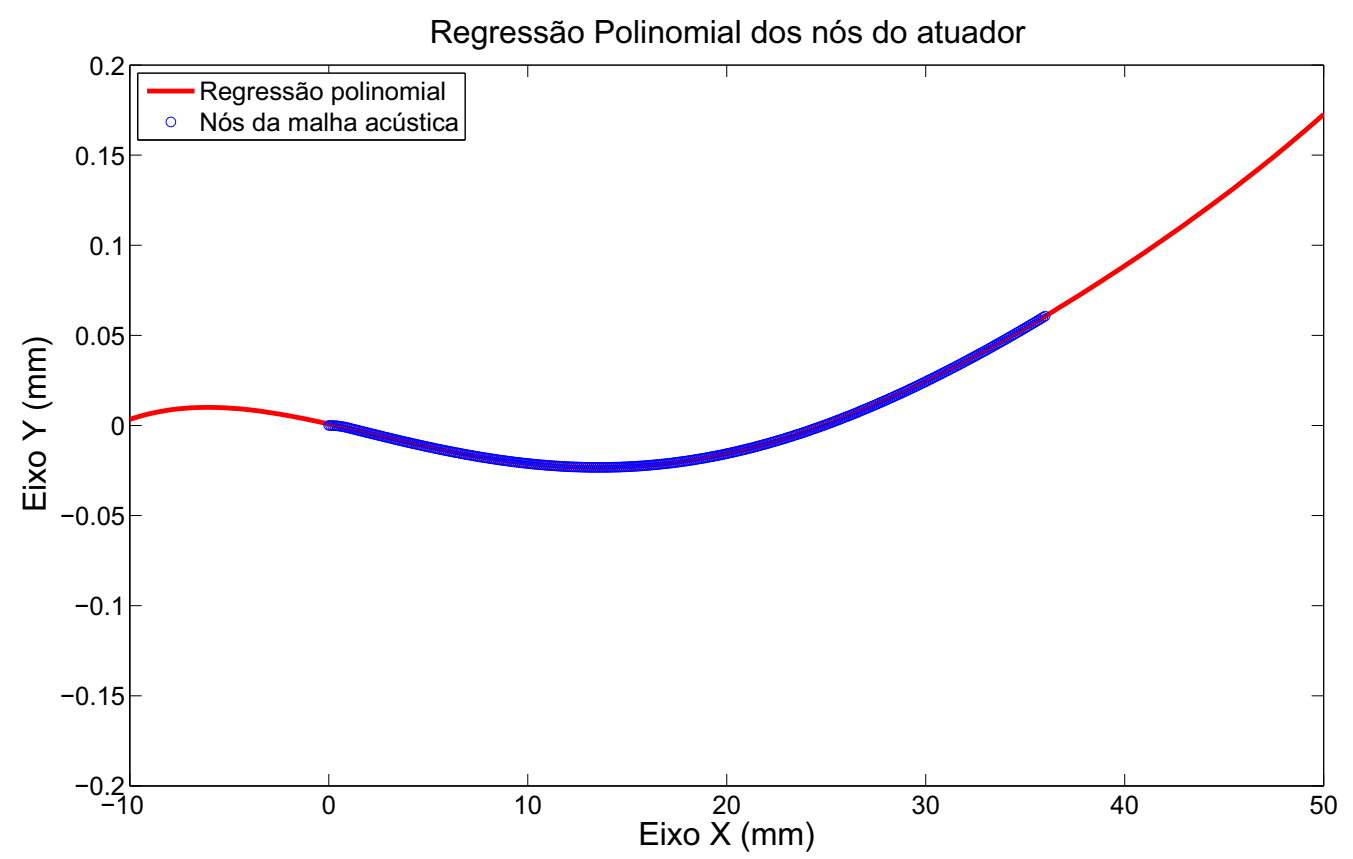

Figura 4.5: Gráfico da equação polinomial obtida da análise acústica para o segundo modo de vibrar.

\subsection{Simulação do Escoamento de Fluido}

Concluída a simulação acústica e obtidas a freqüência de ressonância e as equações polinomiais dos deslocamentos e velocidades que representam o movimento do atuador, o próximo passo é a análise do escoamento do sistema de bombeamento. O objetivo da análise do escoamento é observar o comportamento do sistema, ou seja, a vazão gerada na saída da bomba ao longo do tempo e determinar um valor médio para a vazão até que entre em regime estacionário. 
A fig. 4.6 mostra um desenho esquemático do modelo do escoamento adotado. Este desenho exibe a vista lateral da bomba de fluxo piezelétrica. Os parâmetros $A$ e $f$ são a amplitude de oscilação pico-a-pico na extremidade livre do atuador piezelétrico e a freqüência de oscilação, respectivamente. A fig. 4.7 ilustra a malha de elementos finitos utilizada nas simulações do escoamento, que contém 7.038 elementos, onde também são mostrados detalhes das regiões de entrada e saída do canal e do engaste do atuador piezelétrico.

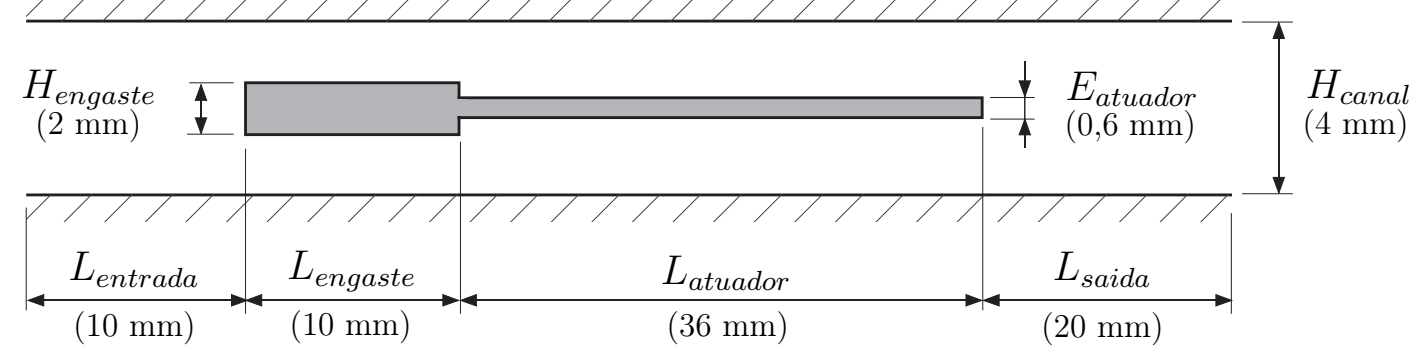

Figura 4.6: Desenho esquemático e dimensões do modelo fluídico adotado.

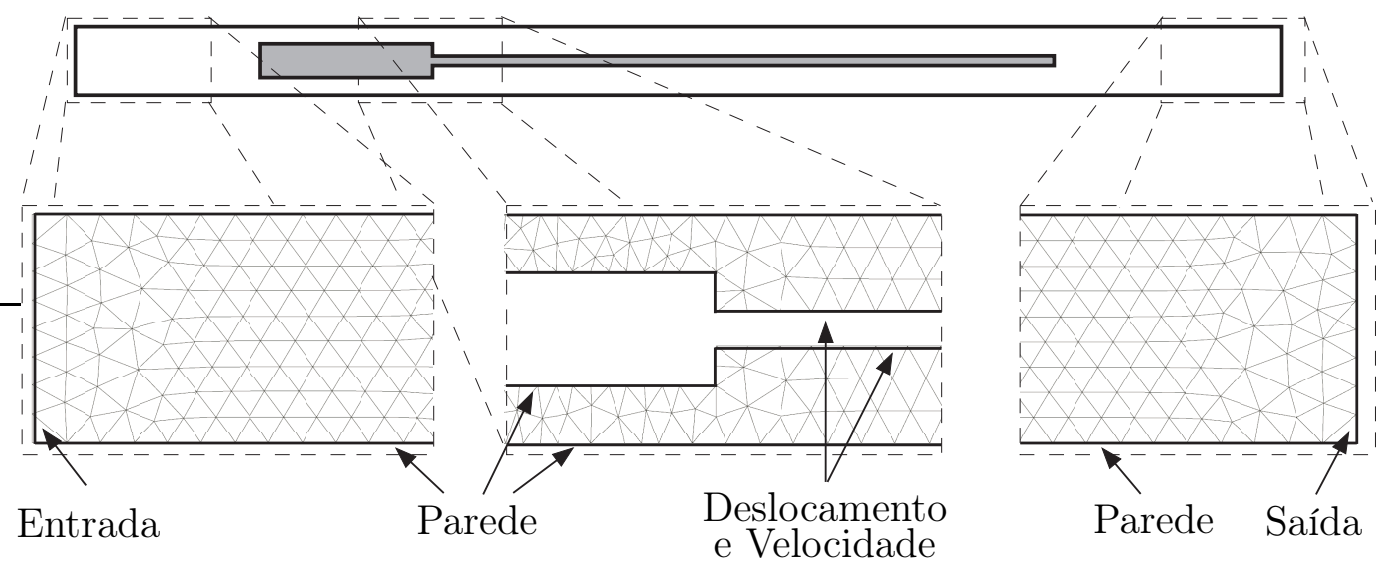

Figura 4.7: Malha de elementos finitos do modelo fluídico e condições de contorno utilizadas.

Na fig. 4.7 vê-se a representação das condições de contorno na região de entrada impostas pelo problema da bomba de fluxo piezelétrica. Nas paredes é imposta a condição de não deslizamento e nos nós do atuador bilaminar são impostos deslocamentos e velocidades de acordo com o modo de vibrar desejado, obtidos de uma análise computacional acústica do atuador. Na entrada (borda esquerda) e na saída (borda direita) são prescritas pressões relativas nulas, isto é, todo o interior do canal está submerso no fluido e a direção do escoamento é horizontal. Tendo definido as condições de contorno, um dos passos finais antes de rodar a simulação propriamente dita é a definição das propriedades do elemento utilizado para a simulação, no caso, o "FLUID142". Para a 
simulação da bomba de fluxo, é necessário definir a densidade e a viscosidade do fluido. O fluido utilizado foi a água, cujas propriedades estão listadas na tabela 4.1. Por fim, deve-se especificar as faces do atuador como fronteira móvel (formulação ALE) para que a malha seja rearranjada a cada iteração, adequando-se às condições impostas.

As dimensões do canal retangular são $4 \mathrm{~mm}$ de altura e $20 \mathrm{~mm}$ de largura. Os parâmetros $A$ e $f$ são obtidos da análise harmônica descrita na seção 4.1, que são consideradas como boas aproximações, especialmente para a amplitude de oscilação, a qual não é possível ser medida experimentalmente no momento. Conforme dito anteriormente, em trabalhos anteriores (NAKASONE et al., 2005; NAKASONE, 2006; PIRES et al., 2006) verificou-se que o segundo modo de vibrar gera vazões maiores do que o primeiro modo de vibrar. Portanto, neste trabalho apenas o segundo modo de vibrar é simulado computacionalmente, devido aos custos computacionais. O primeiro modo de vibrar é analisado nos testes experimentais. O segundo modo de vibrar, considerando o fluido ao redor do atuador piezelétrico, tem a freqüência de $320 \mathrm{~Hz}$ e amplitude pico-a-pico de 150 $\mu \mathrm{m}$ para a tensão de $60 V_{p p}$ (voltagem pico-a-pico) aplicada nos eletrodos. É realizada uma análise transiente até o instante de $2,0 \mathrm{~s}$, pois neste instante o escoamento já é estacionário. A fig. 4.8 mostra os vetores de velocidade do escoamento ao longo do canal no instante 1,52 s (a extremidade do atuador encontra-se no ponto mais alto, isto é, 75 $\mu \mathrm{m})$ e a fig. 4.9 exibe o gráfico da vazão média na saída do canal.

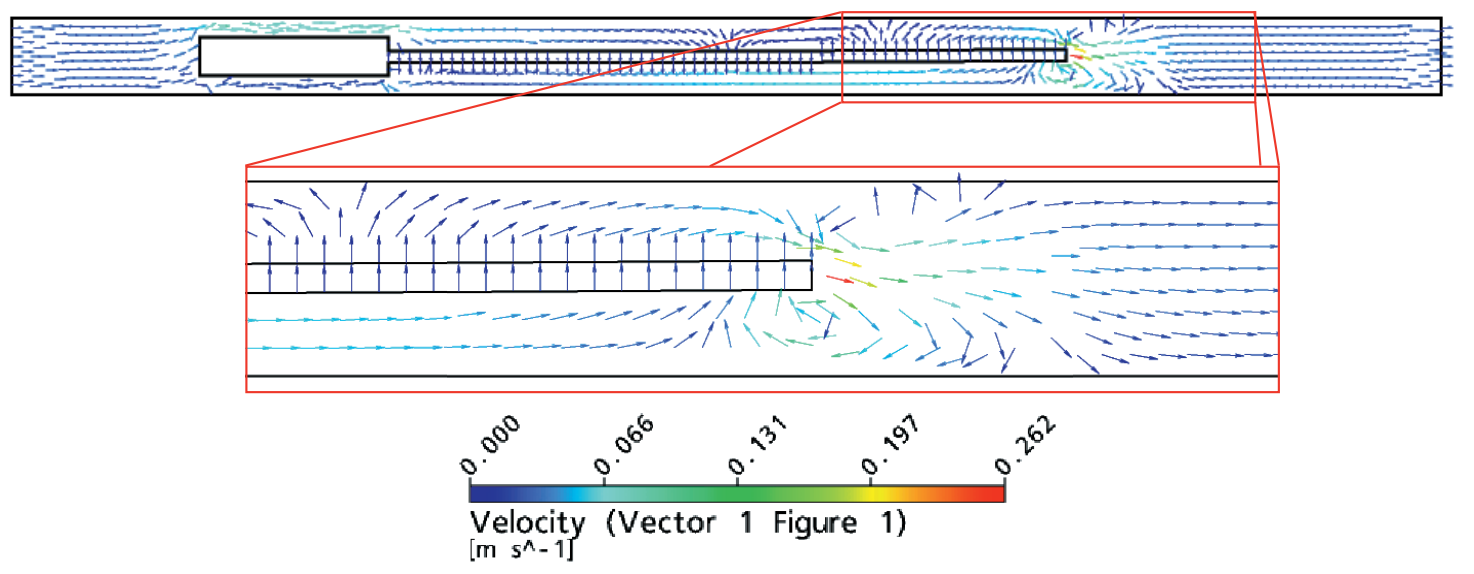

Figura 4.8: Distribuição dos vetores de velocidade no instante 1,52 s.

De acordo com o gráfico apresentado na fig. 4.9, a simulação computacional do escoamento apresenta na saída do canal a vazão média de $111 \mathrm{~cm}^{3} / \mathrm{min}$, que é calculada considerando a seção retangular do canal com as dimensões de $4 \mathrm{~mm} \times 20 \mathrm{~mm}$. A fig. 4.10 mostra a curva de vazão em função da freqüência de excitação do atuador. A curva 


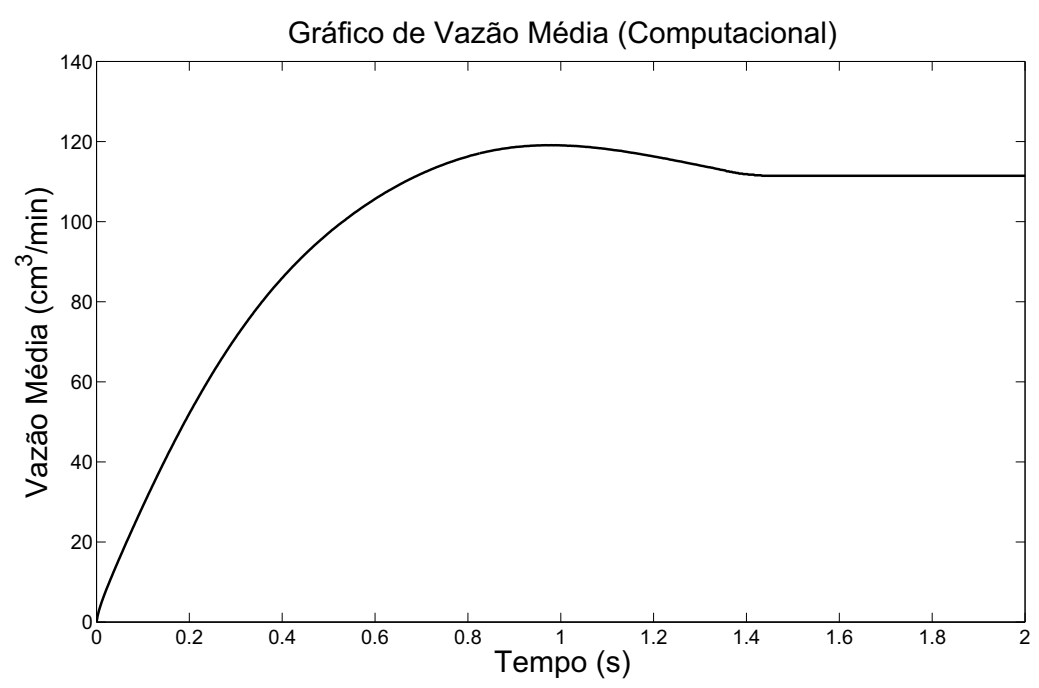

Figura 4.9: Gráfico da vazão média em função do tempo obtido computacionalmente para a freqüência de $320 \mathrm{~Hz}$.

experimental é explicada na seção 4.3 .

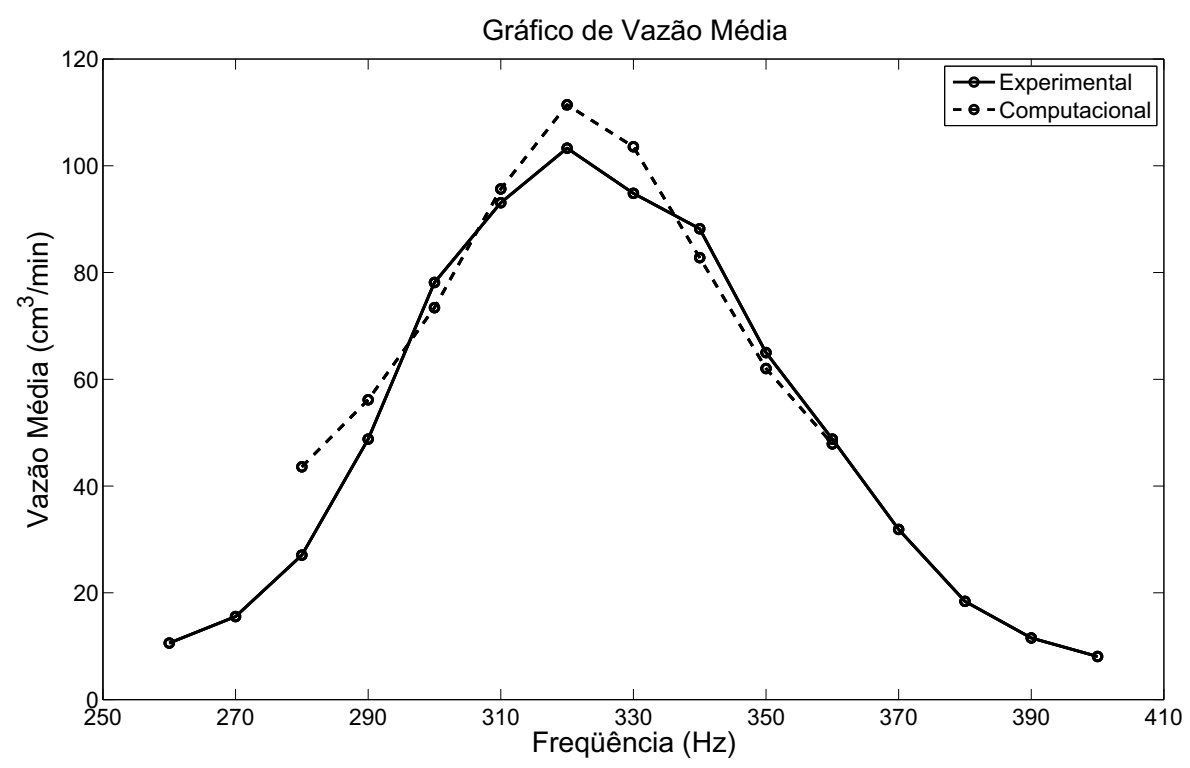

Figura 4.10: Gráfico de vazões médias em função da freqüência, computacional e experimental.

A pressão é calculada da seguinte forma: para um determinado instante de tempo, calcula-se as pressões médias de diversas seções transversais ao longo do canal. Para calcular a pressão efetiva de cada seção transversal do canal, calcula-se a média das pressões de cada seção no intervalo de um ciclo computacional, isto é, uma oscilação completa do atuador piezelétrico. A fig. 4.12 mostra a distribuição de pressão no interior 
do canal no instante 1,75 s e a fig. 4.12 mostra em detalhe a distribuição de pressão na ponta do atuador, juntamente com os vetores de velocidade.

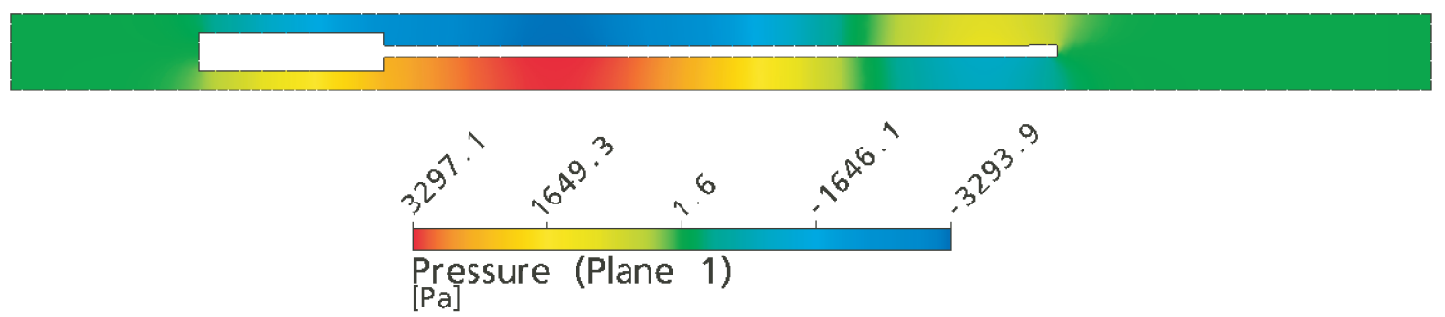

Figura 4.11: Distribuição de pressão ao longo do canal obtida computacionalmente para o instante $1,75 \mathrm{~s}$.

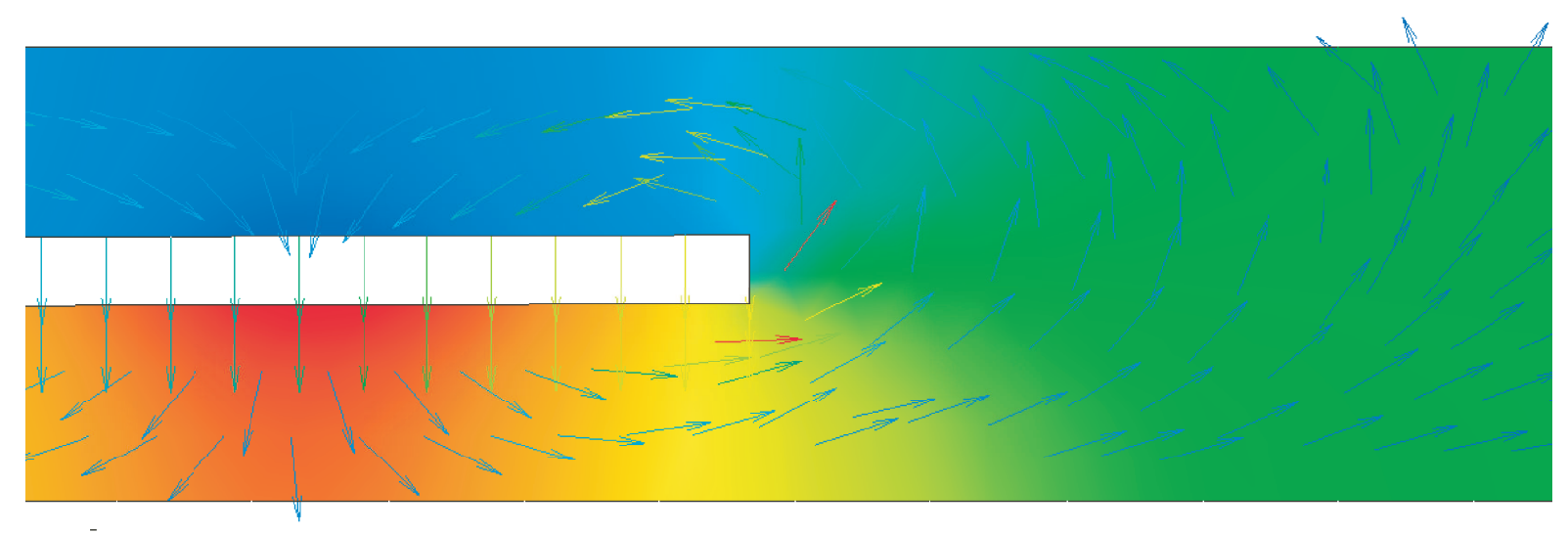

Figura 4.12: Detalhe da distribuição de pressão na ponta do atuador e vetores de velocidade para o instante $1,78 \mathrm{~s}$.

A fig. 4.13 mostra o gráfico das pressões médias máximas para diferentes freqüências, onde pode ser visto o valor máximo computacional de aproximadamente $11 \mathrm{mmH}_{2} \mathrm{O}$ para a freqüência de $320 \mathrm{~Hz}$. A curva de pressão experimental da fig. 4.13 é explicada na seção 4.3 .

Na próxima seção é descrito o protótipo fabricado e os testes experimentais realizados.

\subsection{Verificação Experimental}

Para validar os resultados obtidos computacionalmente, decidiu-se fabricar um protótipo experimental. Nesta seção são descritos a fabricação do protótipo, os testes experimentais realizados e os resultados obtidos.

A fig. 4.14 mostra um desenho de montagem do protótipo fabricado, que é composto 


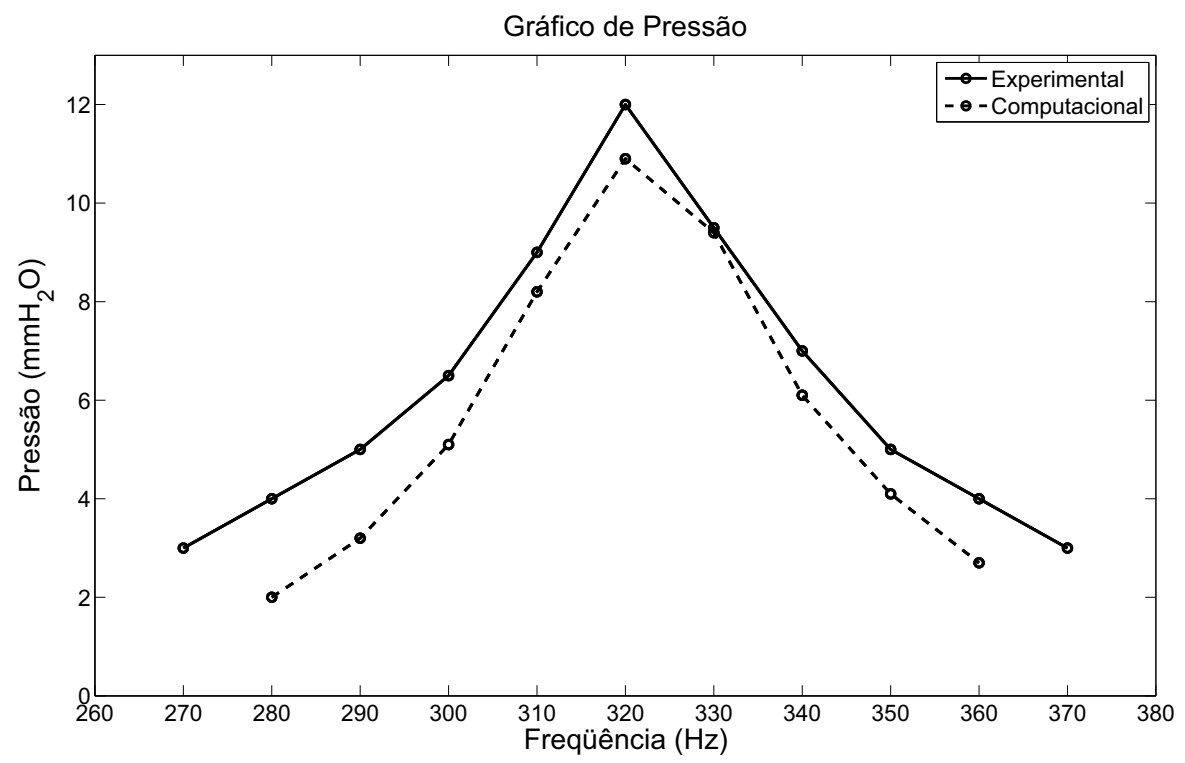

Figura 4.13: Gráfico de pressões médias máximas em função da freqüência, computacional e experimental.

por um par de engastes de alumínio para fixação do atuador, duas peças de acrílico que em conjunto formam o canal de bombeamento e um par de conectores de alumínio para entrada e saída de água e fixação das mangueiras.

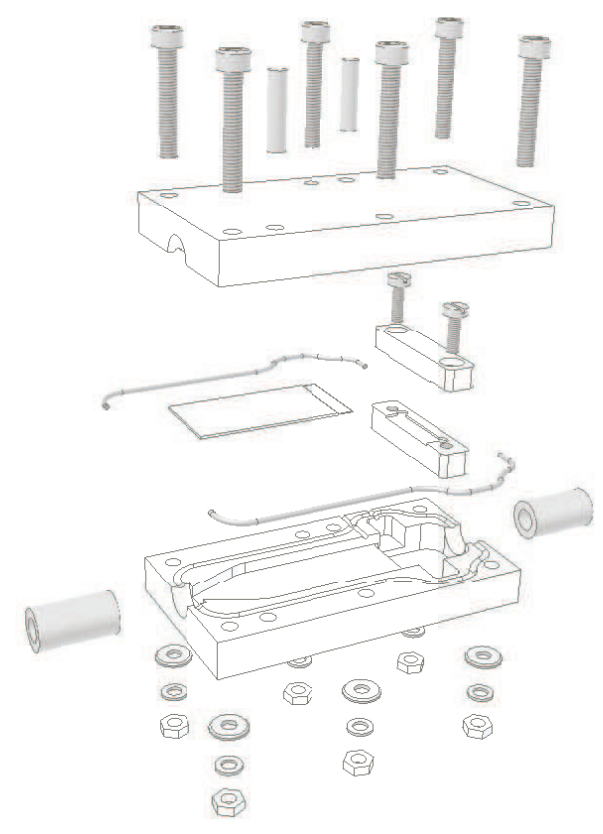

Figura 4.14: Desenho de montagem do protótipo fabricado.

As dimensões do atuador piezelétrico são $40 \times 20 \times 0,6 \mathrm{~mm}$, que fica alojado em um 
canal de seção transversal de $21 \times 4 \mathrm{~mm}$ e comprimento total de $73 \mathrm{~mm}$. O diâmetro dos conectores é de $7 \mathrm{~mm}$.

A conexão elétrica de acionamento do atuador piezelétrico bilaminar é mostrada na fig. 4.15. Um fio elétrico é soldado em uma das faces do atuador, diretamente na cerâmica piezelétrica. Em seguida, o atuador piezelétrico recebe uma camada de tinta isolante, exceto na região de engaste. Um outro fio elétrico é preso entre as duas placas do engaste durante a montagem. A região engastada do atuador, sem tinta isolante, está em contato com o engaste de alumínio, garantindo o fechamento do circuito elétrico.

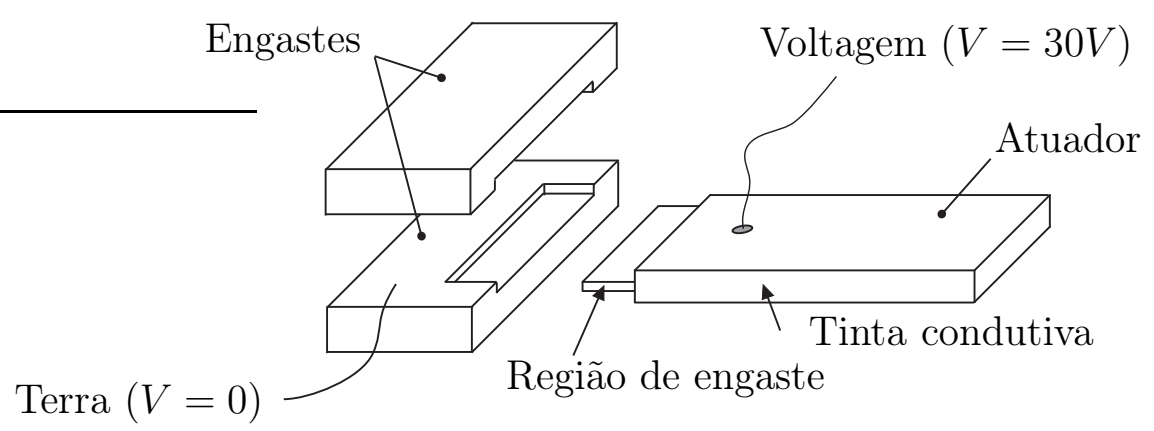

Figura 4.15: Desenho esquemático da conexão elétrica para aplicação da tensão no atuador.

Em todos os testes experimentais realizados no presente trabalho o fluido utilizado é água à temperatura ambiente (aproximadamente $21^{\circ} \mathrm{C}$ ). A temperatura do fluido é importante pois a densidade e a viscosidade dinâmica do meio variam com a temperatura. Variações nestas duas propriedades afetam diretamente as freqüências de ressonância do atuador.

Para acionamento do atuador piezelétrico nos testes experimentais é utilizado um gerador de função INOVEO FG1000. Para determinar as freqüências de ressonância do atuador piezelétrico imerso em água engastado em uma das extremidades, são obtidas curvas experimentais de impedância elétrica (Ohms) em função da freqüência (Hertz) no intervalo de $100 \mathrm{~Hz}$ a $600 \mathrm{~Hz}$, utilizando o impedômetro HEWLETT PACKARD 4194A. O sinal de saída do impedômetro é capturado em um computador com uma placa de aquisição de sinais utilizando o software MATLAB e o gráfico obtido pode ser visto na fig. 4.4a. De acordo com este gráfico, o sistema apresenta uma freqüência de ressonância em $330 \mathrm{~Hz}$.

Conhecendo-se as freqüências de ressonância do protótipo, o próximo teste realizado é a medição da vazão gerada pela bomba de fluxo piezelétrica. O método de medição 
da vazão consiste em associar um tubo de vidro de seção transversal circular, cuja área e comprimento são conhecidos, em série com a saída da bomba de fluxo (ver desenho esquemático da fig. 4.16).

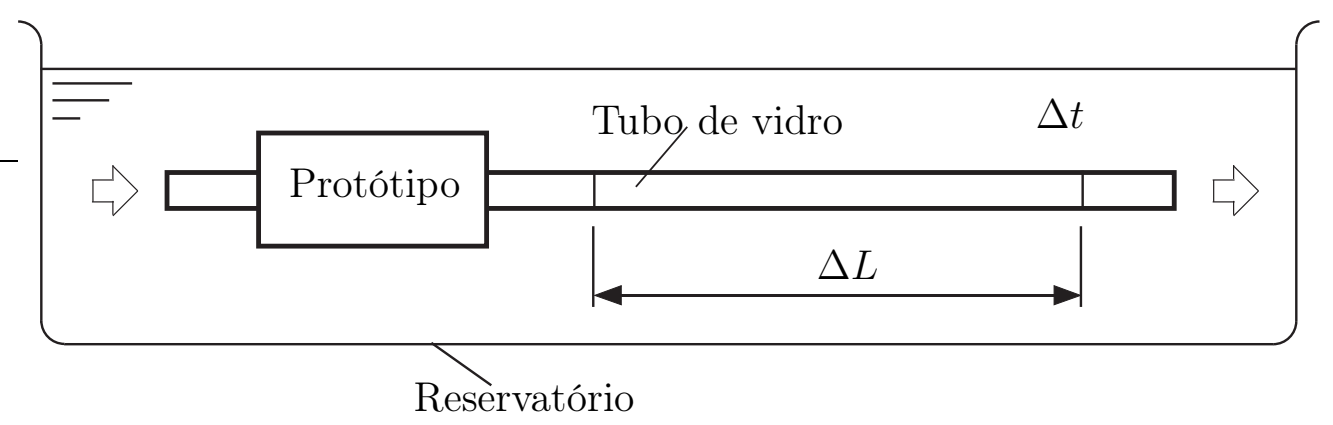

Figura 4.16: Esquema de medição experimental da vazão.

O protótipo é mantido na horizontal em um reservatório de grandes dimensões para que não haja diferença de pressão na entrada e saída do sistema. Ao ligar o gerador de funções, injeta-se um corante na entrada do protótipo a fim de permitir a visualização do escoamento e formação dos vórtices no interior do canal. Na região de saída o escoamento é laminar e é possível visualizar o corante no interior do tubo de vidro. No centro do tubo a velocidade máxima é calculada através da medição do tempo $\Delta t$ que o corante leva para atravessar o comprimento conhecido $\Delta L$ e, conforme é conhecido da teoria da mecânica dos fluidos, a velocidade média de um escoamento laminar no interior de um tubo circular é calculada pela equação $\bar{V}=V_{\max } / 2$. Conhecendo-se a velocidade média no interior do tubo e a área da seção transversal, é possível calcular a vazão $Q$ para uma mesma pressão $P$ na entrada e saída do protótipo e para um determinado sinal senoidal, com freqüência e voltagem conhecidas.

Antes de realizar os testes como o protótipo completo, é necessário verificar se o atuador piezelétrico está funcionando corretamente. Para isso, fixa-se o atuador piezelétrico no engaste de alumínio e, imerso em água, aciona-se o atuador utilizando o gerador de funções. Um fato interessante observado nestes testes preliminares é o surgimento de pequenas ondas nas superfícies do atuador piezelétrico, conforme pode ser visto no desenho esquemático da fig. 4.17. Estas ondas são observadas quando o atuador é posicionado de forma que fique com apenas metade de sua estrutura imersa em água. Uma hipótese levantada para o surgimento destas ondas é a excitação do atuador piezelétrico em uma alta freqüência desconhecida, devido à alguma falha na fabricação do atuador piezelétrico, fazendo com que vibre em outro modo de vibrar. Para amenizar estas ondas de alta freqüência na superfície do atuador, é utilizado uma película 
de isopropileno em torno do atuador piezelétrico. Um fato curioso é que, com a ausência desta película, a vazão observada no protótipo dá-se no sentido contrário ao do escoamento obtido computacionalmente. Após a realização de novos testes experimentais com a película de isopropileno é comprovada a diminuição das ondas geradas nas superfícies do atuador e a vazão gerada pelo atuador dá-se no sentido esperado, conforme os resultados computacionais. Além disso, durante os testes experimentais é verificado que o desempenho do atuador piezelétrico é bastante sensível ao aperto dos engastes, uma vez que o funcionamento correto do atuador depende da rigidez dos engastes.

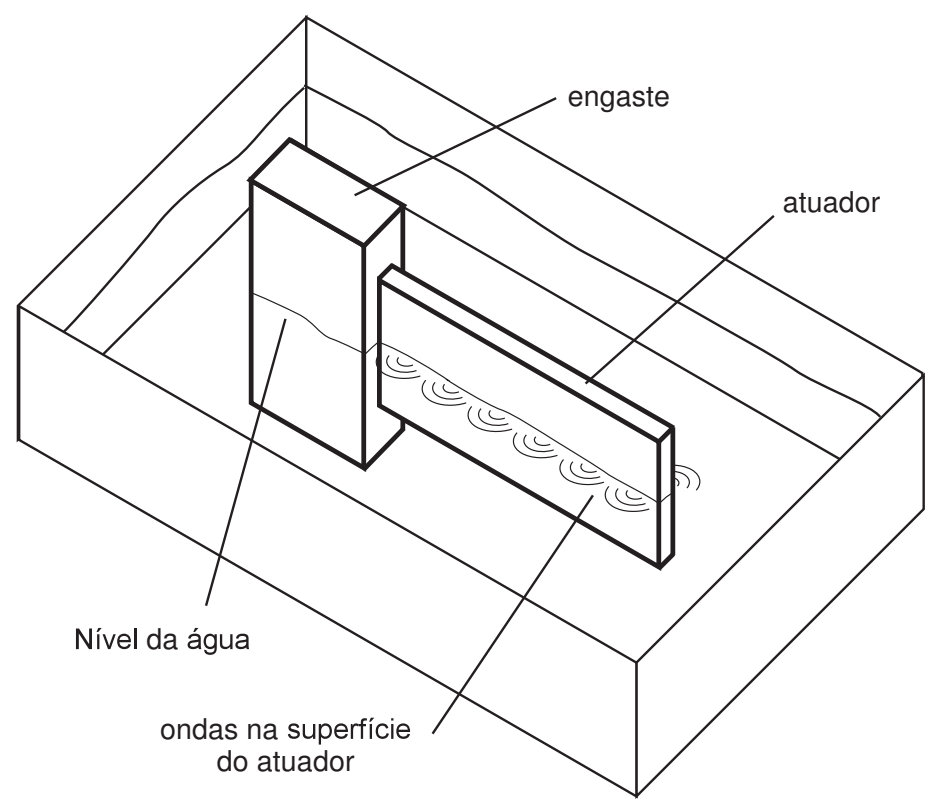

Figura 4.17: Desenho esquemático das ondas geradas nas superfícies do atuador piezelétrico.

Em seguida, a curva de vazão $\left(\mathrm{cm}^{3} / \mathrm{min}\right)$ em função da freqüência $(H z)$ é obtida (ver fig. 4.10), mantendo-se a voltagem aplicada constante $\left(V_{p p}\right)$. Os testes experimentais, de acordo com este método, tem o objetivo de avaliar o desempenho do atuador piezelétrico em aplicações de circulação fechada de líquidos, pois a condição de mesma pressão na entrada e na saída é satisfeita.

A fig. 4.18 apresenta a seqüencia do teste experimental, onde pode ser visto o escoamento na saída do protótipo. O atuador foi revestido com uma película de isopropileno para evitar o modo de vibrar espúrio, conforme descrito anteriormente. O protótipo é acionado com o sinal senoidal de $60 V_{p p}$ e em um intervalo de freqüência entre $270 \mathrm{~Hz}$ e $410 \mathrm{~Hz}$.

Para verificar a repetibilidade dos resultados obtidos nos testes experimentais, são 


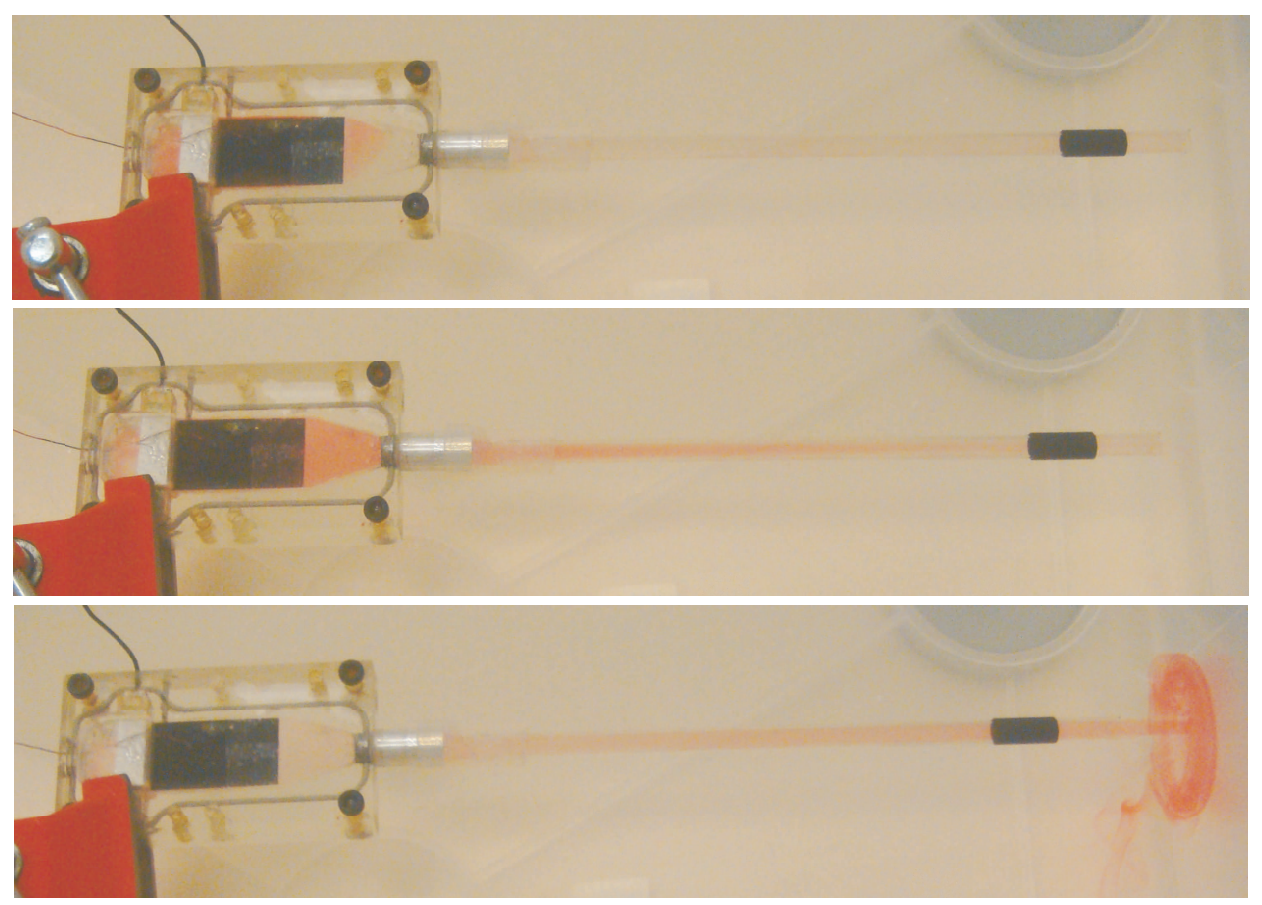

Figura 4.18: Imagens dos testes experimentais de medição de vazão realizados utilizando o protótipo fabricado.

realizados diversos testes semelhantes, sendo que a cada teste o protótipo é desmontado e montado novamente. Em todas as montagens percebe-se que os engastes utilizados para fixação do atuador devem estar rígidos o suficiente para garantir a repetibilidade dos dados obtidos. A rigidez necessária pode ser verificada através do impedômetro descrito anteriormente, a fim de verificar se a freqüência de ressonância está em um valor próximo ao do padrão $(320 \mathrm{~Hz})$. Assim, todos os testes realizados apresentaram uma curva de vazão semelhante à curva experimental apresentada na fig. 4.10.

Da fig. 4.10 é possível identificar a vazão máxima em aproximadamente $103 \mathrm{~cm}^{3} / \mathrm{min}$ quando o protótipo é acionado em $330 \mathrm{~Hz}$. Para este valor de vazão o número de Reynolds é de 546, o que indica que o escoamento está no regime laminar. A fig. 4.10 também mostra que é possível obter diferentes vazões apenas variando-se a freqüência de excitação do atuador piezelétrico.

Além dos testes de vazão, também são realizados testes de pressão utilizando o mesmo protótipo fabricado. Para avaliar a pressão gerada pelo atuador piezelétrico, o protótipo é fixado na vertical, totalmente imerso em água, de forma que apenas o duto de saída fique fora d'água. Ao acionar o atuador piezelétrico, é possível medir a coluna de água que se forma no duto de saída. A fig. 4.19 exibe um dos testes realizados com o protótipo. 


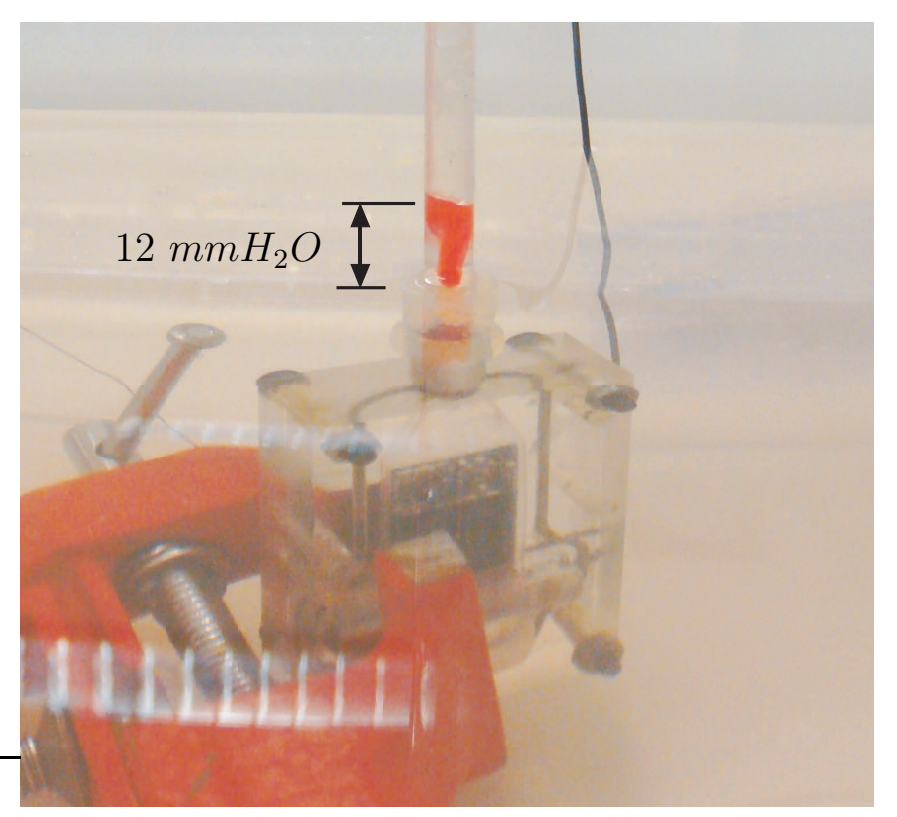

Figura 4.19: Imagem do teste experimental para medição de coluna d'água gerada pelo protótipo.

O teste de pressão é repetido para diversos valores de freqüência, sempre em $60 V_{p p}$. O gráfico da fig. 4.13 apresenta a distribuição de pressão em função da freqüência de excitação do atuador piezelétrico. Deste gráfico é possível ver a pressão máxima gerada pelo atuador piezelétrico de $12 \mathrm{mmH}_{2} \mathrm{O}$ (precisão de $0,5 \mathrm{~mm}$ ) quando o protótipo é acionado a $330 \mathrm{~Hz}$, ou seja, na freqüência de ressonância.

Conforme descrito nas seções 4.2 e 4.3, as fig. 4.4a, 4.10 e 4.13 apresentam, respectivamente, as curvas de impedância elétrica, vazão média e pressão média máxima, obtidas tanto computacional quanto experimentalmente. As curvas apresentadas nestas figuras mostram a concordância entre os resultados computacionais e experimentais (ver tabela 4.2), validando o procedimento computacional utilizado.

Um resumo dos resultados computacionais e experimentais é apresentado na tabela 4.2. A amplitude máxima de oscilação do atuador piezelétrico não pôde ser medida nos testes experimentais.

Tabela 4.2: Resultados computacionais e experimentais.

\begin{tabular}{lccc}
\hline & Computacional & Experimental & Diferença \\
\hline Freqüência de ressonância $(\mathrm{Hz})$ & 320 & 330 & $3,0 \%$ \\
Amplitude máxima pico-a-pico $(\mu \mathrm{m})$ & 150 & - & - \\
Vazão média $\left(\mathrm{cm}^{3} / \mathrm{min}\right)$ & 111 & 103 & $7,2 \%$ \\
Pressão máxima $\left(\mathrm{mmH}_{2} \mathrm{O}\right)$ & 11 & 12 & $8,3 \%$ \\
\hline
\end{tabular}


Comparando os resultados obtidos neste trabalho com os resultados apresentados nos trabalhos anteriores (NAKASONE et al., 2005; NAKASONE, 2006; PIRES et al., 2006), nota-se a importância da utilização de fluido viscoso nas simulações computacionais, pois a ordem de grandeza da vazão obtida é maior neste caso.

Ao longo desta investigação é possível verificar que a análise dos modos de vibrar e freqüências de ressonância do atuador piezelétrico são passos importantes no projeto da bomba de fluxo, uma vez que estas informações são necessárias nas simulações do escoamento. Além disso, testes experimentais mostram que o atuador piezelétrico gera vazões maiores quando o atuador vibra no segundo modo de vibrar, ao invés do primeiro modo, de acordo com o que foi apresentado em trabalhos anteriores (NAKASONE et al., 2005; NAKASONE, 2006; PIRES et al., 2006).

Podem ser definidos alguns parâmetros de maior influência no desempenho da bomba de fluxo piezelétrica estudada, como freqüência de operação, voltagem aplicada e altura do canal de bombeamento. 


\section{BOMBA DE FLUXO PIEZELÉTRICA COM DOIS ATUADORES EM PARALELO}

No capítulo anterior é mostrado o desempenho da bomba de fluxo piezelétrica de um único atuador. Baseando-se no que foi apresentado por Sfakiotakis et al. (SFAKIOTAKIS; LANE; DAVIES, 1999) sobre a formação dos peixes em forma de diamante quando nadam em cardume (ver fig. 1.7), pode-se dividir o estudo de novas configurações de atuadores piezelétricos em dois grupos: atuadores em série e em paralelo. Espera-se que os atuadores configurados em série apresentem um ganho na pressão de saída, enquanto que os atuadores configurados em paralelo apresentem um ganho na vazão de saída.

Neste capítulo é estudada a vantagem de se utilizar a configuração de atuadores piezelétricos bilaminares em paralelo de forma a explorar a interação entre os vórtices gerados por cada atuador, para maximizar a vazão gerada pela bomba de fluxo piezelétrica. A configuração de atuadores em série será estudada no próximo capítulo.

\subsection{Configuração dos Atuadores em Paralelo}

Quando os atuadores piezelétricos em paralelo vibram, duas esteiras de vórtices são geradas. Caso os atuadores sejam excitados em fase, isto é, com o mesmo sinal senoidal de entrada, os vórtices gerados pelos atuadores se intercalarão na região entre eles, conforme mostrado na fig. 5.1a, favorecendo o escoamento do fluido. Caso os atuadores piezelétricos sejam excitados com uma defasagem de $180^{\circ}$, isto é, caso haja uma inversão dos pólos positivo e negativo em um dos atuadores, os vórtices gerados pelos atuadores se alinharão na região entre eles, conforme a fig. 5.1b, dificultando o escoamento do fluido. Como não é visada uma aplicação para a configuração da fig. 5.1b no momento, neste capítulo é estudado o modelo para o caso dos atuadores excitados em fase (ver fig. 5.1a), que tem a 
possibilidade de gerar maiores vazões.

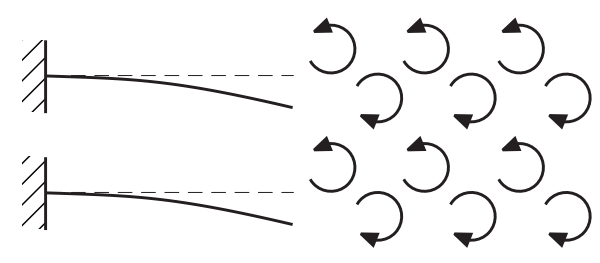

(a)

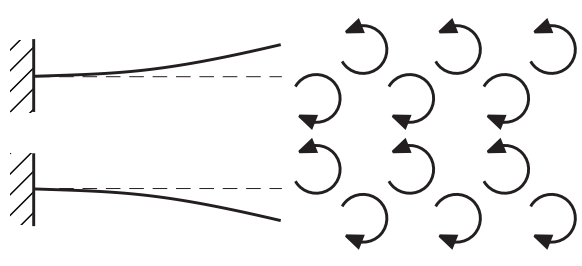

(b)

Figura 5.1: Atuadores em paralelo excitados em: (a) fase; (b) defasados de $180^{\circ}$.

O que se espera desta nova configuração é que dois atuadores piezelétricos em paralelo, montados em um mesmo canal, gerem maiores vazões do que dois modelos de um único atuador montados em paralelo (ver fig. 5.18).

Seguindo o mesmo procedimento apresentado no capítulo anterior, a seguir são descritas as simulações acústicas e de escoamento de fluido, sendo apresentado o estudo de viabilidade desta nova configuração proposta.

\subsection{Simulação Acústica}

Conforme descrito na seção 4.1, a primeira etapa a ser realizada é simular a estrutura dos atuadores piezelétricos a fim de verificar seus modos de vibrar, freqüências de ressonância e amplitudes de oscilação.

O modelo adotado para a configuração de dois atuadores piezelétricos bilaminares pode ser visto na fig. 5.2, juntamente com suas dimensões. Estas dimensões foram adotadas devido à escolha do atuador N.$^{\circ}$ 40-1040 da APC International, cujas dimensões são $20 \times 40 \times 0,6 \mathrm{~mm}$.

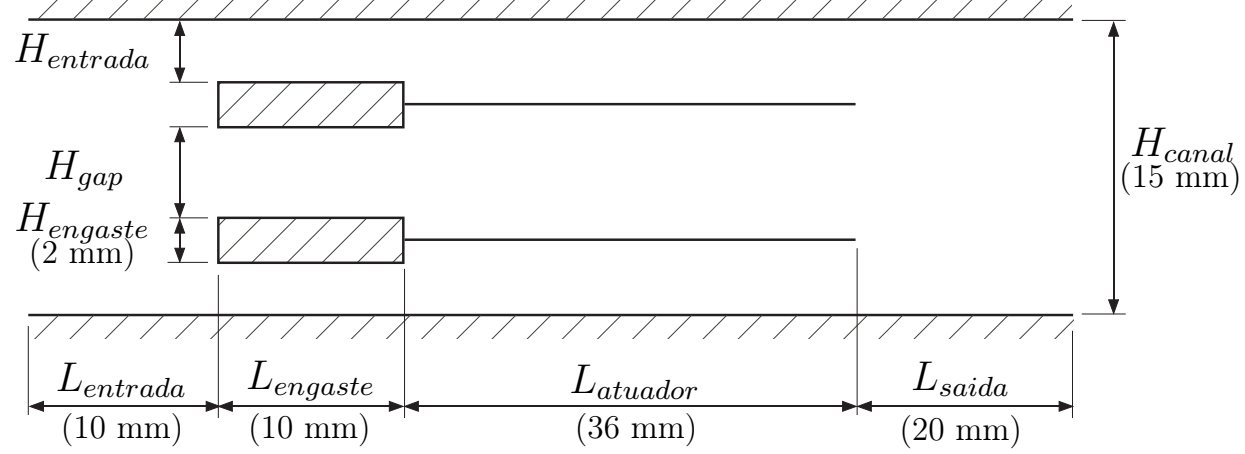

Figura 5.2: Desenho esquemático e dimensões do modelo acústico adotado. 
Para otimizar o aproveitamento dos vórtices gerados pelos atuadores piezelétricos bilaminares é necessário avaliar qual o melhor posicionamento dos atuadores, isto é, qual a melhor dimensão da entrada $H_{\text {entrada }}$ e da distância entre os atuadores $H_{\text {gap }}$, satisfazendo a equação $2 H_{\text {entrada }}+H_{\text {gap }}+2 H_{\text {engaste }}=H_{\text {canal }}$. A altura do canal é fixada em $H_{\text {canal }}=$ $15 \mathrm{~mm}$ e a espessura dos engastes são $H_{\text {engaste }}=2 \mathrm{~mm}$. Assim, é realizada uma análise de sensibilidade dos dois parâmetros $H_{\text {entrada }}$ e $H_{\text {gap }}$. Para uma análise prévia, são definidos os valores 2, 4 e $6 \mathrm{~mm}$ para $H_{\text {gap }}$ (conseqüentemente, os valores para $H_{\text {entrada }}$ são: 2,5, 3,5 e $4,5 \mathrm{~mm}$ ). As propriedades dos materiais utilizados estão listadas na tabela 4.1.

A malha de elementos dos atuadores em meio água para o caso $H_{g a p}=2 \mathrm{~mm}$ e $H_{\text {entrada }}=4,5 \mathrm{~mm}$ pode ser vista na fig. 5.3. Esta malha apresenta um total de 56.260 elementos e 56.864 nós. As cores indicam os diferentes materiais utilizados e também é possível ver as condições de contorno aplicadas no modelo. As paredes do canal e do engaste são consideradas como superfícies sem reflexão de ondas.

Definido o modelo acústico, são rodadas simulações harmônicas a fim de se obter a curva de impedância elétrica e as freqüências de ressonância dos atuadores. A fig. 5.4 ilustra o segundo modo de vibrar dos atuadores piezelétricos em paralelo, excitados em fase e defasados de $180^{\circ}$.

A curva de impedância elétrica dos atuadores em paralelo imersos em água para o caso $H_{\text {gap }}=2 \mathrm{~mm}$ e $H_{\text {entrada }}=4,5 \mathrm{~mm}$ é obtida em função da freqüência do sinal elétrico aplicado ao atuador (60 $V_{p p}$, em fase), mostrada na fig. 5.5a. Neste gráfico é possível ver os pontos de ressonância e anti-ressonância, em $325 \mathrm{~Hz}$ e $380 \mathrm{~Hz}$, respectivamente. A fig. 5.5b mostra a curva da amplitude pico-a-pico das extremidades livres dos atuadores piezelétricos em função da freqüência, cujo valor máximo é de $164 \mu \mathrm{m}$ na freqüência de $335 \mathrm{~Hz}$. A diferença nos valores das freqüências significa que, do ponto de vista elétrico, a corrente elétrica conduzida é máxima (local) em $325 \mathrm{~Hz}$, ou seja, nesta freqüência a potência elétrica é maxima (local). Já do ponto de vista estrutural, a freqüência de ressonância é de $325 \mathrm{~Hz}$.

A partir da análise harmônica obtém-se os deslocamentos verticais dos nós da linha de centro dos atuadores quando excitados na segunda freqüência de ressonância. Com estas informações, é possível obter uma equação polinomial que represente a forma do segundo modo de vibrar dos atuadores piezelétricos, da mesma forma realizada para a bomba de fluxo de um único atuador (ver seção 4.1). Desta equação polinomial obtém-se as equações de deslocamento e velocidade dos nós dos atuadores, que podem ser utilizadas 


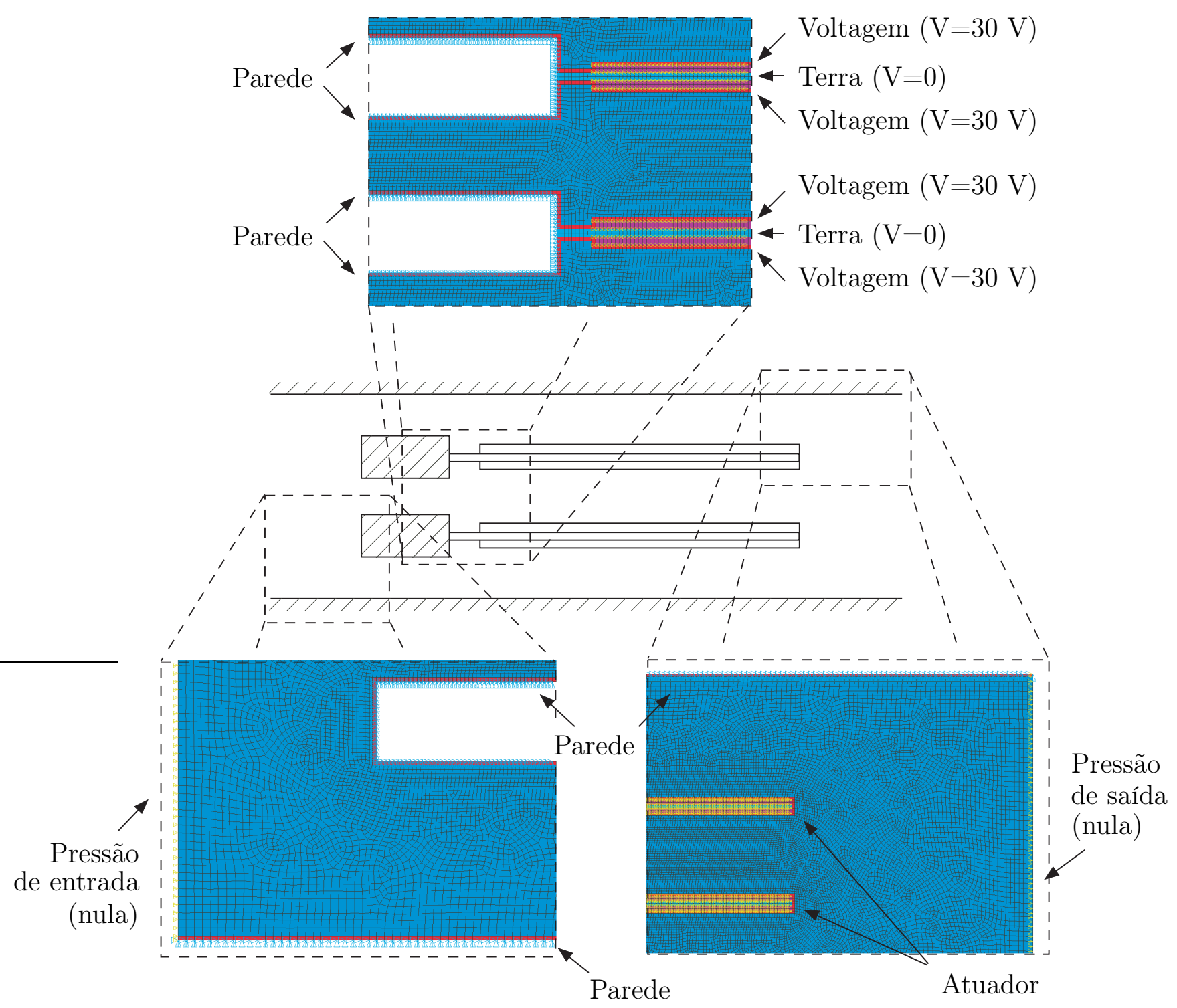

Figura 5.3: Condições de contorno aplicadas no modelo acústico.

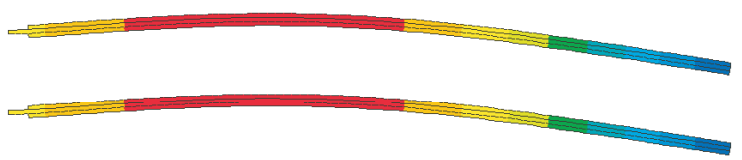

(a)

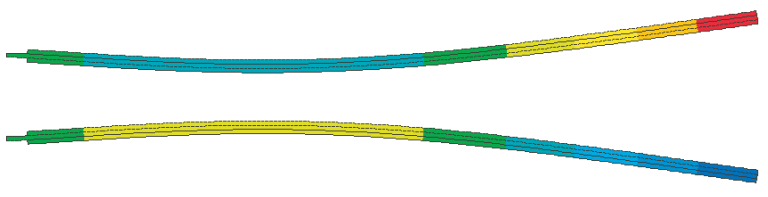

(b)

Figura 5.4: Segundo modo de vibrar $(325 \mathrm{~Hz})$ dos atuadores piezelétricos em paralelo, imersos na água, excitados em: (a) fase e (b) defasados de $180^{\circ}$

como condições de contorno nas simulações de escoamento de fluido.

As simulações harmônicas considerando os outros valores de $H_{\text {gap }}$ e $H_{\text {entrada }}$ citados anteriormente apresentam curvas de impedância elétrica e amplitude semelhantes às 

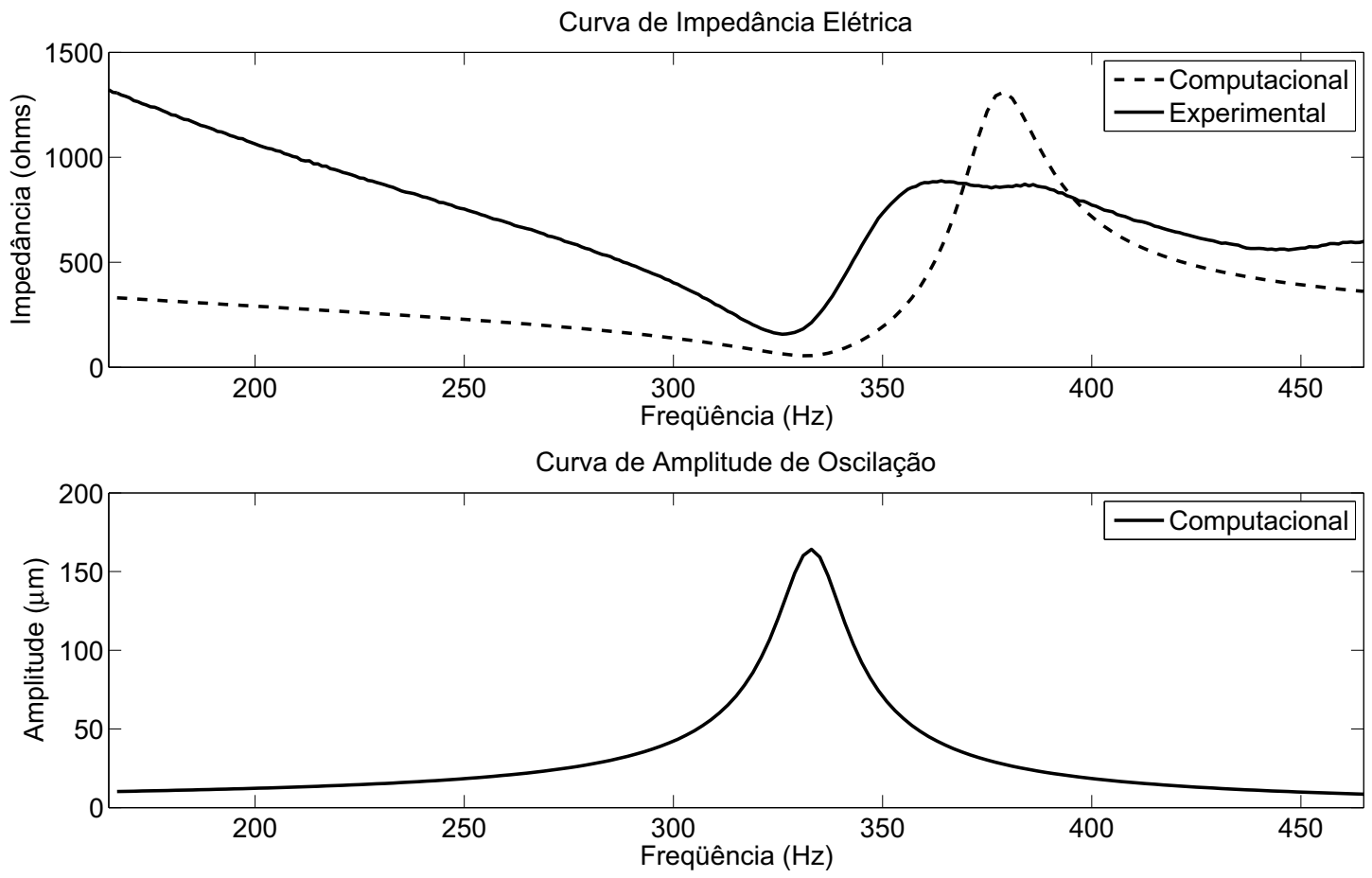

Figura 5.5: (a)Curva de impedância elétrica dos atuadores em paralelo, imersos em água, quando excitados em fase (segundo modo de vibrar); (b) Curva de amplitude pico-a-pico das extremidades livres dos atuadores piezelétricos.

curvas apresentadas na fig. 5.5. Isto significa que os modos de vibrar dos atuadores piezelétricos em paralelo não dependem das suas posições para os valores de $H_{\text {gap }}$ e $H_{\text {entrada }}$ considerados, para um canal com altura $H_{\text {canal }}=15 \mathrm{~mm}$. Portanto, pode-se utilizar as mesmas equações de deslocamento e velocidade do atuador piezelétrico para as distâncias entre os atuadores piezelétricos definidas anteriormente nas simulações do escoamento. No caso da bomba de fluxo piezelétrica oscilatória estudada neste trabalho, é desejável operar os atuadores piezelétricos com o maior deslocamento possível, pois deslocamentos maiores geram maiores vazões (NAKASONE, 2006). Assim, a partir da fig. 5.5, adota-se a freqüência de operação de $335 \mathrm{~Hz}$.

\subsection{Simulação de Escoamento de Fluido}

Concluída a simulação acústica e obtidas a freqüência de ressonância e as equações polinomiais dos deslocamentos e velocidades que representam o movimento dos atuadores, o próximo passo é a análise do escoamento do sistema de bombeamento. 
A fig. 5.6 mostra um desenho esquemático do modelo adotado. Este desenho esquemático exibe a vista lateral da bomba de fluxo piezelétrica, onde $H_{\text {canal }}$ é a altura do canal. Os parâmetros $A$ e $f$ são a amplitude de oscilação pico-a-pico na extremidade livre do atuador piezelétrico e a freqüência de oscilação, respectivamente. A fig. 5.7 ilustra a malha de elementos finitos utilizada nas simulações do escoamento, que contém 15.745 elementos e 15.968 nós, onde também são mostrados detalhes das regiões de entrada e saída do canal e do engaste dos atuadores piezelétricos.

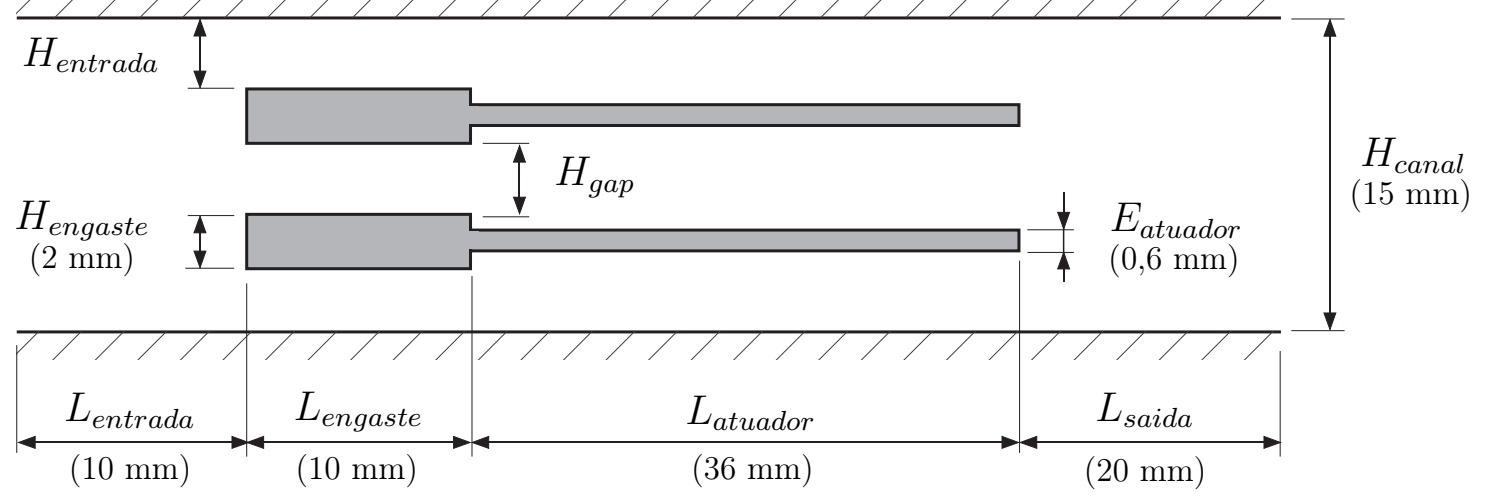

Figura 5.6: Desenho esquemático e dimensões do modelo fluídico adotado para a configuração de dois atuadores em paralelo.

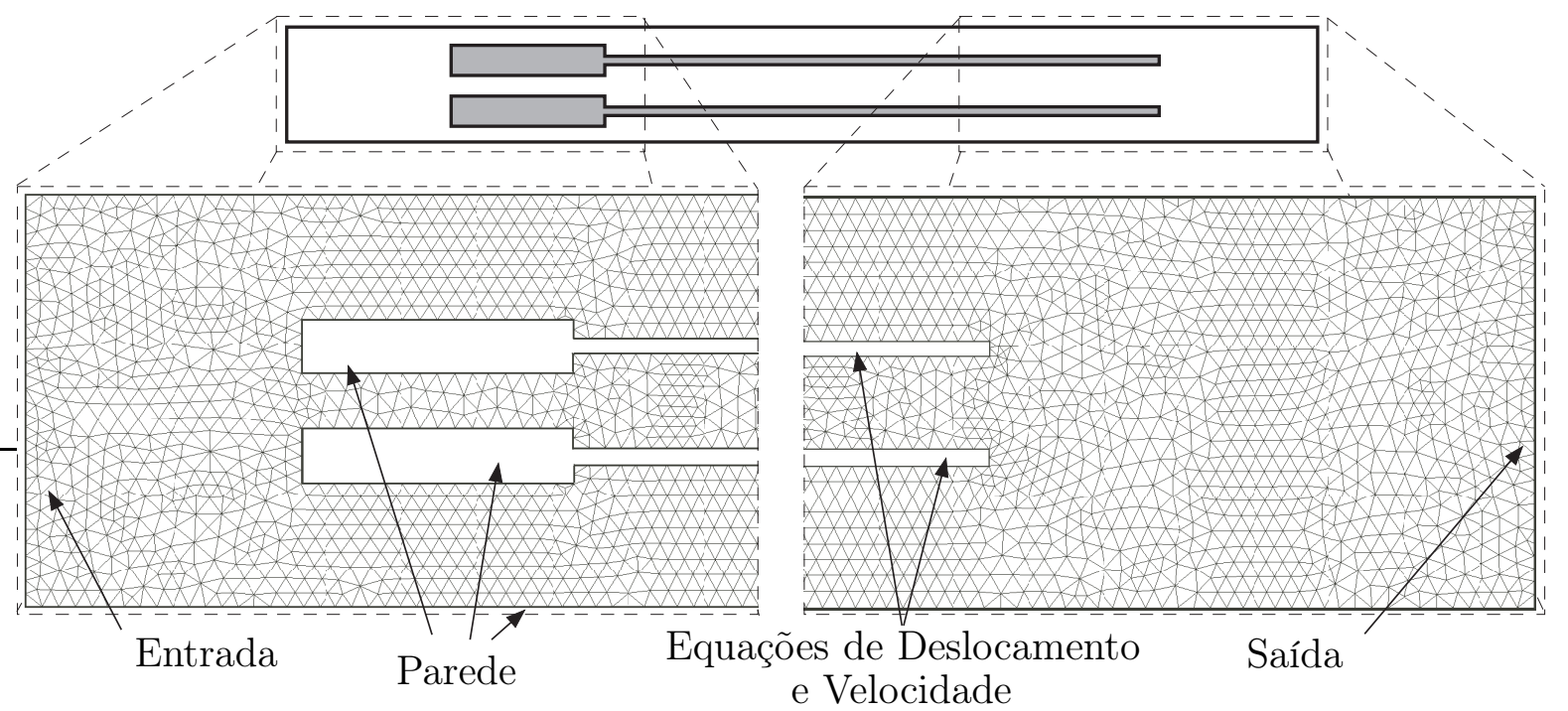

Figura 5.7: Malha de elementos finitos do modelo fluídico de dois atuadores em paralelo.

Na fig. 5.7 vê-se a representação das condições de contorno na região de entrada impostas pelo problema da bomba de fluxo piezelétrica. Nos nós das bordas superior e inferior do duto são impostos deslocamentos e velocidades nulas e nos nós dos atuadores piezelétricos são impostos os deslocamentos e velocidades obtidos na análise acústica. 
Na entrada (borda esquerda) e na saída (borda direita) são prescritas pressões relativas nulas, isto é, todo o interior do canal está submerso no meio fluídico e a direção do escoamento é horizontal. Tendo definido as condições de contorno, um dos passos finais antes de rodar a simulação propriamente dita é a definição das propriedades do elemento utilizado para a simulação, no caso, o "FLUID142". Para a simulação da bomba de fluxo, é necessário definir a densidade e a viscosidade do fluido. O fluido utilizado foi a água, cujas propriedades estão listadas na tabela 4.1. Por fim, deve-se especificar as faces dos atuadores como fronteira móvel (formulação ALE) para que a malha seja rearranjada a cada iteração, adequando-se às condições impostas.

As dimensões do canal retangular são $15 \mathrm{~mm}$ de altura e $20 \mathrm{~mm}$ de largura. Os parâmetros $A$ e $f$ são obtidos da análise harmônica descrita na seção 5.2. O segundo modo de vibrar, considerando o fluido ao redor do atuador piezelétrico, tem a freqüência de 335 $\mathrm{Hz}$ e amplitude pico-a-pico de $164 \mu \mathrm{m}$ para a tensão de $60 V_{p p}$ (voltagem pico-a-pico) aplicada nos eletrodos. É realizada uma análise transiente até o instante de 2,5 s, pois neste instante o escoamento já é estacionário.

A fig. 5.8 mostra os vetores de velocidade do escoamento ao longo do canal no instante $2,09 \mathrm{~s}$, para o caso $H_{\text {gap }}=2 \mathrm{~mm}$ e $H_{\text {entrada }}=4,5 \mathrm{~mm}$. Na fig. 5.9, que mostra os vetores de velocidade na região dos engastes, é possível ver a ocorrência de refluxo na região acima do engaste superior. Na fig. 5.10, que mostra a região das extremidades dos atuadores, pode-se ver a formação de vórtices nos atuadores e o desenvolvimento do escoamento entre eles.
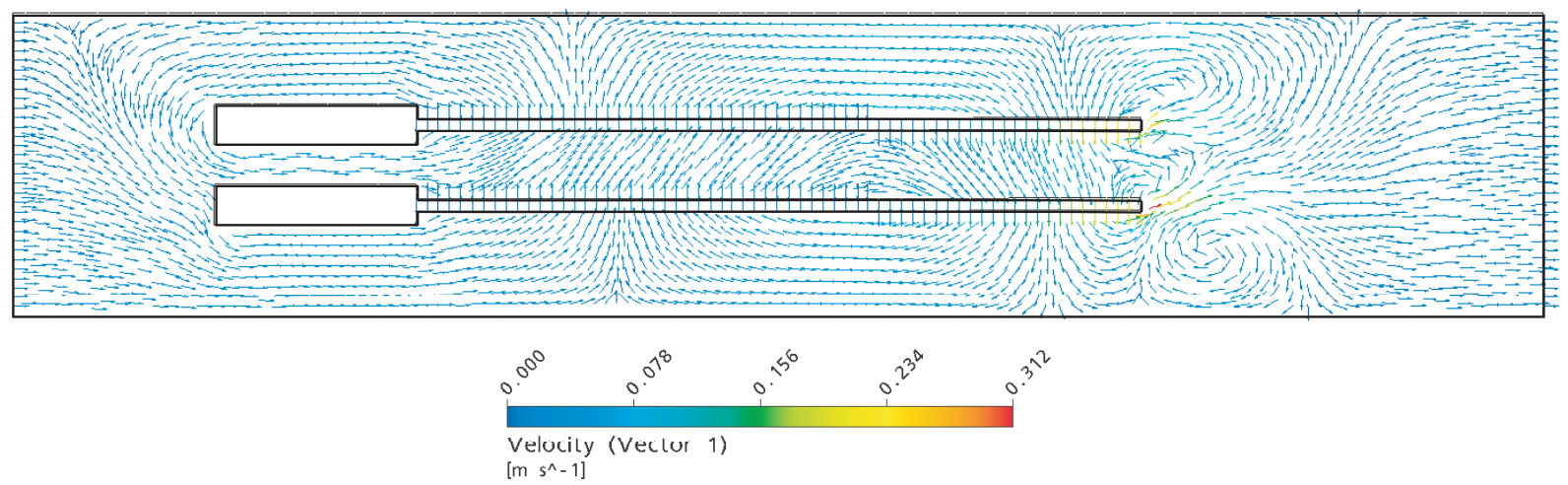

Figura 5.8: Distribuição dos vetores de velocidade no instante 2,09 s.

A fig. 5.11 exibe o gráfico da vazão média na saída do canal até atingir o regime estacionário. De acordo com este gráfico, a simulação computacional do escoamento com os parâmetros $H_{\text {gap }}=2 \mathrm{~mm}$ e $H_{\text {entrada }}=4,5 \mathrm{~mm}$ apresenta na saída do canal a vazão 


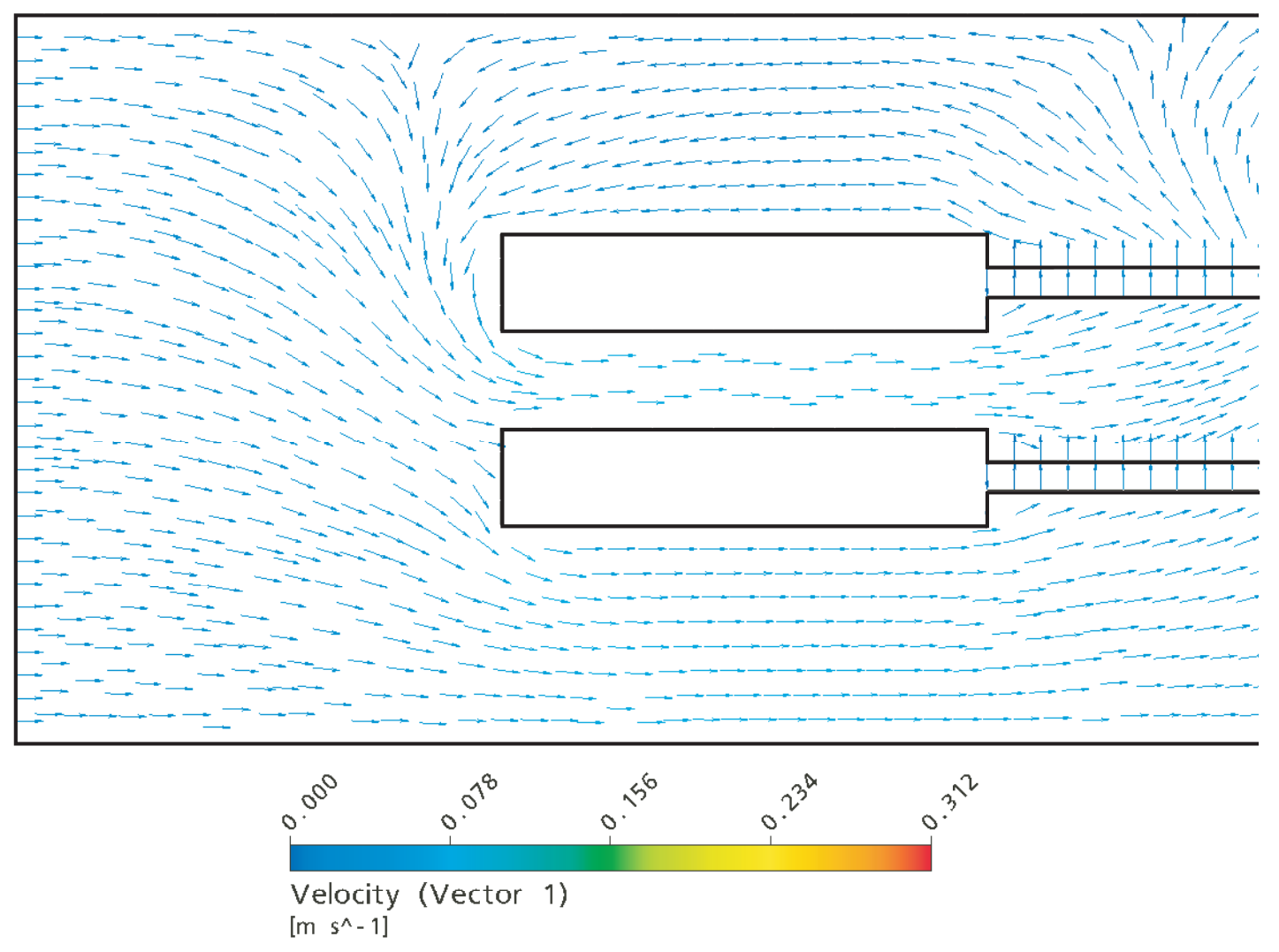

Figura 5.9: Distribuição dos vetores de velocidade na região dos engastes, no instante 2,09 s.

média de $434 \mathrm{~cm}^{3} / \mathrm{min}$, que é calculada considerando a seção retangular do canal com as dimensões de $15 \mathrm{~mm} \times 20 \mathrm{~mm}$.

Os modelos com distâncias diferentes entre os atuadores piezelétricos também são simulados e a fig. 5.12 mostra o gráfico da vazão máxima obtida para cada caso.

Para avaliar a influência da freqüência de excitação dos atuadores piezelétricos na vazão gerada pela bomba de fluxo, adota-se o modelo do caso ótimo visto anteriormente $\left(H_{\text {gap }}=2 \mathrm{~mm}\right.$ e $\left.H_{\text {entrada }}=4,5 \mathrm{~mm}\right)$ e é levantada a curva de vazão média em função da freqüência, mostrada na fig. 5.13.

A pressão gerada pelos atuadores piezelétricos em paralelo é periódica e os valores médios máximos também ocorrem nas extremidades livres dos atuadores. A fig. 5.14 mostra o gráfico das pressões médias máximas para diferentes freqüências considerando as mesmas dimensões de $H_{\text {gap }}$ e $H_{\text {entrada }}$, onde pode ser visto o valor máximo de 11,9 $\mathrm{mmH}_{2} \mathrm{O}$ para a freqüência de $335 \mathrm{~Hz}$. 

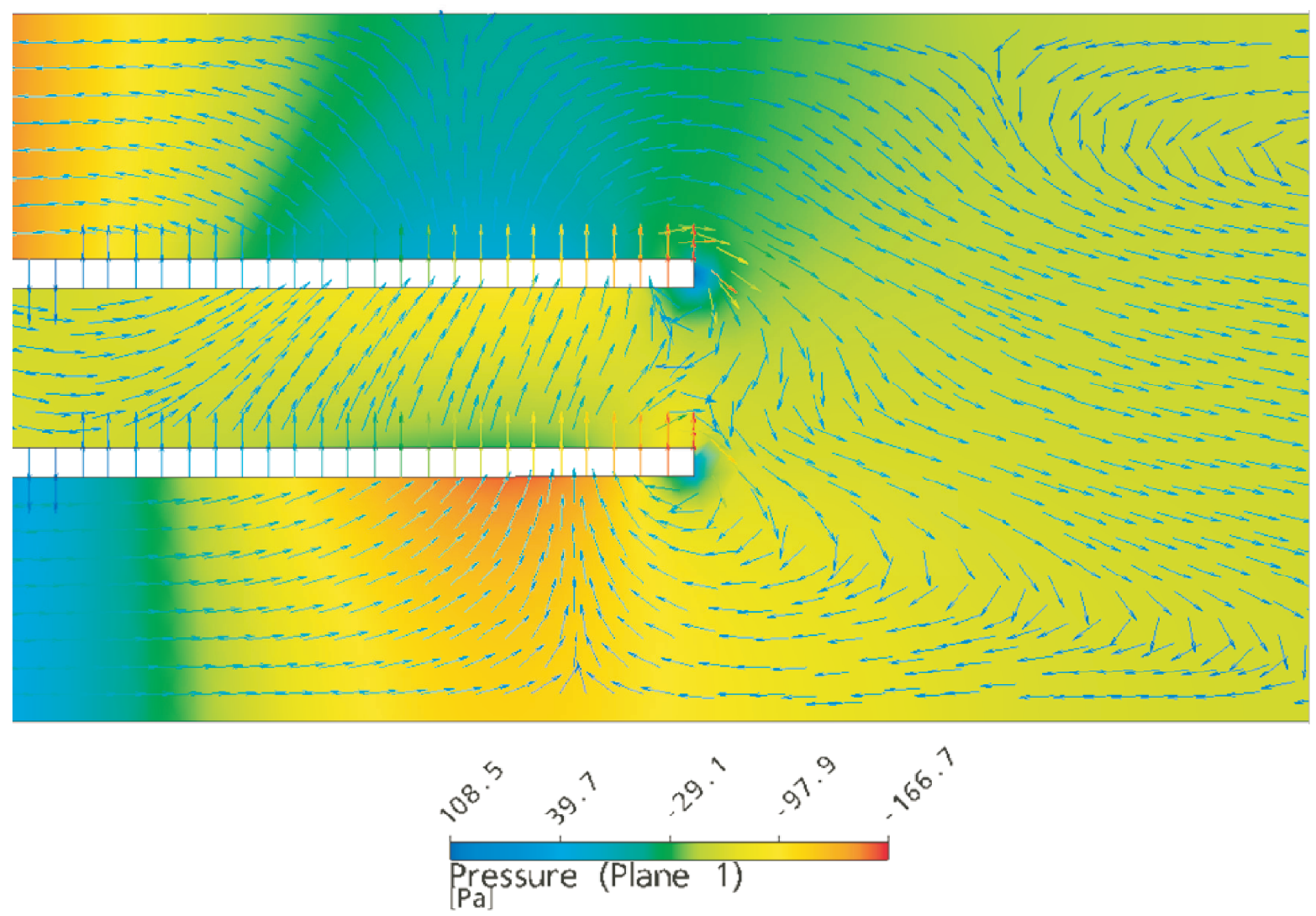

Figura 5.10: Distribuição da pressão e dos vetores de velocidade na região das extremidades dos atuadores, no instante 2,09 s.

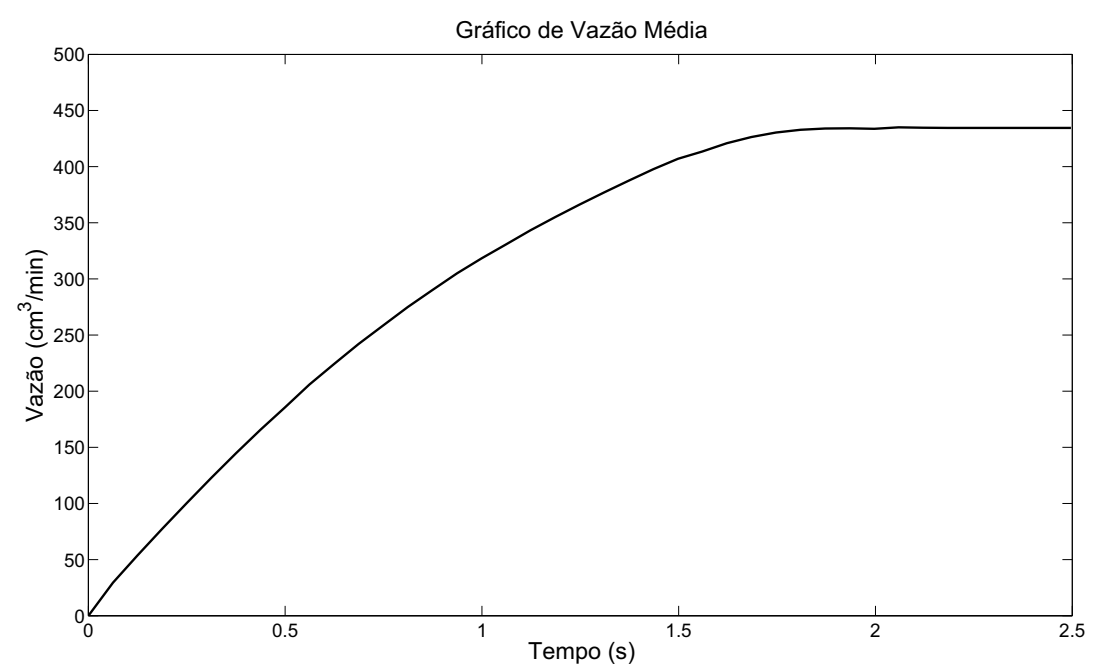

Figura 5.11: Gráfico da vazão média em função do tempo utilizando dois atuadores em paralelo para freqüência de $335 \mathrm{~Hz}$.

\subsection{Verificação Experimental}

Para validar os resultados obtidos computacionalmente, decidiu-se fabricar um protótipo experimental. Nesta seção são descritos a fabricação do protótipo, os testes 


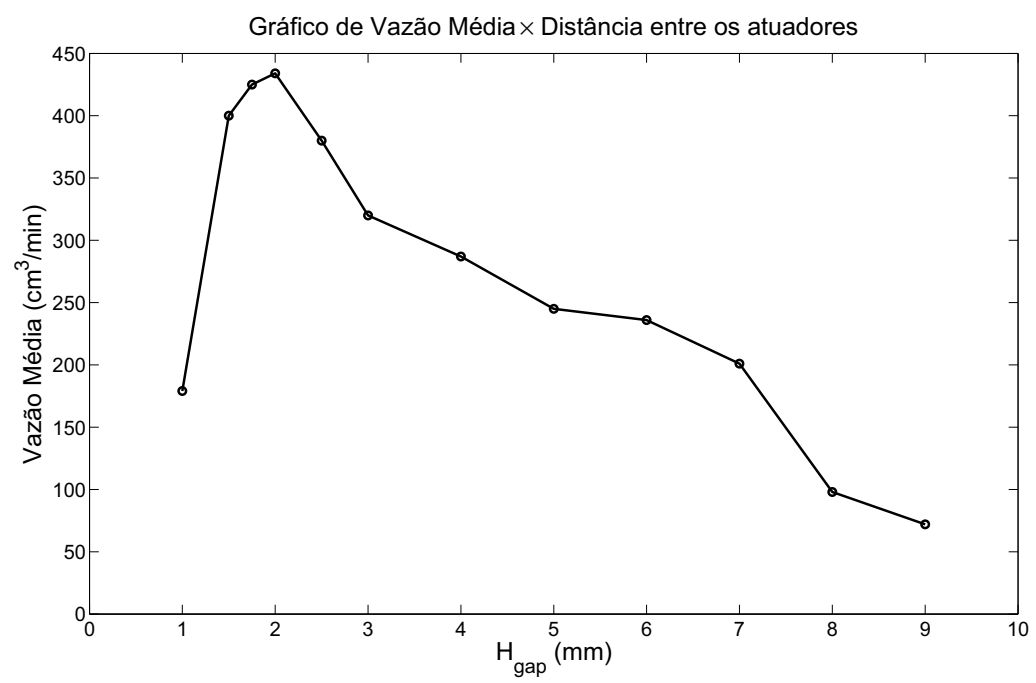

Figura 5.12: Gráfico da vazão média variando a distância entre os atuadores $\left(H_{g a p}\right)$.

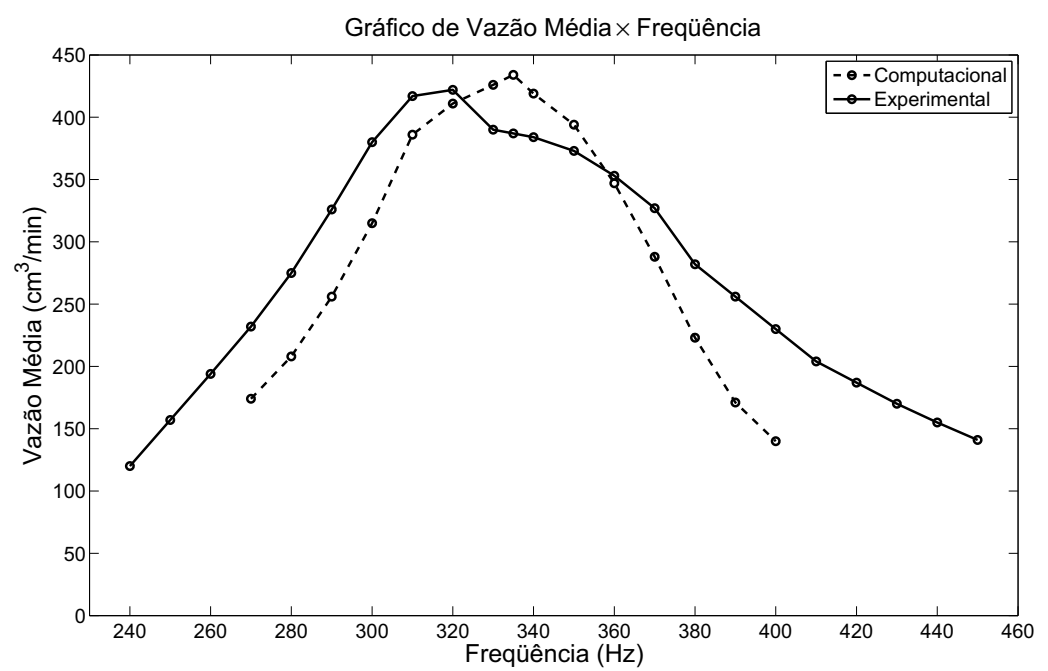

Figura 5.13: Gráfico da vazão média em função da freqüência utilizando dois atuadores em paralelo.

experimentais realizados e os resultados obtidos.

A fig. 5.15 mostra o protótipo de dois atuadores em paralelo. As dimensões do atuador piezelétrico são $40 \times 20 \times 0,6 \mathrm{~mm}$, que fica alojado em um canal de seção transversal de $21 \times 4 \mathrm{~mm}$ e comprimento total de $75 \mathrm{~mm}$. O diâmetro dos conectores é de $7 \mathrm{~mm}$.

Para acionamento dos atuadores piezelétricos nos testes experimentais é utilizado um gerador de função INOVEO FG1000. Para determinar as freqüências de ressonância dos atuadores piezelétricos obtém-se a curva de impedância elétrica seguindo o mesmo procedimento descrito na seção 4.3 e o gráfico obtido pode ser visto na fig. 5.5a. De 


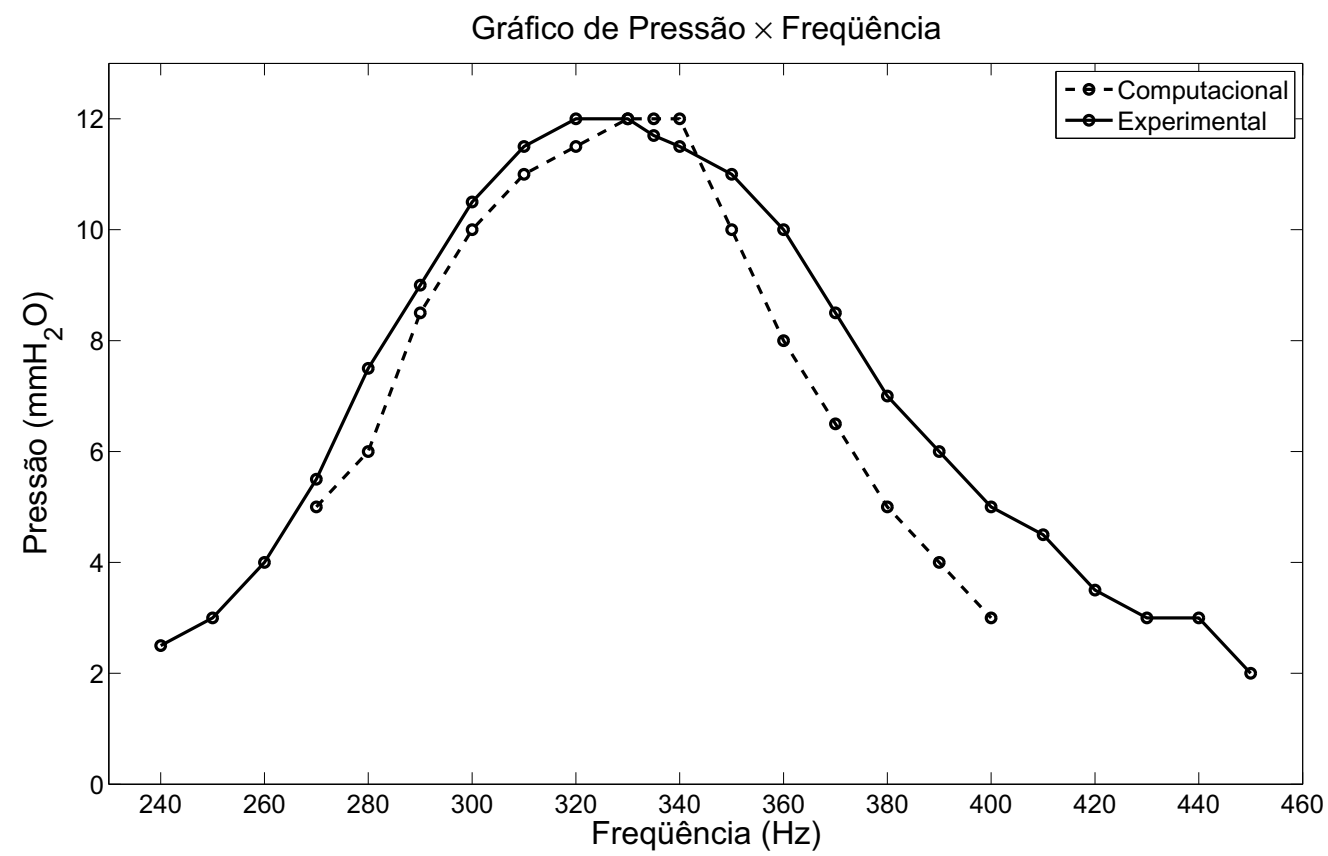

Figura 5.14: Curva de pressão média máxima em função da freqüência.

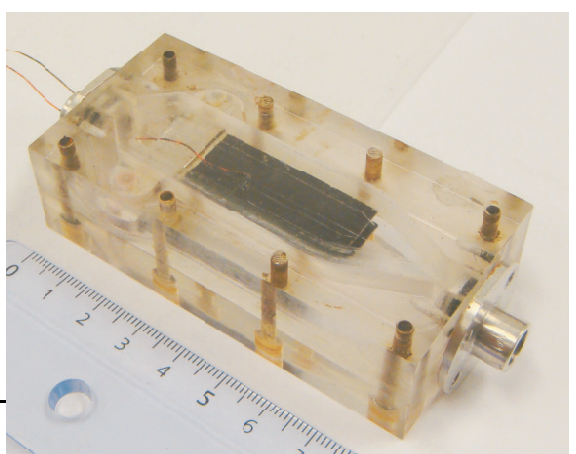

(a)

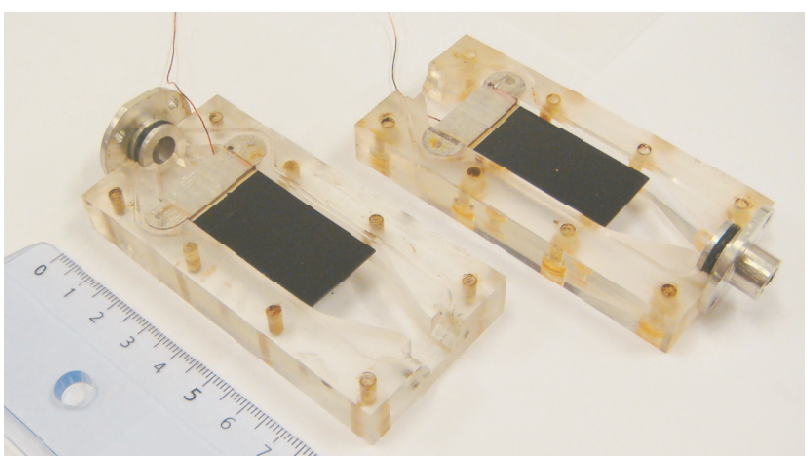

(b)

Figura 5.15: Imagem do protótipo de dois atuadores em paralelo.

acordo com este gráfico, o sistema apresenta uma freqüência de ressonância em $325 \mathrm{~Hz}$.

Conhecendo-se a freqüência de ressonância do protótipo, o próximo teste realizado é a medição da vazão e pressão geradas pela bomba de fluxo piezelétrica. Os métodos de medição de vazão e pressão são descritos na seção 4.3. A curva de vazão em função da freqüência é obtida (ver fig. 5.13), mantendo-se a voltagem aplicada em 60 V. A fig. 5.16 apresenta a seqüência do teste experimental, onde pode ser visto o escoamento na saída do protótipo. Os atuadores são acionados com o sinal senoidal de $60 V_{p p}$ e em fase.

Da fig. 5.13 é possível identificar a vazão máxima em aproximadamente $422 \mathrm{~cm}^{3} / \mathrm{min}$ quando o protótipo é acionado em $325 \mathrm{~Hz}$. Para este valor de vazão o número de Reynolds 

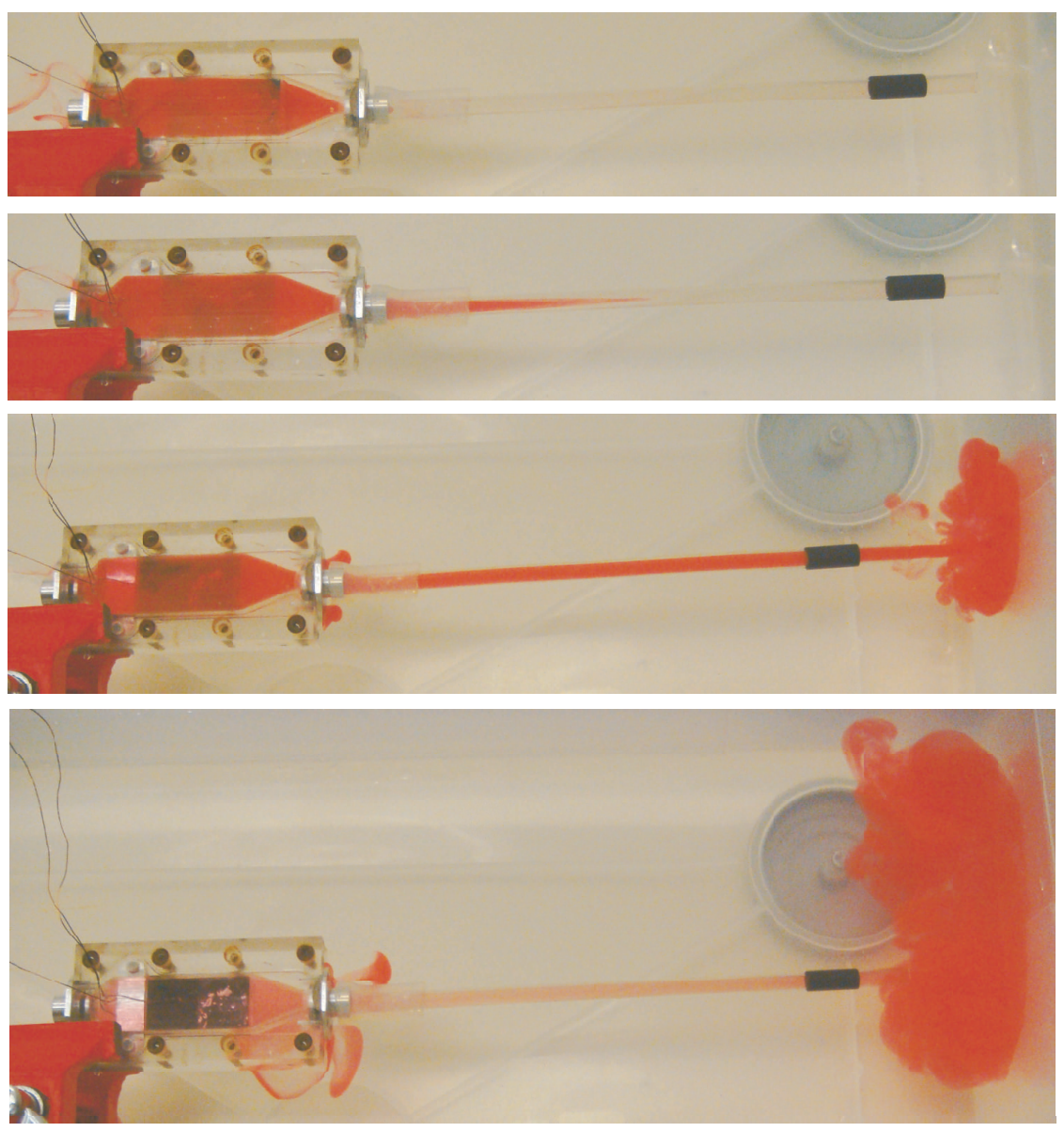

Figura 5.16: Imagens dos testes experimentais para medição de vazão realizados utilizando o protótipo de atuadores em série.

é de 2.079, o que indica que o escoamento está no regime laminar. Esta figura também mostra que há um intervalo de freqüência no qual é possível obter diferentes vazões apenas variando-se a freqüência de excitação dos atuadores piezelétricos.

Além dos testes de vazão, também são realizados testes de pressão utilizando o mesmo protótipo fabricado. Para avaliar a pressão gerada pelos atuadores em paralelo, o protótipo é fixado na vertical, totalmente imerso em água, de forma que apenas o duto de saída fique fora d'água. Ao acionar os atuadores, é possível medir a coluna de água que se forma no duto de saída. A fig. 5.17 exibe um dos testes realizados com o protótipo.

O teste de pressão é repetido para diversos valores de freqüência, sempre em $60 V_{p p}$. O gráfico da fig. 5.14 apresenta a distribuição de pressão em função da freqüência de excitação dos atuadores piezelétricos, onde é possível ver a pressão máxima gerada de 12 $\mathrm{mm} \mathrm{H}_{2} \mathrm{O}$ (precisão de $0,5 \mathrm{~mm}$ ) quando o protótipo é acionado a $325 \mathrm{~Hz}$.

Conforme descrito nas seções 5.3 e 5.4, as fig. 5.5a, 5.13 e 5.14 apresentam, 


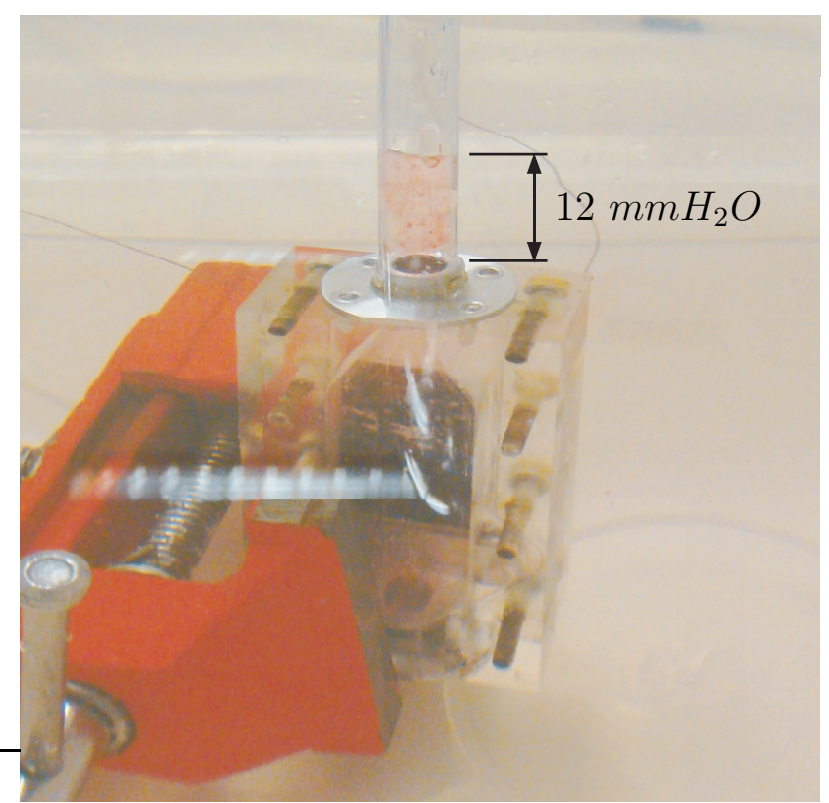

Figura 5.17: Imagem do teste experimental para medição de coluna d'água gerada pelo protótipo de atuadores em paralelo.

respectivamente, as curvas de impedância elétrica, vazão média e pressão máxima, obtidas tanto computacional quanto experimentalmente. As curvas apresentadas nestas figuras anteriores mostram a concordância entre os resultados computacionais e experimentais, validando o procedimento computacional utilizado.

Um resumo dos resultados computacionais e experimentais é apresentado na tabela 5.1. A amplitude máxima de oscilação dos atuadores piezelétricos não pôde ser medida nos testes experimentais.

Tabela 5.1: Resultados computacionais e experimentais da configuração em paralelo.

\begin{tabular}{lccc}
\hline & Computacional & Experimental & Diferença \\
\hline Freqüência de ressonância $(\mathrm{Hz})$ & 335 & 325 & $2,9 \%$ \\
Amplitude máxima pico-a-pico $(\mu \mathrm{m})$ & 164 & - & - \\
Vazão média $\left(\mathrm{cm}^{3} / \mathrm{min}\right)$ & 426 & 422 & $0,9 \%$ \\
Pressão máxima $\left(\mathrm{mm} \mathrm{H}_{2} \mathrm{O}\right)$ & 12 & 12 & $0 \%$ \\
\hline
\end{tabular}

No gráfico da fig. 5.14 é possível notar que o modelo que atinge a maior vazão utilizando dois atuadores piezelétricos é o que possui as dimensões $H_{\text {gap }}=2 \mathrm{~mm}$ e $H_{\text {entrada }}=4,5 \mathrm{~mm}$, cujo valor é de $426 \mathrm{~cm}^{3} / \mathrm{min}$. Se associarmos em paralelo duas bombas de fluxo de um único atuador mostrada no capítulo 4, obteríamos $222 \mathrm{~cm}^{3} / \mathrm{min}$ (a soma de $111 \mathrm{~cm}^{3} /$ min de cada uma). Com o modelo de dois atuadores em paralelo contidos em um mesmo canal, obtém-se $426 \mathrm{~cm}^{3} / \mathrm{min}$, ou seja, um aumento de $92 \%$ na vazão. 


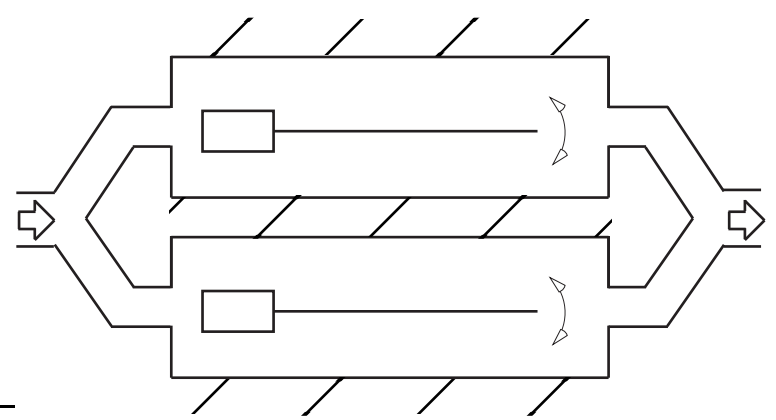

$222 \mathrm{~cm}^{3} / \mathrm{min}$

(a)

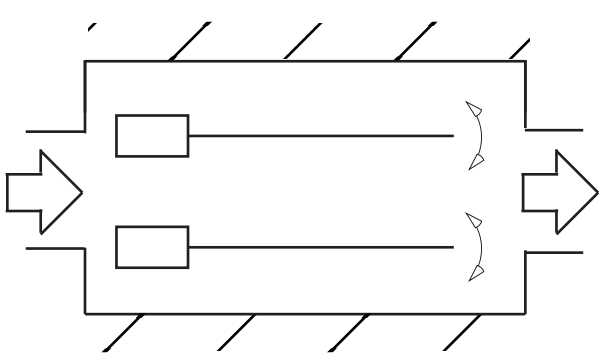

$434 \mathrm{~cm}^{3} / \mathrm{min}$

(b)

Figura 5.18: Comparação das vazões geradas pelo (a) dois modelos de um único atuador em paralelo e pelo (b) modelo de dois atuadores em paralelo.

Portanto, conclui-se que é vantajoso utilizar dois atuadores piezelétricos em paralelo em um mesmo canal a fim de se obter maiores vazões, ao invés de se utilizar duas bombas de fluxo de um único atuador ligadas em paralelo, conforme a fig. 5.18. 


\section{BOMBA DE FLUXO PIEZELÉTRICA COM DOIS ATUADORES EM SÉRIE}

Conforme mencionado no início do capítulo anterior, pode-se dividir o estudo de novas configurações de atuadores piezelétricos em dois grupos: atuadores em série e em paralelo. Neste capítulo será abordada a configuração em série com o intuito de estudar o aumento na pressão de saída da bomba de fluxo, devido à interação entre os vórtices gerados por cada atuador (ver fig. 6.14). Portanto, em vista de maximizar a pressão gerada na saída da bomba de fluxo piezelétrica, propõe-se estudar a configuração utilizando dois atuadores piezelétricos bilaminares associados em série.

\subsection{Configuração dos Atuadores em Série}

Seguindo o mesmo procedimento apresentado nos capítulos anteriores, a seguir são descritas as simulações acústica e do escoamento e é apresentado o estudo de viabilidade desta nova configuração proposta.

\subsection{Simulação Acústica}

Conforme descrito na seção 4.1, a primeira etapa a ser realizada é simular a estrutura dos atuadores piezelétricos a fim de verificar seus modos de vibrar, freqüências de ressonância e amplitudes de oscilação.

O modelo adotado para a configuração de dois atuadores piezelétricos bilaminares pode ser visto na fig. 6.1, juntamente com suas dimensões. Estas dimensões foram adotadas devido à escolha do atuador N.$^{\circ}$ 40-1040 da APC International, cujas dimensões 
são $20 \times 40 \times 0,6 \mathrm{~mm}$.

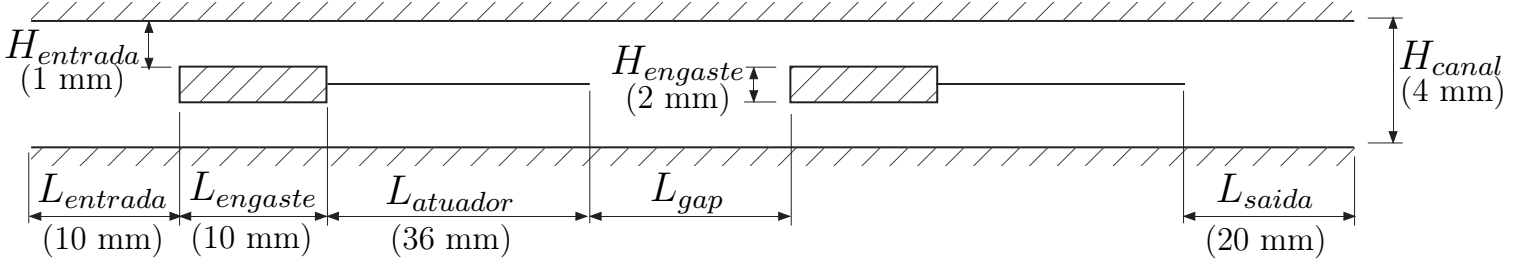

Figura 6.1: Desenho esquemático e dimensões do modelo acústico adotado.

Para otimizar o aproveitamento dos vórtices gerados pelos atuadores piezelétricos bilaminares é necessário avaliar qual o melhor posicionamento dos atuadores, isto é, qual é a melhor distância entre os atuadores $L_{\text {gap }}$. A altura do canal é fixada em $H_{\text {canal }}=4 \mathrm{~mm}$ e a espessura dos engastes são $H_{\text {engaste }}=2 \mathrm{~mm}$. Assim, é realizada uma análise de sensibilidade do parâmetro $L_{\text {gap }}$, cujos valores adotados são 30, 40, 50, 60 e $70 \mathrm{~mm}$. As propriedades dos materiais utilizados estão listadas na tabela 4.1.

A malha de elementos dos atuadores imersos na água para o caso $L_{g a p}=60 \mathrm{~mm}$ pode ser vista na fig. 6.2. Esta malha apresenta aproximadamente 68 mil elementos e 70 mil nós. As cores indicam os diferentes materiais utilizados e também é possível ver as condições de contorno aplicadas no modelo. As paredes do canal e do engaste são consideradas como superfícies sem reflexão de ondas.

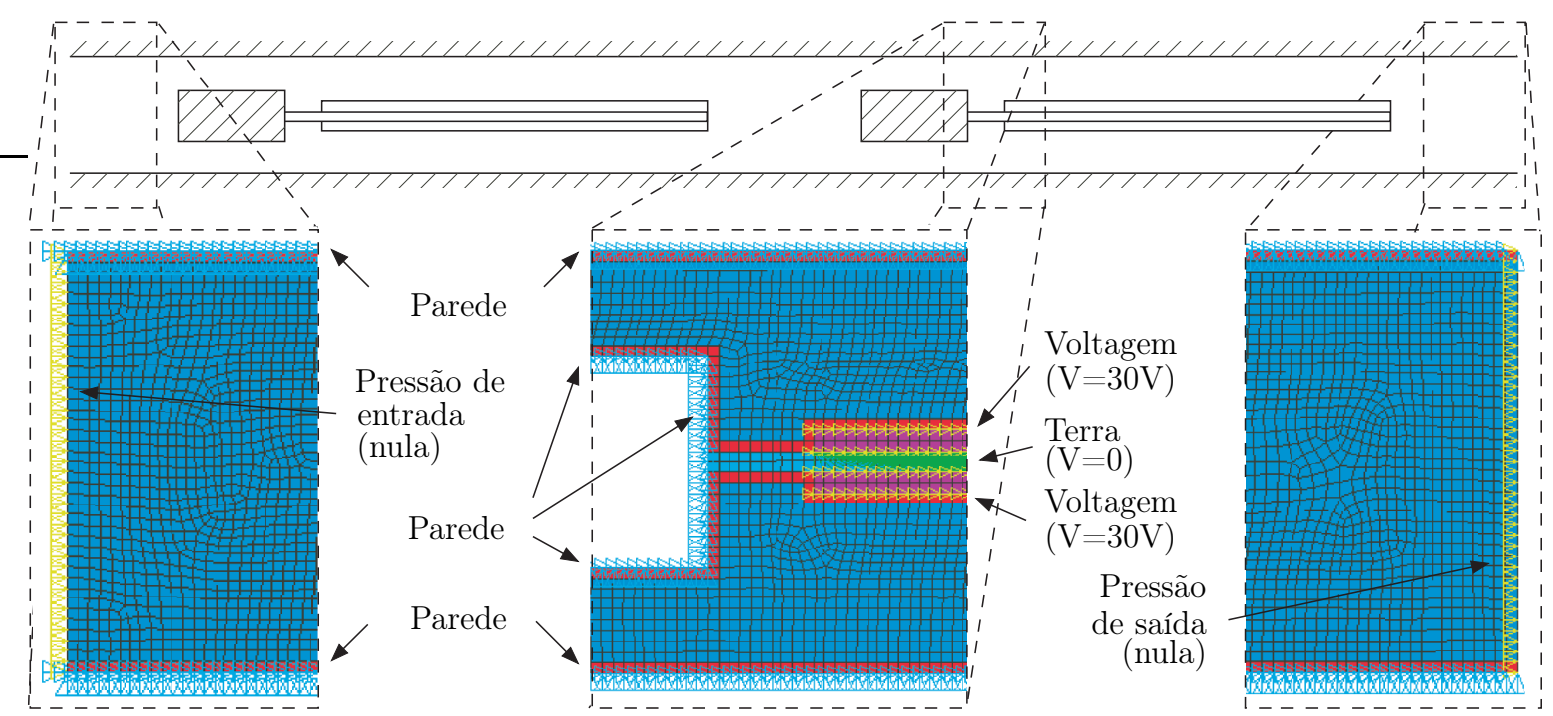

Figura 6.2: Condições de contorno aplicadas no modelo acústico.

Definido o modelo acústico, são rodadas simulações harmônicas a fim de se obter a curva de impedância elétrica e as freqüências de ressonância dos atuadores. A curva de impedância elétrica dos atuadores em série imersos em água para o caso $L_{\text {gap }}=60 \mathrm{~mm}$ 
é obtida em função da freqüência do sinal elétrico aplicado ao atuador $\left(60 V_{p p}\right.$, em fase), mostrada na fig. 6.3a. Neste gráfico é possível ver os pontos de ressonância e anti-ressonância, em $320 \mathrm{~Hz}$ e $360 \mathrm{~Hz}$, respectivamente. A fig. 6.3b mostra a curva da amplitude pico-a-pico das extremidades livres dos atuadores piezelétricos em função da freqüência, cujo valor máximo é de $150 \mu \mathrm{m}$ na freqüência de $325 \mathrm{~Hz}$. A diferença nos valores das freqüências significa que, do ponto de vista elétrico, a corrente elétrica conduzida é máxima (local) em $320 \mathrm{~Hz}$, ou seja, nesta freqüência a potência elétrica é maxima (local). Já do ponto de vista estrutural, a freqüência de ressonância é de $325 \mathrm{~Hz}$.
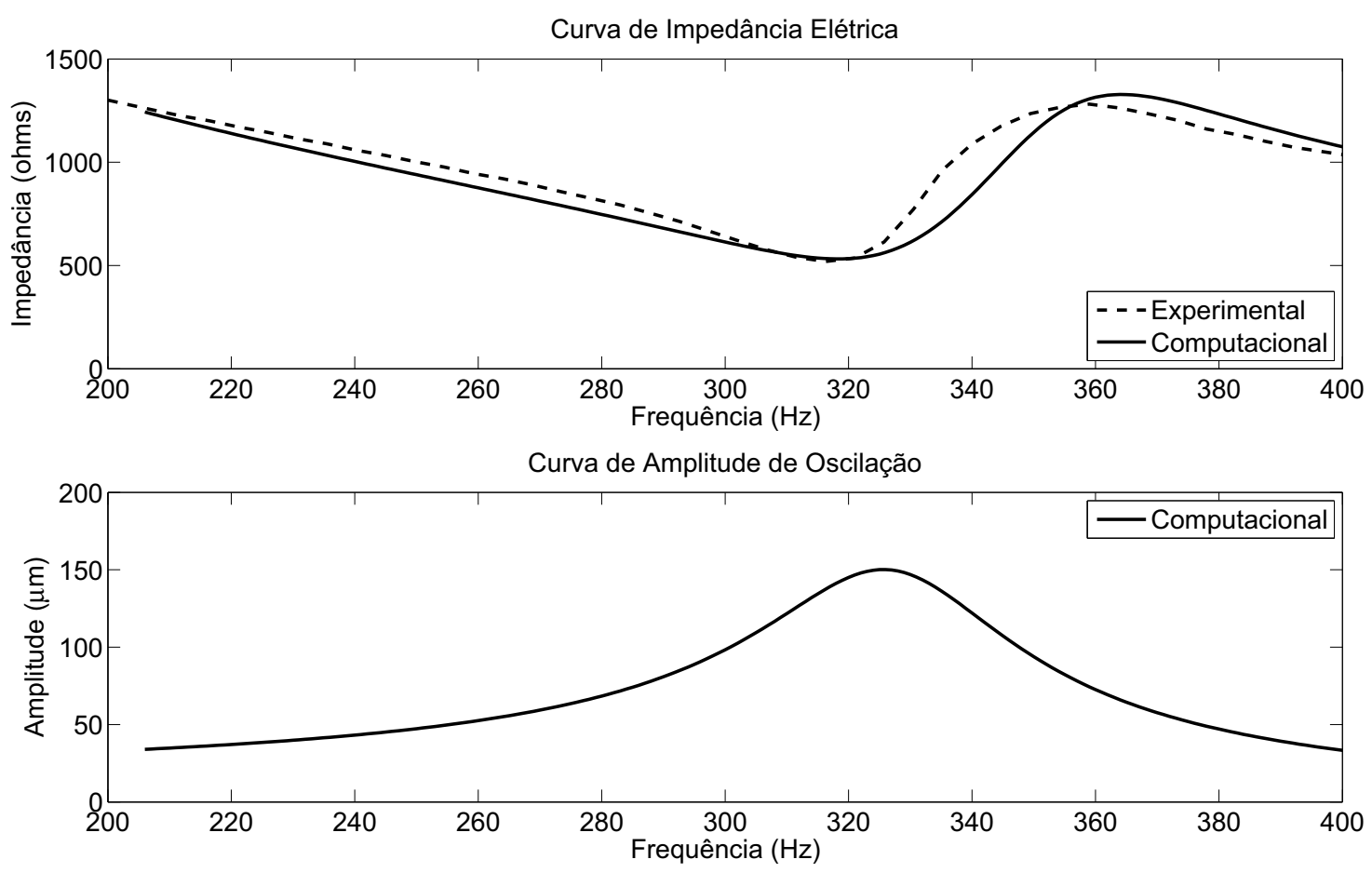

Figura 6.3: (a)Curva de impedância elétrica dos atuadores em série, imersos em água, no segundo modo de vibrar; (b) Curva de amplitude pico-a-pico das extremidades livres dos atuadores piezelétricos.

A partir da análise harmônica obtém-se os deslocamentos verticais dos nós da linha de centro dos atuadores quando excitados na freqüência de $325 \mathrm{~Hz}$. Com estas informações, é possível obter uma equação polinomial que represente a forma do segundo modo de vibrar dos atuadores piezelétricos, da mesma forma realizada nos capítulos anteriores. Desta equação polinomial obtém-se as equações de deslocamento e velocidade dos nós dos atuadores, que podem ser utilizadas como condições de contorno nas simulações fluídicas.

As simulações harmônicas considerando os outros valores de $L_{\text {gap }}$ citados anteriormente apresentam curvas de impedância elétrica e amplitude semelhantes às 
curvas apresentadas na fig. 6.3. Isto significa que os modos de vibrar dos atuadores piezelétricos em série não dependem das suas posições para os valores de $L_{g a p}$ considerados, para um canal com altura $H_{\text {canal }}=4 \mathrm{~mm}$. Portanto, pode-se utilizar as mesmas equações de deslocamento e velocidade do atuador piezelétrico para as distâncias entre os atuadores piezelétricos definidas anteriormente nas simulações do escoamento, assim como a mesma freqüência de ressonância de 325 Hz.

\subsection{Simulação do Escoamento de Fluido}

Concluída a simulação acústica e obtidas a freqüência de ressonância e as equações polinomiais dos deslocamentos e velocidades que representem o movimento dos atuadores, o próximo passo é a simulação do escoamento do sistema de bombeamento.

A fig. 6.4 mostra um desenho esquemático do modelo adotado. Este desenho esquemático exibe a vista lateral da bomba de fluxo piezelétrica, onde $L_{g a p}$ é a distância entre os atuadores. Os parâmetros $A$ e $f$ são a amplitude de oscilação pico-a-pico na extremidade livre do atuador piezelétrico e a freqüência de oscilação, respectivamente. A fig. 6.5 ilustra a malha de elementos finitos utilizada nas simulações do escoamento, que contém 16 mil elementos, onde também são mostrados detalhes das regiões de entrada e saída do canal e do engaste dos atuadores piezelétricos.

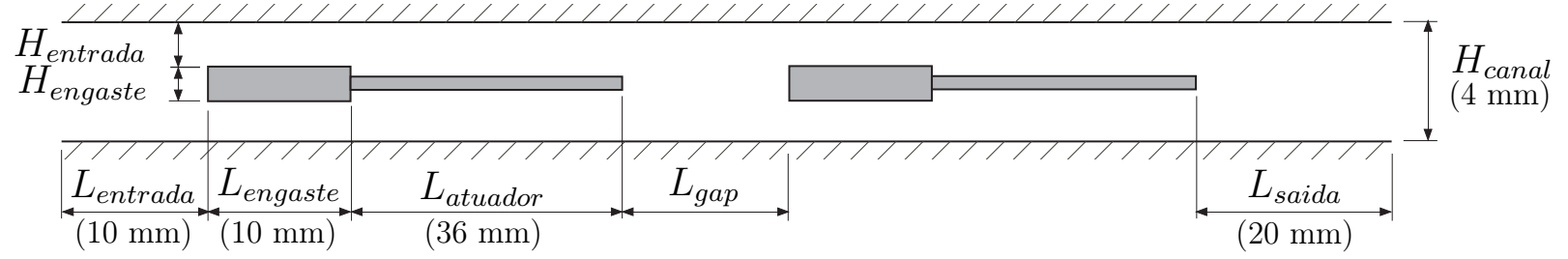

Figura 6.4: Desenho esquemático e dimensões do modelo fluídico adotado para a configuração de dois atuadores em série.

Na fig. 6.5 vê-se a representação das condições de contorno na região de entrada impostas pelo problema da bomba de fluxo piezelétrica. Nos nós das bordas superior e inferior do duto são impostos deslocamentos e velocidades nulas e nos nós dos atuadores piezelétricos são impostos os deslocamentos e velocidades obtidos na análise acústica. Na entrada (borda esquerda) e na saída (borda direita) são prescritas pressões relativas nulas, isto é, todo o interior do canal está submerso no meio fluídico e a direção do escoamento é horizontal. Tendo definido as condições de contorno, um dos passos finais antes de rodar a simulação propriamente dita é a definição das propriedades do elemento 


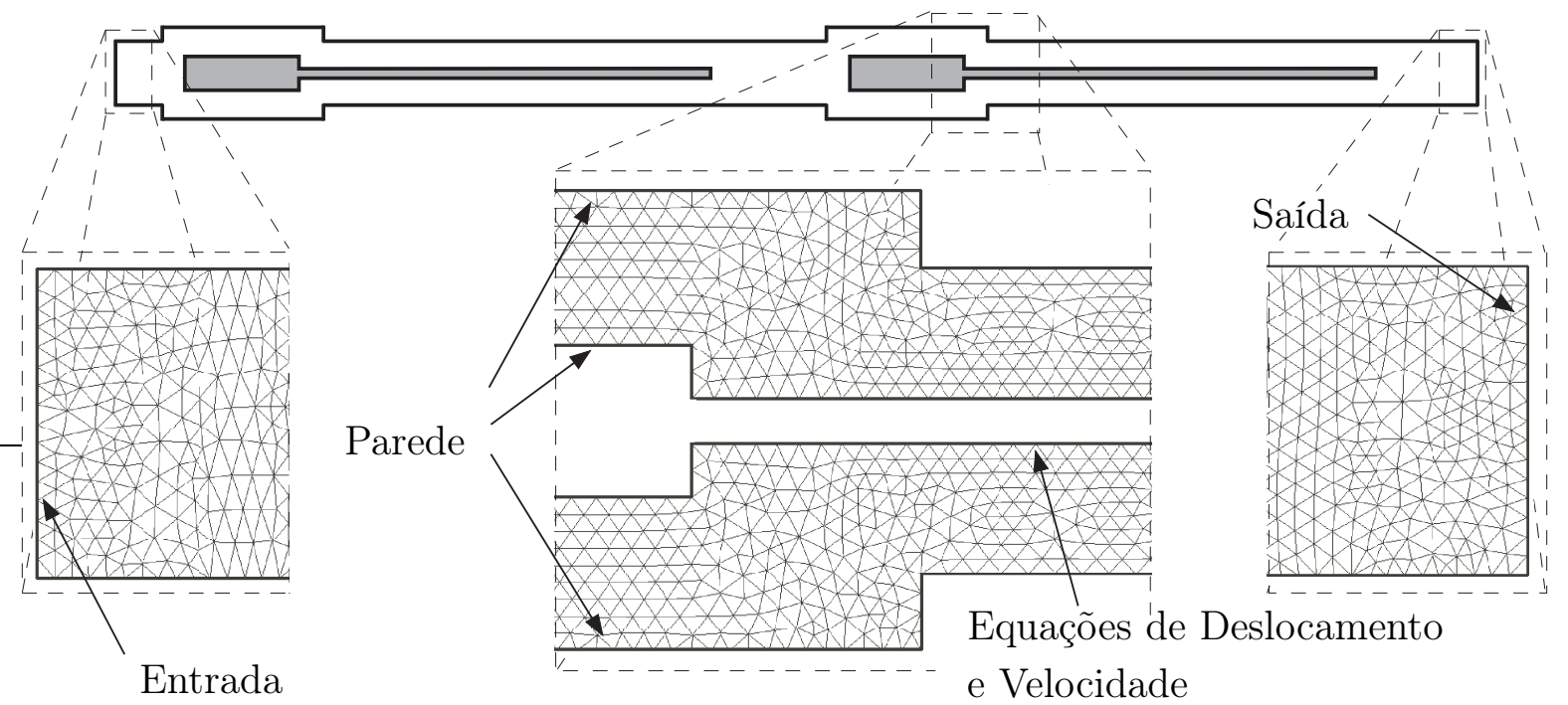

Figura 6.5: Malha de elementos finitos do modelo fluídico de dois atuadores em série.

utilizado para a simulação, no caso, o "FLUID142". Para a simulação da bomba de fluxo, é necessário definir a densidade e a viscosidade do fluido. O fluido utilizado foi a água, cujas propriedades estão listadas na tabela 4.1. Por fim, deve-se especificar as faces dos atuadores como fronteira móvel (formulação ALE) para que a malha seja rearranjada a cada iteração, adequando-se às condições impostas.

As dimensões do canal retangular são $4 \mathrm{~mm}$ de altura e $20 \mathrm{~mm}$ de largura. Os parâmetros $A$ e $f$ são obtidos da análise harmônica descrita na seção 6.2. O segundo modo de vibrar, considerando o fluido ao redor do atuador piezelétrico, tem a freqüência de 320 $\mathrm{Hz}$ e amplitude pico-a-pico de $150 \mu \mathrm{m}$ para a tensão de $60 V_{p p}$ (voltagem pico-a-pico) aplicada nos eletrodos. É realizada uma análise transiente até o instante de $2.0 \mathrm{~s}$, pois neste instante o escoamento já é estacionário.

A fig. 6.6 exibe o gráfico da vazão média na saída do canal até atingir o regime estacionário. De acordo com este gráfico, a simulação computacional do escoamento com o parâmetro $L_{g a p}=60 \mathrm{~mm}$ apresenta na saída do canal a vazão média de $101 \mathrm{~cm}^{3} / \mathrm{min}$, que é calculada considerando a seção retangular do canal com as dimensões de $4 \mathrm{~mm} \times$ $20 \mathrm{~mm}$.

Também são simulados modelos com valores de $L_{\text {gap }}$ variando entre 10 e $80 \mathrm{~mm}$ e os gráficos da vazão média e da pressão de saída em função da distância entre os atuadores podem ser vistos nas fig. 6.7 e 6.8. Em ambos os gráficos é possível notar que a vazão atinge um valor máximo de $101 \mathrm{~cm}^{3} / \min$ e pressão máxima de $36 \mathrm{~mm}$ de coluna d'água para $L_{g a p}=60 \mathrm{~mm}$. Para valores menores de $60 \mathrm{~mm}$, a vazão e pressão geradas decrescem 


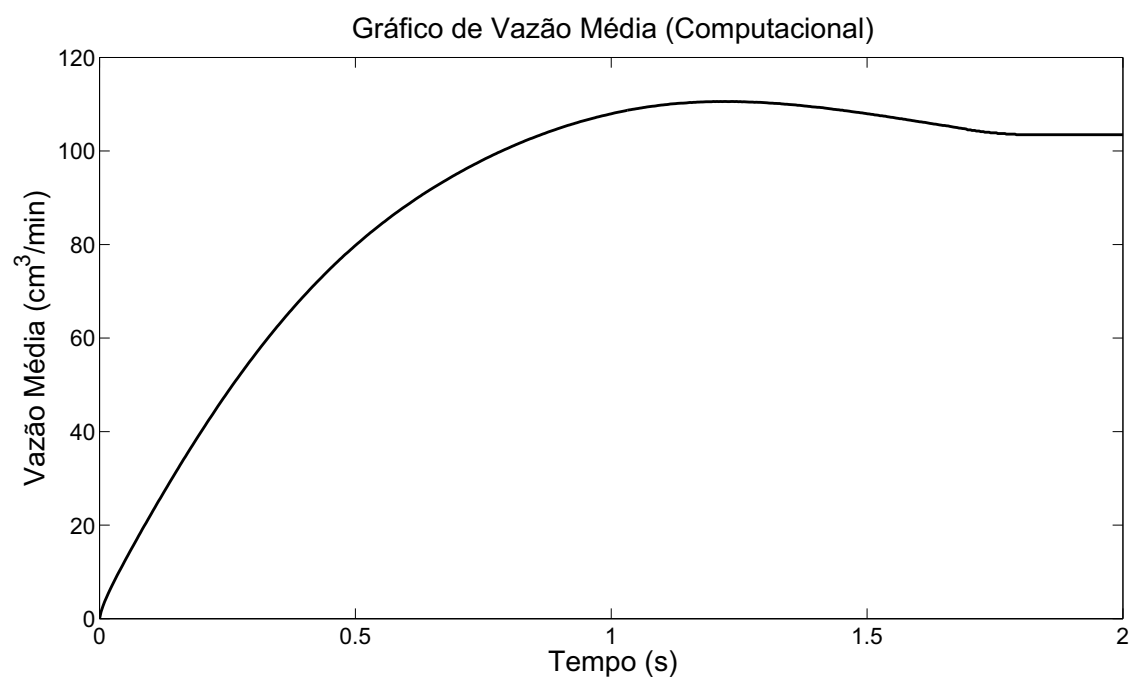

Figura 6.6: Gráfico da vazão média em função do tempo utilizando dois atuadores em paralelo.

devido ao refluxo existente na região entre os atuadores. Já para valores maiores do que $60 \mathrm{~mm}$, a vazão decresce devido ao aumento da perda de carga nas paredes do canal.

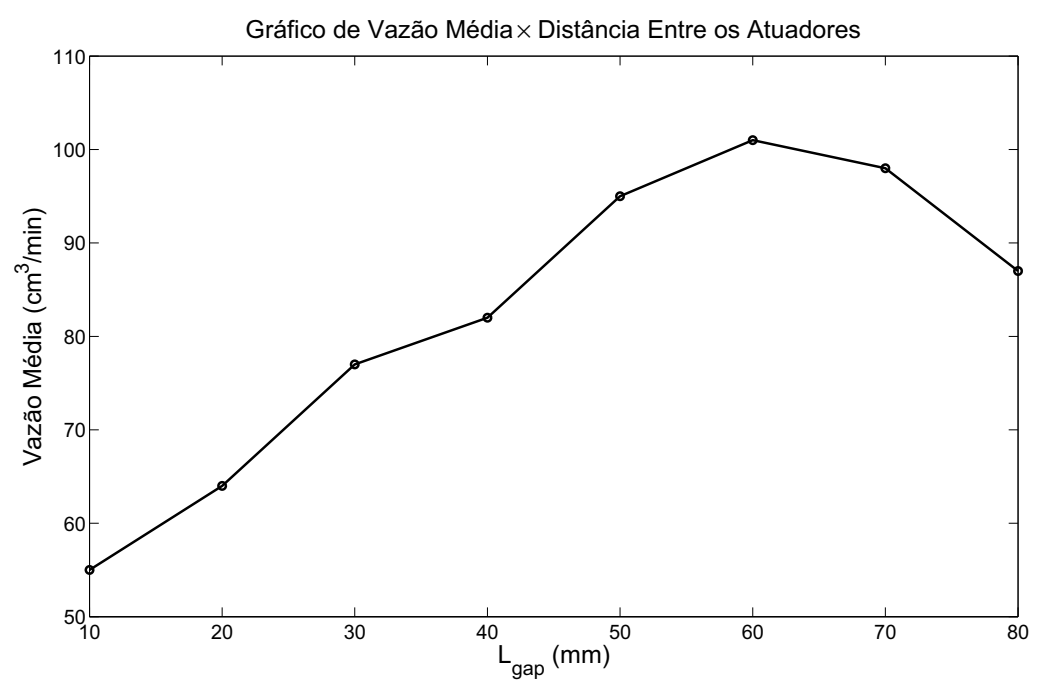

Figura 6.7: Gráfico da vazão média variando a distância entre os atuadores $\left(L_{\text {gap }}\right)$.

Para avaliar a influência da freqüência de excitação dos atuadores piezelétricos na vazão gerada pela bomba de fluxo, é adotado o modelo do caso ótimo visto anteriormente $\left(L_{g a p}=60 \mathrm{~mm}\right)$ e é levantada a curva de vazão média em função da freqüência, mostrada na fig. 6.9. Deste gráfico é possível observar que a vazão é máxima quando os atuadores vibram na freqüência de ressonância.

A fig. 6.10 mostra o gráfico das pressões médias de saída em função da freqüência 


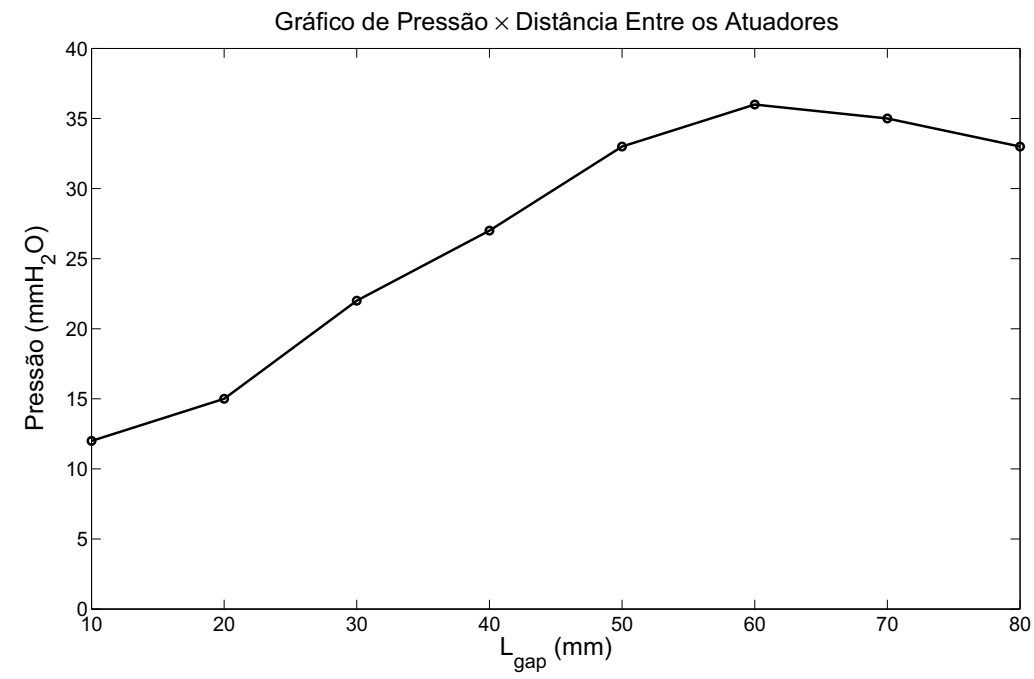

Figura 6.8: Gráfico da pressão média na saída variando a distância entre os atuadores $\left(L_{\text {gap }}\right)$.

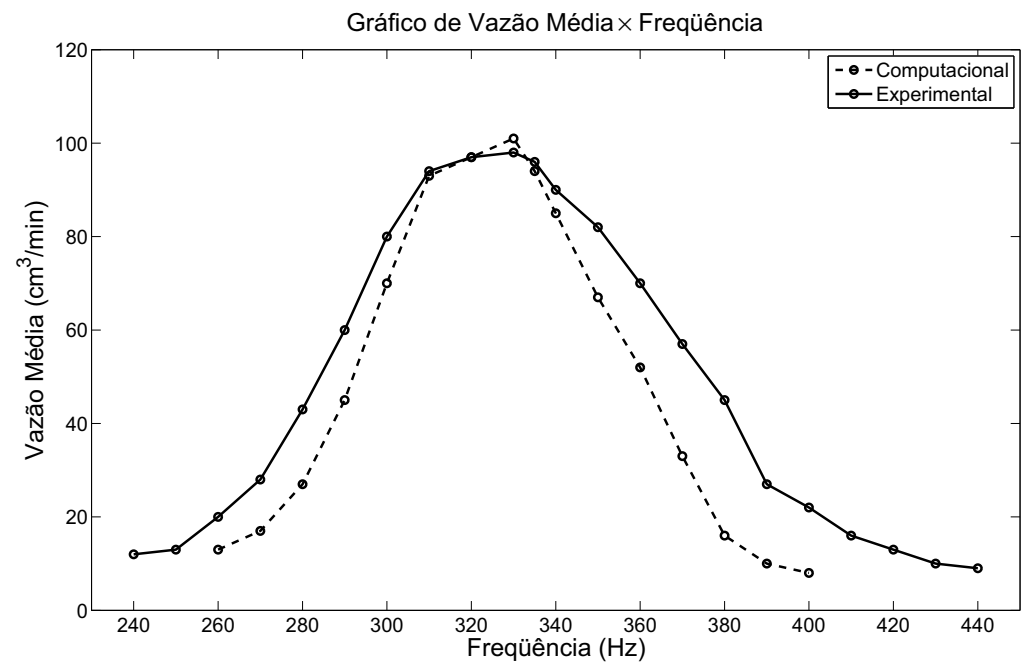

Figura 6.9: Gráfico da vazão média em função da freqüência utilizando dois atuadores em série.

para o caso ótimo $L_{\text {gap }}=60 \mathrm{~mm}$, onde pode ser vista a pressão máxima de $36 \mathrm{~mm} \mathrm{H}_{2} \mathrm{O}$ para a freqüência de $320 \mathrm{~Hz}$.

Na próxima seção é descrito o protótipo fabricado e os testes experimentais realizados.

\subsection{Verificação Experimental}

Para validar os resultados obtidos computacionalmente, decidiu-se fabricar um protótipo experimental. Nesta seção são descritos a fabricação do protótipo, os testes 


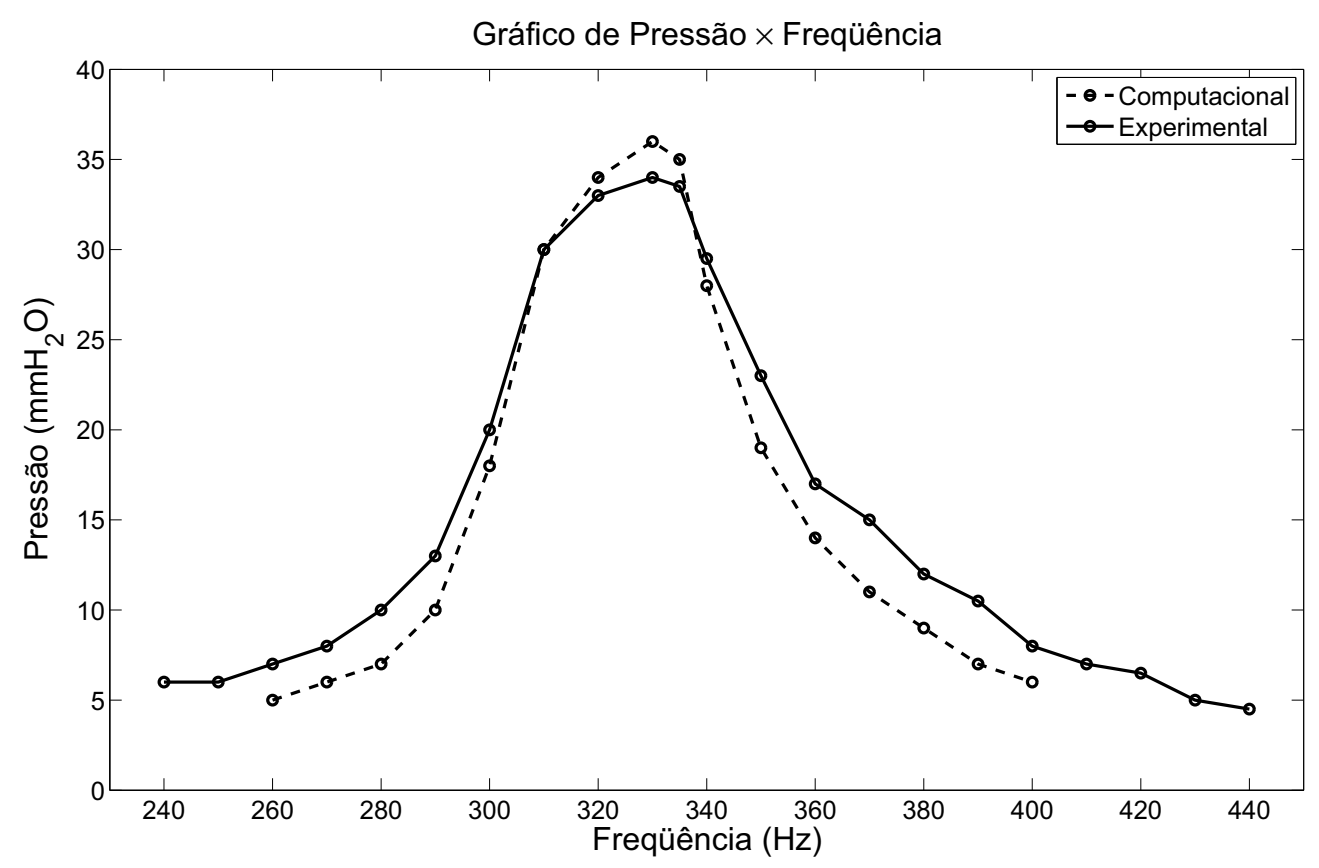

Figura 6.10: Curva de pressão média máxima em função da freqüência.

experimentais realizados e os resultados obtidos.

A fig. 6.11 mostra o protótipo de dois atuadores em série. As dimensões do atuador piezelétrico são $40 \times 20 \times 0,6 \mathrm{~mm}$, que fica alojado em um canal de seção transversal de $21 \times 4 \mathrm{~mm}$ e comprimento total de $180 \mathrm{~mm}$. O diâmetro dos conectores é de $7 \mathrm{~mm}$.

Para acionamento dos atuadores piezelétricos nos testes experimentais é utilizado um gerador de função INOVEO FG1000. Para determinar as freqüências de ressonância dos atuadores piezelétricos obtém-se a curva de impedância elétrica seguindo o mesmo procedimento descrito na seção 4.3 e o gráfico obtido pode ser visto na fig. 6.3a. De acordo com este gráfico, o sistema apresenta uma freqüência de ressonância em $315 \mathrm{~Hz}$.

Conhecendo-se a freqüência de ressonância do protótipo, o próximo teste realizado é a medição da vazão e pressão geradas pela bomba de fluxo piezelétrica. Os métodos de medição de vazão e pressão são descritos na seção 4.3. A curva de vazão em função da freqüência é obtida (ver fig. 6.9), mantendo-se a voltagem aplicada em $60 \mathrm{~V}$. A fig. 6.12 apresenta a seqüência do teste experimental, onde pode ser visto o escoamento na saída do protótipo. Os atuadores são acionados com o sinal senoidal de $60 V_{p p}$ e em fase. Porém, não há diferença no escoamento quando os atuadores são excitados defasados de $180^{\circ}$. 


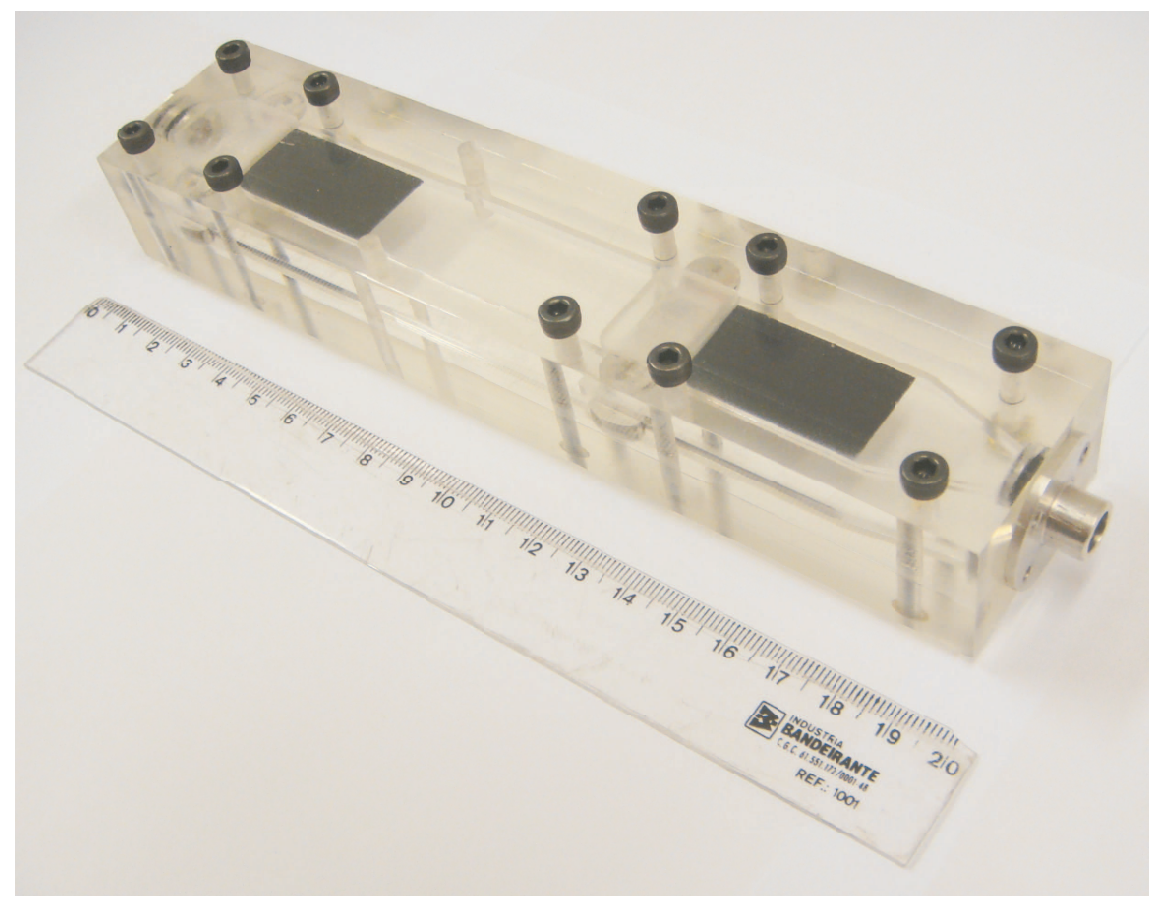

Figura 6.11: Imagem do protótipo de dois atuadores em série.
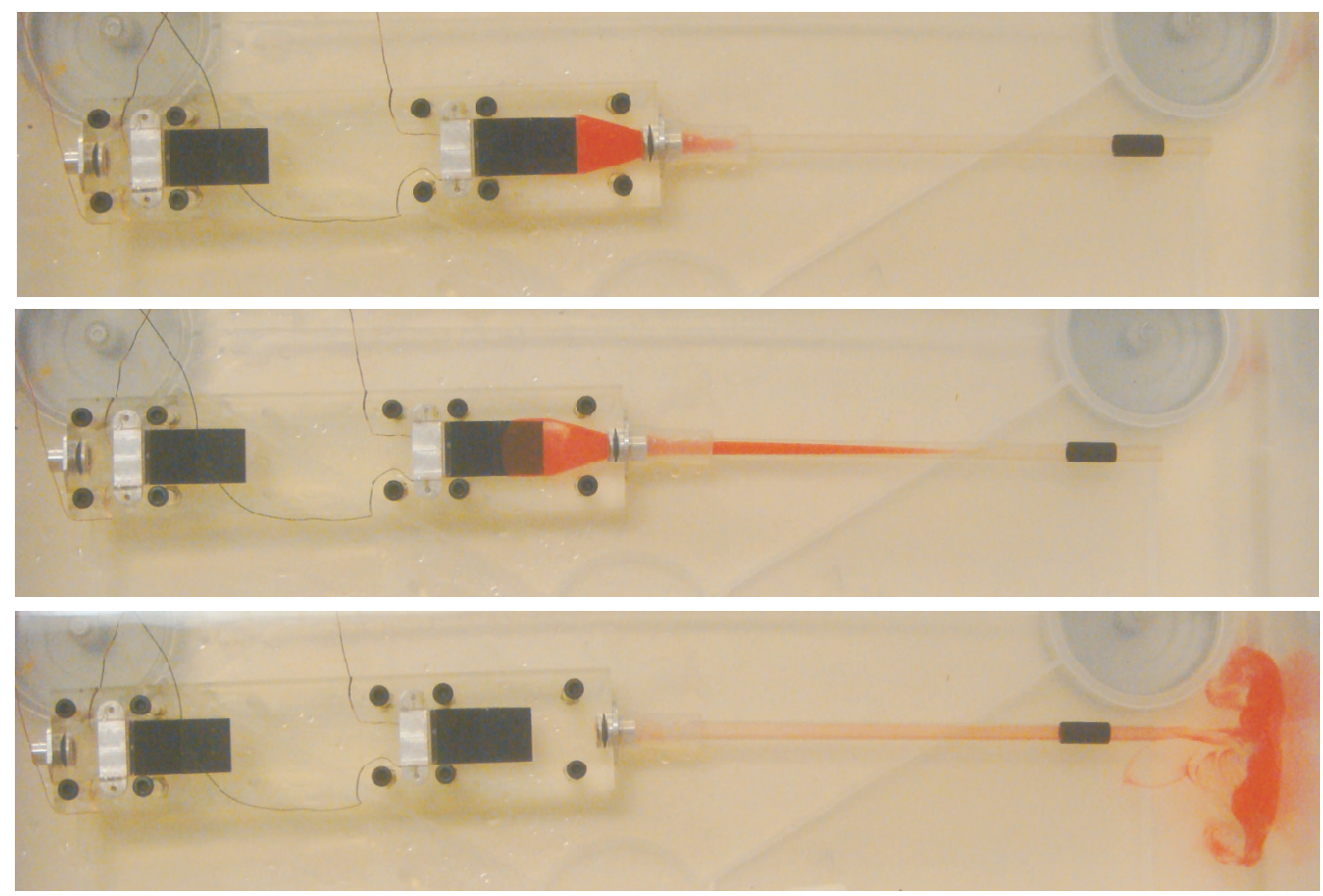

Figura 6.12: Imagens dos testes experimentais para medição de vazão realizados utilizando o protótipo de atuadores em série.

Da fig. 6.9 é possível identificar a vazão máxima em aproximadamente $98 \mathrm{~cm}^{3} / \mathrm{min}$ quando o protótipo é acionado em $315 \mathrm{~Hz}$. Para este valor de vazão o número de Reynolds é de 519, o que indica que o escoamento está no regime laminar. Esta figura também 
mostra que há um intervalo de freqüência no qual é possível obter diferentes vazões apenas variando-se a freqüência de excitação dos atuadores piezelétricos.

Além dos testes de vazão, também são realizados testes de pressão utilizando o mesmo protótipo fabricado. Para avaliar a pressão gerada pelos atuadores em série, o protótipo é fixado na vertical, totalmente imerso em água, de forma que apenas o duto de saída fique fora d'água. Ao acionar os atuadores, é possível medir a coluna de água que se forma no duto de saída. A fig. 6.13 exibe um dos testes realizados com o protótipo.
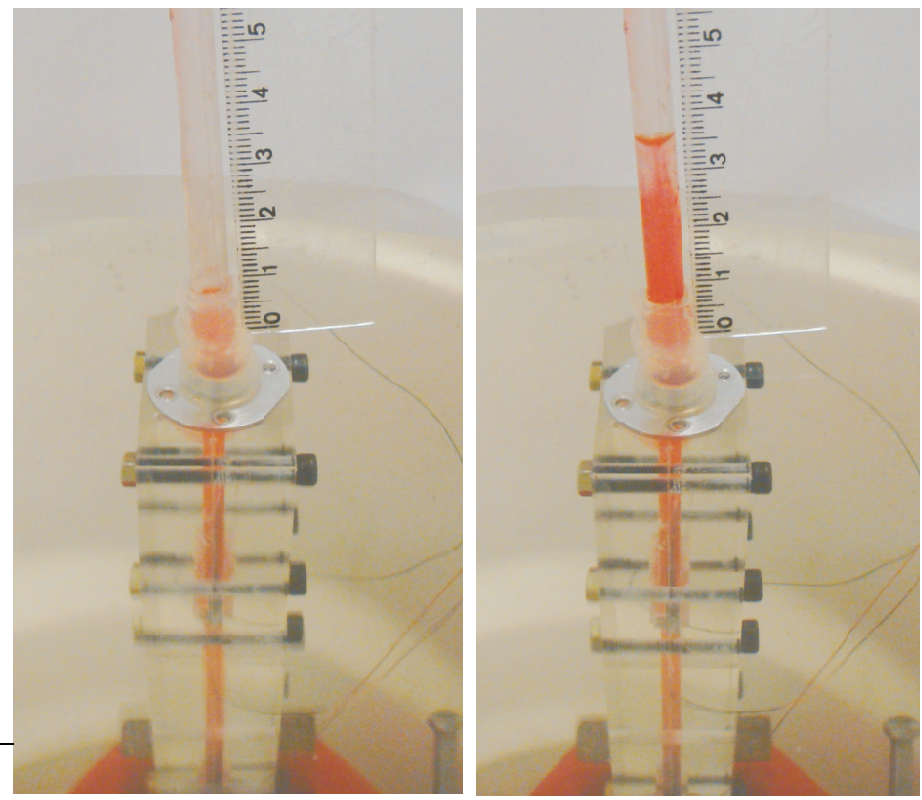

Figura 6.13: Imagem do teste experimental para medição de coluna d'água gerada pelo protótipo de atuadores em série.

O teste de pressão é repetido para diversos valores de freqüência, sempre em $60 V_{p p}$. O gráfico da fig. 6.10 apresenta a distribuição de pressão em função da freqüência de excitação do atuador piezelétrico, onde é possível ver a pressão máxima gerada de 34 $m \mathrm{mH}_{2} \mathrm{O}$ (precisão de $0,5 \mathrm{~mm}$ ) quando o protótipo é acionado a $315 \mathrm{~Hz}$.

Conforme descrito nas seções 6.3 e 6.4, as fig. 6.3a, 6.9 e 6.10 apresentam, respectivamente, as curvas de impedância elétrica, vazão média e pressão máxima, obtidas tanto computacional quanto experimentalmente. As curvas apresentadas nestas figuras anteriores mostram a concordância entre os resultados computacionais e experimentais, validando o procedimento computacional utilizado.

Um resumo dos resultados computacionais e experimentais é apresentado na tabela 6.1. A amplitude máxima de oscilação do atuador piezelétrico não pôde ser medida nos testes experimentais. 
Tabela 6.1: Resultados computacionais e experimentais da configuração em série.

\begin{tabular}{lccc}
\hline & Computacional & Experimental & Diferença \\
\hline Freqüência de ressonância $(\mathrm{Hz})$ & 320 & 315 & $1,5 \%$ \\
Amplitude máxima pico-a-pico $(\mu \mathrm{m})$ & 150 & - & - \\
Vazão média $\left(\mathrm{cm}^{3} / \mathrm{min}\right)$ & 101 & 98 & $2,9 \%$ \\
Pressão máxima $\left(\mathrm{mm} \mathrm{H}_{2} \mathrm{O}\right)$ & 36 & 34 & $5,6 \%$ \\
\hline
\end{tabular}

No gráfico da fig. 6.10 é possível notar que o modelo que atinge a maior pressão utilizando dois atuadores piezelétricos é o que possui a dimensão $L_{\text {gap }}=60 \mathrm{~mm}$, cujo valor é de $36 \mathrm{~mm}$ de coluna d'água. Se associarmos em série duas bombas de fluxo de um único atuador mostrada no capítulo 4, obteríamos $24 \mathrm{~mm}$ de coluna d'água (12 mm de coluna d'água de cada uma). Com o modelo de dois atuadores em série contidos em um mesmo canal e com a distância entre eles de $60 \mathrm{~mm}$, obtém-se $36 \mathrm{~mm}$ de coluna d'água, ou seja, um aumento de $50 \%$ na pressão de saída. Portanto, conclui-se que é vantajoso utilizar dois atuadores piezelétricos ligados em série em um mesmo canal, ao invés de se utilizar duas bombas de fluxo de um único atuador ligadas em série, conforme a fig. 6.14.

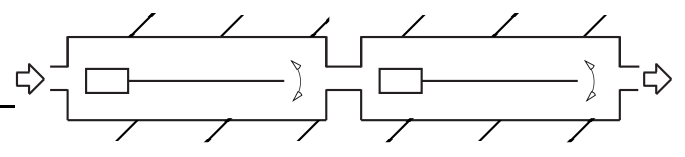

$24 \mathrm{mmH}_{2} \mathrm{O}$

(a)

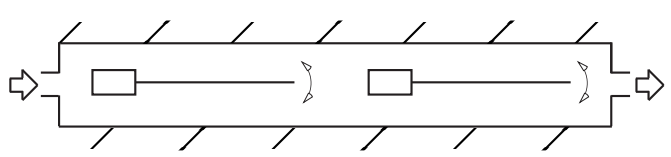

$36 \mathrm{mmH}_{2} \mathrm{O}$

(b)

Figura 6.14: Comparação das vazões geradas pelo (a) dois modelos de um único atuador em série e pelo (b) modelo de dois atuadores em série. 


\section{CONCLUSÕES}

O presente trabalho de mestrado teve como objetivo aplicar a modelagem através do método de elementos finitos para o estudo de novas configurações de atuadores piezelétricos bilaminares associados em paralelo e série para bombeamento de líquidos através do princípio oscilatório, a fim de se obter maiores vazões ou pressões.

O escopo deste projeto abrange, computacionalmente, análises estruturais de atuadores piezelétricos bilaminares e simulações de escoamento de fluido e, experimentalmente, construções de protótipos para validação de resultados. A utilização da simulação computacional mostrou-se ser bastante importante no estudo de viabilidade, pois permite realizar análises de sensibilidade que direcionam a pesquisa de forma ágil, rápida e econômica. A fabricação de protótipos também se mostrou importante como complemento das simulações computacionais, permitindo a verificação dos resultados obtidos computacionalmente e análise de fenômenos não considerados nos modelos computacionais.

Inicialmente foi investigado o comportamento do um único atuador piezelétrico bilaminar no fluido, considerando a viscosidade dinâmica da água nas simulações computacionais. Antes de realizar os testes com o protótipo completo, verificou-se o funcionamento do atuador piezelétrico e um fato interessante observado em testes preliminares foi o surgimento de ondas de alta freqüência nas superfícies do atuador piezelétrico. Estas ondas são observadas quando o atuador é posicionado de forma que fique com apenas metade de sua estrutura imersa em água. Uma hipótese levantada para o surgimento destas ondas é a excitação do atuador piezelétrico em uma alta freqüência desconhecida, devido à alguma falha na fabricação do atuador piezelétrico, fazendo com que vibre em outro modo de vibrar. Para amenizar estas ondas de alta freqüência na superfície do atuador, foi utilizado uma película de isopropileno em torno do atuador piezelétrico. Um fato curioso é que, com a ausência desta película, a vazão observada no protótipo deu-se no sentido contrário ao do escoamento obtido computacionalmente. Após 
a realização de novos testes experimentais com a película de isopropileno foi comprovada a diminuição das ondas geradas nas superfícies do atuador e a vazão gerada pelo atuador deu-se no sentido esperado, conforme os resultados computacionais. Além disso, durante os testes experimentais foi verificado que o desempenho do atuador piezelétrico é bastante sensível ao aperto dos engastes, uma vez que o funcionamento correto do atuador depende da rigidez dos engastes.

No trabalho de mestrado de Nakasone (NAKASONE, 2006) as vazões obtidas foram de aproximadamente $17 \mathrm{~cm}^{3} / \mathrm{min}$. Assim, comparando este valor com os resultados obtidos no presente trabalho nota-se a importância da utilização de fluido viscoso nas simulações computacionais. Além disso, ao longo desta investigação foi possível verificar que a análise dos modos de vibrar e freqüências de ressonância do atuador piezelétrico são passos importantes no projeto da bomba de fluxo, uma vez que estas informações são necessárias nas simulações do escoamento. Os testes experimentais comprovaram que o atuador piezelétrico gera vazões maiores quando o atuador vibra no segundo modo de vibrar, ao invés do primeiro modo, de acordo com o que foi apresentado em trabalhos anteriores (NAKASONE et al., 2005; NAKASONE, 2006; PIRES et al., 2006). A vazão obtida com o protótipo foi de $103 \mathrm{~cm}^{3} /$ min operando a $330 \mathrm{~Hz}$ e pressão de saída de $12 \mathrm{~mm} \mathrm{H}_{2} \mathrm{O}$. Para o modelo de bomba de fluxo piezelétrica adotado podem ser definidos alguns parâmetros de maior influência no desempenho, como freqüência de operação, voltagem aplicada e altura do canal de bombeamento.

Ao término do trabalho foi possível verificar que as novas configurações estudadas, de dois atuadores piezelétricos em paralelo e em série, são viáveis. Se associarmos em paralelo duas bombas de fluxo de um único atuador, obteríamos $222 \mathrm{~cm}^{3} / \mathrm{min}$ (a soma de $111 \mathrm{~cm}^{3} / \mathrm{min}$ de cada uma das bombas de fluxo). Com o modelo de dois atuadores em paralelo contidos em um mesmo canal, obtém-se $426 \mathrm{~cm}^{3} /$ min, ou seja, um aumento de $92 \%$ na vazão. Portanto, conclui-se que é vantajoso utilizar dois atuadores piezelétricos em paralelo em um mesmo canal a fim de se obter maiores vazões, ao invés de se utilizar duas bombas de fluxo de um único atuador ligadas em paralelo. Já se associarmos em série duas bombas de fluxo de um único atuador, obteríamos $24 \mathrm{~mm}$ de coluna d'água (12 mm de coluna d'água de cada uma das bombas de fluxo). Com o modelo de dois atuadores em série contidos em um mesmo canal e com a distância entre eles de $60 \mathrm{~mm}$, obtém-se $36 \mathrm{~mm}$ de coluna d'água, ou seja, um aumento de 50\% na pressão de saída. Portanto, conclui-se que é vantajoso utilizar dois atuadores piezelétricos ligados em série em um mesmo canal a fim de se obter maiores pressões de saída, ao invés de se utilizar 
duas bombas de fluxo de um único atuador ligadas em série.

\subsection{Sugestões de Trabalhos Futuros}

O autor deixa como sugestão de trabalhos futuros analisar a viabilidade de miniaturização do conjunto, realizar testes de eficiência do sistema de bombeamento e verificar o desempenho da bomba de fluxo piezelétrica com outros fluidos.

Além disso, é interessante realizar o estudo de viabilidade de bombas de fluxo piezelétricas utilizando mais de dois atuadores piezelétricos bilaminares, associados tanto em série quanto em paralelo, a fim de se avaliar a geração de maiores vazões ou pressões. Outra configuração interessante é a disposição dos atuadores em forma de cardume, mostrada na fig. 7.1, a fim de se gerar maiores vazões e pressões com o mesmo sistema de bombeamento.

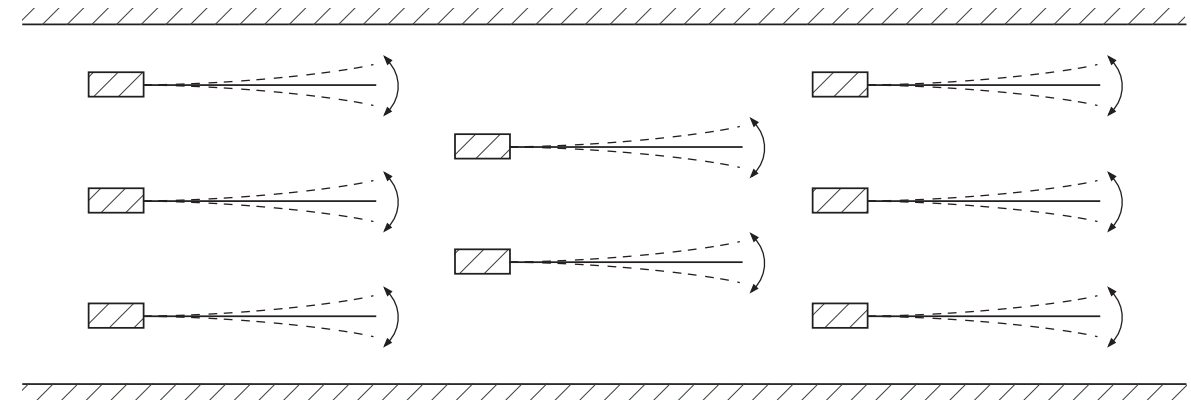

Figura 7.1: Sugestão de estudo: atuadores piezelétricos em forma de cardume. 


\section{Referências}

ACIKALIN, T.; RAMAN, A.; GARIMELLA, S. V. Two-dimensional streaming flows induced by resonating, thin beams. Journal Of The Acoustical Society Of America, v. 114 , n. 4 , p. $1785-1795$, out. 2003.

ACIKALIN, T.; WAIT, S. M.; GARIMELLA, S. V.; RAMAN, A. Experimental investigation of the thermal performance of piezoelectric fans. Heat Transfer Engineering, v. 25, n. 1, p. 4-14, jan. 2004.

ANDRADE, A.; BISCEGLI, J.; DINKHUYSEN, J.; SOUSA, J. E.; OHASHI, Y.; HEMMINGS, S.; GLUECK, J.; KAWAHITO, K.; NOSE, Y. Characteristics of a blood pump combining the centrifugal and axial pumping principles: The spiral pump. Artificial Organs, v. 20, n. 6, p. 605-612, jun. 1996.

ANSYS, INC. Release 11.0 Documentation for ANSYS. [S.1.], 2007.

BAR-COHEN, Y.; CHANG, Z. Piezoelectrically actuated miniature peristaltic pump. In: Proceedings of SPIE's 8th Annual International Symposium on Smart Structures and Materials. [S.l.: s.n.], 2001. p. 425-432.

BURGREEN, G. W.; ANTAKI, J. F.; WU, Z. J.; HOLMES, A. J. Computational fluid dynamics as a development tool for rotary blood pumps. Artificial Organs, v. 25, p. 336-340, 2001.

BURMANN, P.; RAMAN, A.; GARIMELLA, S. V. Dynamics and topology optimization of piezoelectric fans. IEEE Transactions On Components And Packaging Technologies, v. 25 , n. 4 , p. 592-600, dez. 2002.

DONEA, J.; HUERTA, A.; PONTHOT, J.-P.; RODRíGUEZ-FERRAN, A. Arbitrary Lagrangian-Eulerian Methods. [S.l.]: John Wiley \& Sons, Ltd., 2004.

FOX, R. W.; MCDONALD, A. T. Introdução à Mecânica dos Fluidos. [S.1.]: LTC, 2006. GARIMELLA, S. V.; SINGHAL, V.; LIU, D. On-chip thermal management with microchannel heat sinks and integrated micropumps. Proceedings Of The Ieee, v. 94, p. 1534-1548, ago. 2006.

GULICH, J. F. Impact of three-dimensional phenomena on the design of rotodynamic pumps. Proceedings of The Institution of Mechanical Engineers Part-C Journal of Mechanical Engineering Science, v. 213, p. 59-70, 1999.

HENMI N.AND OHYAMA, R.; TANAKA, M.; SUDA, A.; KARASAWA, F.; ICHIKAWA, M.; OHSHIMA, K.; MIYAHARA, N. A study on a progressive wave type 
novel piezoelectric pump. In: Proceedings of the 18th Congress of Mechanical Engineering (COBEM 2005). [S.1.]: ABCM, Ouro Preto, Minas Gerais, Brasil, 2005.

IEEE. Ieee standard on piezoelectricity 176-1987. IEEE - Transactions on Ultrasonics, Ferroelectrics and Frequency Control, v. 43, n. 5, p. 5-54, 1996.

IHARA, A.; WATANABE, H. On the flow around flexible plates, oscillating with large-amplitude. Journal Of Fluids And Structures, v. 8, n. 6, p. 601-619, ago. 1994.

IKEDA, T. Fundamentals of Piezoelectricity. Oxford, Inglaterra: Oxford University Press, 1996.

KAR, S.; MCWHORTER, S.; FORD, S. M.; SOPER, S. A. Piezoelectric mechanical pump with nanoliter per minute pulse-free flow delivery for pressure pumping in micro-channels. Analyst, v. 123, n. 7, p. 1435-1441, jul. 1998.

KIM, Y. H.; WERELEY, S. T.; CHUN, C. H. Phase-resolved flow field produced by a vibrating cantilever plate between two endplates. Physics Of Fluids, v. 16, n. 1, p. 145-162, jan. 2004.

KINSLER, L.; FREY, A.; COPPENS, A.; SANDERS, J. Fundamentals of Acoustics. 3. ed. Nova York, EUA: John Wiles \& Sons, 1982.

KOCH, M.; HARRIS, N.; MAAS, R.; EVANS, A. G. R.; WHITE, N. M.; BRUNNSCHWEILER, A. A novel micropump design with thick-film piezoelectric actuation. Measurement Science \& Technology, v. 8, n. 1, p. 49-57, jan. 1997.

LASER, D. J.; SANTIAGO, J. G. A review of micropumps. Journal Of Micromechanics And Microengineering, v. 14, n. 6, p. R35-R64, jun. 2004.

LERCH, R. Simulation of piezoelectric devices by 2-dimensional and 3-dimensional finite-elements. IEEE Transactions On Ultrasonics Ferroelectrics And Frequency Control, v. 37, n. 3, p. 233-247, maio 1990.

MIYAZAKI, S.; KAWAI, T.; ARARAGI, M. A piezo-electric pump driven by a flexural progressive wave. In: IEEE-MEMS Workshop, Nara, Anais. [S.l.]: IEEE, 1991. p. $283-288$.

MU, Y. H.; HUNG, N. P.; NGOI, K. A. Optimisation design of a piezoelectric micropump. International Journal Of Advanced Manufacturing Technology, v. 15, n. 8, p. $573-576,1999$.

NADER, G. Desenvolvimento de Técnicas de Caracterização de Transdutores Piezelétricos. Tese (Doutorado) - Escola Politécnica da Universidade de São Paulo, 2002.

NAKASONE, P. Estudo de Viabilidade de uma Bomba de Fluxo Piezelétrica Utilizando Simulação Computacional. Dissertação (Mestrado) — Escola Politécnica da Universidade de São Paulo, 2006. 
NAKASONE, P.; PIRES, R.; LIMA, C.; SILVA, E. Computational simulation and experimental characterization of a piezoelectric pump. In: Proceedings of XXVI CILAMCE 2005 (Iberian Latin America Congress on Computational Methods in Engineering). Guarapari, ES: [s.n.], 2005.

NAKASONE, P.; PIRES, R.; SILVA, E. Análise de viabilidade de uma bomba de fluxo piezelétrica. In: Anais do XV CBA (Congresso Brasileiro de Automática). Gramado, RS: [s.n.], 2004.

NGUYEN, N. T.; TRUONG, T. Q. A fully polymeric micropump with piezoelectric actuator. Sensors And Actuators B-Chemical, v. 97, n. 1, p. 137-143, jan. 2004.

NGUYEN, N. T.; WHITE, R. M. Design and optimization of an ultrasonic flexural plate wave micropump using numerical simulation. Sensors And Actuators A-Physical, v. 77, n. 3, p. 229-236, nov. 1999.

NYBORG, W. Acoustic streaming. Physical Acoustics, Academic. Press, Nova York, EUA, v. 2B, p. 265-331, 1965.

OSTERGAARD, D. F.; PAWLAK, T. P. 3-dimensional finite-elements for analyzing piezoelectric structures. IEEE Transactions On Ultrasonics Ferroelectrics And Frequency Control, v. 34, n. 3, p. 421-421, maio 1987.

PIRES, R.; NAKASONE, P.; CUNHA, M.; ANDRADE, A.; LIMA, C.; SILVA, E. Mechatronic pump characterization: The mech-pump. In: Proceedings of the 18th Congress of Mechanical Engineering (COBEM 2005). [S.l.]: ABCM, Ouro Preto, Minas Gerais, Brasil, 2005.

PIRES, R.; NAKASONE, P.; LIMA, C.; SILVA, E. A miniature bimorph piezoelectrically actuated flow pump. Proceedings of the SPIE 13th Annual Symposium on Smart Structures and Materials, 2006.

SASHIDA, T.; KENJO, T. An Introduction to ultrasonic Motors. Oxford, Inglaterra: Clarendon Press, 1993.

SFAKIOTAKIS, M.; LANE, D. M.; DAVIES, J. B. C. Review of fish swimming modes for aquatic locomotion. IEEE Journal Of Oceanic Engineering, v. 24, n. 2, p. 237-252, abr. 1999.

SHERRIT, S.; BAR-COHEN, S. P. L. Y.; DOLGIN, B. P.; TASKER, R. Analysis of the impedance resonance of piezoelectric stacks. 2000 Ieee Ultrasonics Symposium Proceedings, Vols 1 And 2, Ieee, p. 1037-1040, 2000.

TEYMOORI, M. M.; ABBASPOUR-SANI, E. Design and simulation of a novel electrostatic peristaltic micromachined pump for drug delivery applications. Sensors And Actuators A-Physical, v. 117, n. 2, p. 222-229, jan. 2005.

TRIANTAFYlloU, G. S.; TRIANTAFYlloU, M. S.; GROSENBAUGH, M. A. Optimal thrust development in oscillating foils with application to fish propulsion. Journal Of Fluids And Structures, v. 7, n. 2, p. 205-224, fev. 1993. 
UCHINO, K.; GINIEWICZ, J. R. Micromechatronics. [S.l.]: Marcel Dekker, Inc., 2003.

ULLMANN, A.; FONO, I.; TAITEL, Y. A piezoelectric valve-less pump-dynamic model. Journal Of Fluids Engineering-Transactions Of The Asme, v. 123, n. 1, p. 92-98, mar. 2001.

VIDELER, J. J.; MULLER, U. K.; STAMHUIS, E. J. Aquatic vertebrate locomotion: Wakes from body waves. Journal Of Experimental Biology, v. 202, n. 23, p. 3423-3430, dez. 1999.

VOORDE, J. V.; VIERENDEELS, J.; DICK, E. Flow simulations in rotary volumetric pumps and compressors with the fictitious domain method. Journal of Computational And Applied Mathematics, v. 168, p. 491-499, 2004.

WU, T.; RO, P. I.; KINGON, A. I.; MULLING, J. F. Piezoelectric resonating structures for microelectronic cooling. Smart Materials $\&$ Structures, Iop Publishing Ltd, v. 12, n. 2 , p. $181-187$, abr. 2003.

YANO, T.; SEKINE, K.; MITOH, A.; MITAMURA, Y.; OKAMOTO, E.; KIM, D. W.; NISHIMURA, I.; MURABAYASHI, S.; YOZU, R. An estimation method of hemolysis within an axial flow blood pump by computational fluid dynamics analysis. Artificial Organs, v. 27, n. 10, p. 920-925, out. 2003.

YOO, J. H.; HONG, J. I.; CAO, W. Piezoelectric ceramic bimorph coupled to thin metal plate as cooling fan for electronic devices. Sensors And Actuators A-Physical, v. 79, n. 1, p. 8-12, jan. 2000. 


\section{Apêndice A - Programas em APDL}

\section{A.1 Simulação acústica de um único atuador}

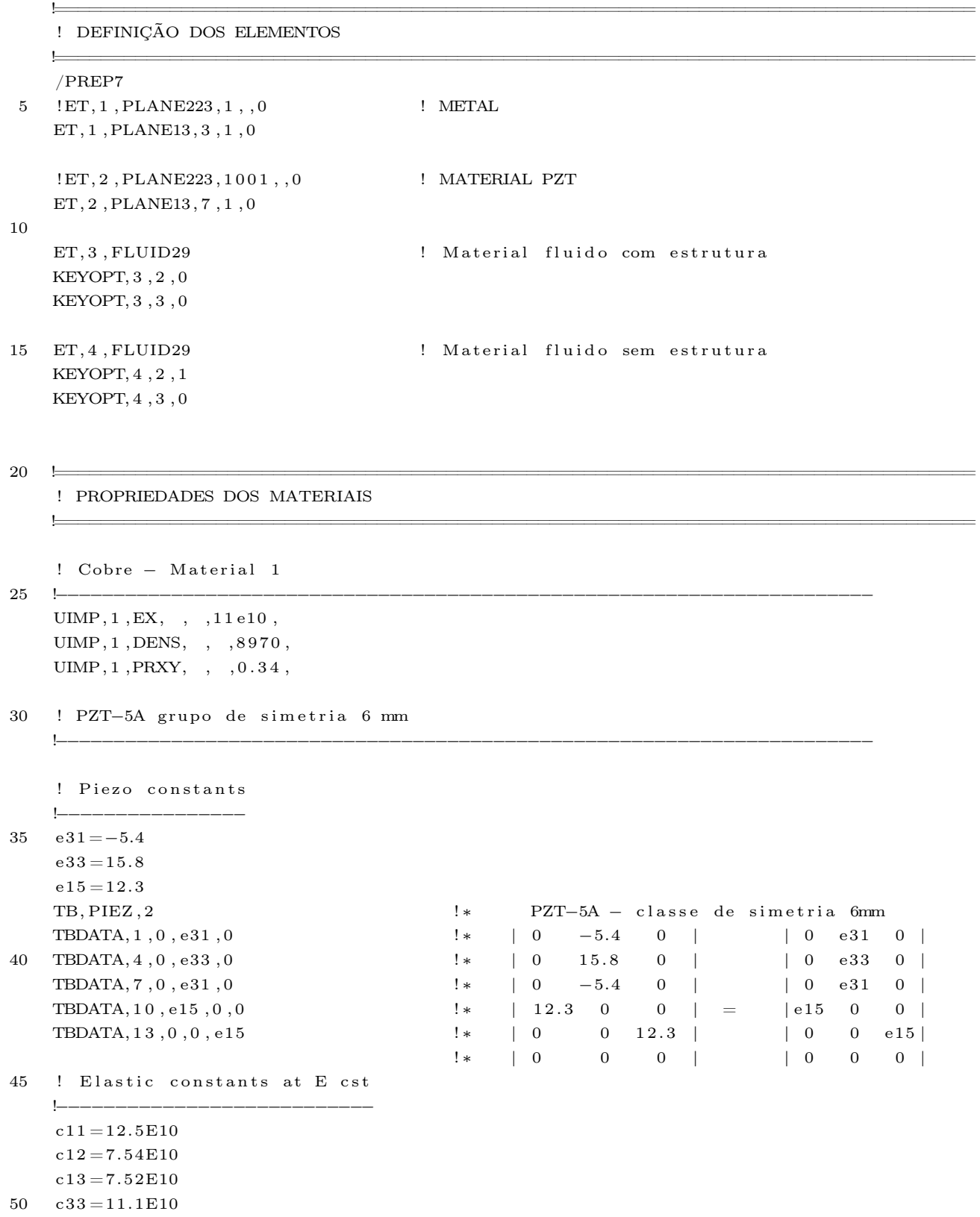


c $44=2.11 \mathrm{E} 10$

c $66=.5 *(\mathrm{c} 11-\mathrm{c} 12)$

TB, ANEL, $2 \quad$ ! $\quad$ PZT $-5 \mathrm{~A}-$ classe de simetria $6 \mathrm{~mm}(* 10-10)$

TBDATA $1, \mathrm{c} 11, \mathrm{c} 13, \mathrm{c} 12,0,0,0$, TBDATA, 7, , 33, , $13,0,0,0$

TBDATA, 12, c $11,0,0,0$

TBDATA, $16, \mathrm{c} 44,0,0$

TBDATA, 19, c 44,0

TBDATA, 21 , с 66

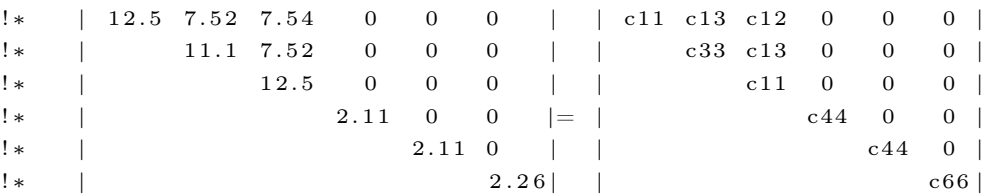

60

! Constantes dieletricas a strain (S) constante

$\mathrm{e} 00=8.85 \mathrm{E}-12$

eps $1=916 * 8.85 \mathrm{E}-12$

65 eps $3=830 * 8.85 \mathrm{E}-12$

MP, PERX, 2 , eps 1

MP, PERY, 2 , eps 3

MP, PERZ, 2, eps 1

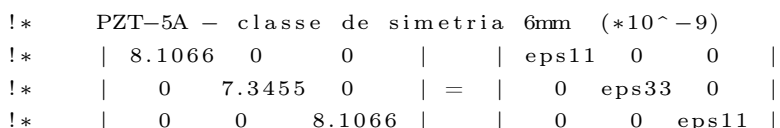

70

Densidade e amortecimento

MP, DENS, 2,7650

$\mathrm{QM}=75$

$\mathrm{FR}=47000$

$75 \quad \mathrm{OMEGA}=2 * 3.1416 * \mathrm{FR}$

$\mathrm{BETA}=1 /(\mathrm{OMEGA} * \mathrm{QM})$

I Meio fluídico: Agua

80 UIMP, 4 , DENS, , ,998,

UIMP , 4, MU, , , 1.0 ,

UIMP , 4 , SONC, , , 1500 ,

85

! PARÂMETROS DA SIMULAÇÃO

\begin{tabular}{llll}
\hline \hline tensao & $=38.5$ & & ! Voltagem aplicada nos PZTs \\
Lmetal & $=0.040$ & & ! Comprimento do metal \\
Lpzt & $=0.035$ & & ! Comprimento do PZT \\
Lfix & $=0.004$ & & ! Comprimento do engaste \\
Hmetal & $=0.0002$ & & ! Espessura do metal \\
Hpzt & $=0.0002$ & & ! Espessura do PZT \\
Hcanal & $=0.004$ & & ! Altura do canal \\
Lentrada & $=0.010$ & & ! Comprimento da entrada do canal \\
Lsaida & $=0.010$ & & ! Comprimento da saida do canal \\
Hengast & $=0.002$ & & ! Altura do engaste \\
Lengast & $=0.010$ & & ! Comprimento do engaste \\
elemento $=0.00005$ & & ! Dimensão do elemento \\
flstr & elemento & & ! Espessura do fluido com estrutura
\end{tabular}

Geometria

BLC4,-Lfix,-Hmetal / 2, Lfix , Hmetal

BLC4,0,-Hmetal /2, Lmetal-Lpzt-Lfix , Hmetal

BLC4, Lmetal-Lpzt-Lfix,-Hmetal/2, Lpzt, Hmetal

BLC4, Lmetal-Lpzt-Lfix,-Hpzt-Hmetal/2, Lpzt, Hpzt

BLC4, Lmetal-Lpzt-Lfix, Hmetal/2, Lpzt, Hpzt

110

BLC4, - Lengast , - Hengast / 2 , Lengast , Hengast

$\mathrm{BLC} 4,-$ Lengast $-\mathrm{F}$ lstr, - Hengast $/ 2-\mathrm{F}$ lstr, Lengast $+2 * \mathrm{~F} 1 \mathrm{str}$, Hengast $+2 * \mathrm{~F}$ lst

BLC4, 0,-Hmetal/2-Flstr, Lmetal-Lpzt-Lfix, Hmetal+2*Flstr

BLC4, Lmetal-Lpzt-Lfix-Flstr, -Hmetal $/ 2-\mathrm{Hpzt}-\mathrm{Flstr}, \mathrm{Lpzt}+2 * \mathrm{Flstr}, \mathrm{Hmetal}+2 * \mathrm{Hpzt}+2 * \mathrm{Flstr}$

115

BLC4, - Lengast -Lentrada, - Hcanal $/ 2$, Lentrada+Lengast+Lmetal-Lfix +Lsaida, Hcanal

BLC4, - Lengast - Lentrada,- Hcanal $/ 2+\mathrm{F} 1$ str , Lentrada + Lengast + Lmetal - Lfix + Lsaida, Hcanal $-2 *$ F 1 str

ASBA, 10,11, , DELETE , KEEP

120

AADD $, 7,8,9$

ASBA, 11,10 , ,DELETE, KEEP 
ASBA, 10,6

ASEL $, \mathrm{S},,, 1,5$

ASEL , A , , , 8

125 ASBA, 8, all, , DELETE, KEEP

ALLS

AGLUE, a 11

NUMCMP, a 11

130

! Atribuição dos elementos e materiais

ASEL, $\mathrm{S}$, , , 1 ! Propriedades do metal

135 ASEL, A, , , 4, 5

AATT $, 1,, 1$

ASEL, $, \quad,, 6,7$ Propriedades do PZT

AATT, $2,, 2$

140

ASEL $, \mathrm{S},,,, 2$

! Propriedades do Fluido com estrutura

ASEL , A , , , 8,9

AATT, $3,, 3$

14

ASEL , S , , , 3

AATT, $3,, 4$

ALLS

150

! GERAÇÃO DA MALHA

ESIZE, elemento

155 AMESH, a 11

! APLICAÇÃO DE FSI (Fluid-Solid Interface)

LSEL , S , , , 6,8

LSEL , A , , , 9

LSEL , A , , , 11,12

LSEL , A , , , $14,18,4$

165 LSEL, A, , $17,19,2$

LSEL , A , , , $20,24,4$

LSEL , A , , , 41,42

NSLL, S , 1

SFL, all, FSI

170

alls

! DEFINIÇÃO DE IMPEDÂNCIA UNITÁRIA NOS CONTORNOS DO MODELO

175

LSEL , S , , , 6,8

LSEL , A , , , 9

LSEL , A, , , 11,12

LSEL, A , , $14,18,4$

180 LSEL, A, , , $17,19,2$

LSEL , A , , , $20,24,4$

LSEL, A, , , $25,27,2$

LSEL , A , , , $30,32,2$

LSEL , A , , , 41,42

185 NSLL, S , 1

SFL , ALL , IMPD , 1

ALLS

190

! ACOPLAMENTO DOS NÓS DAS SUPERFÍCIES DOS PZTs 


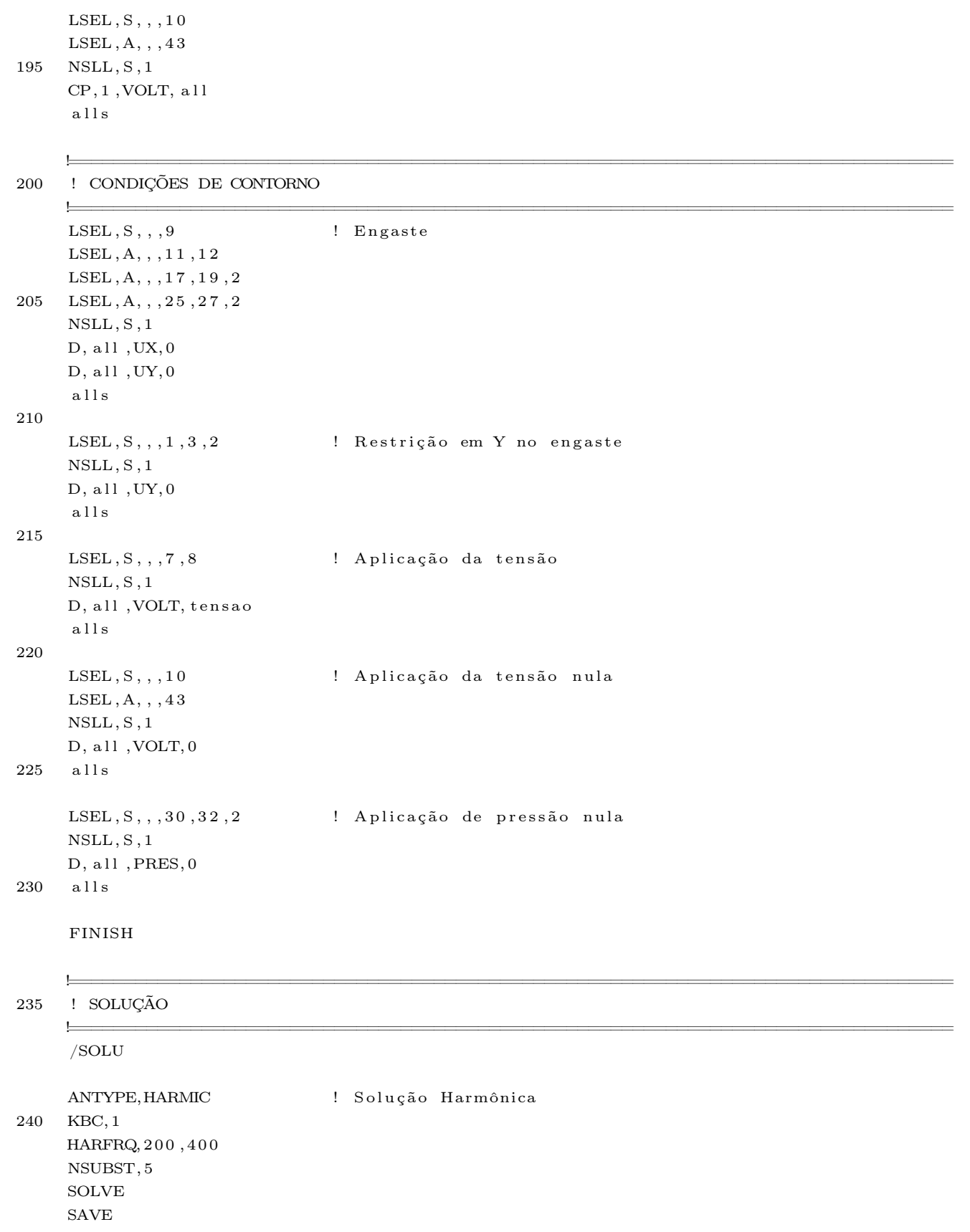

\section{A.2 Simulação acústica de dois atuadores em paralelo}

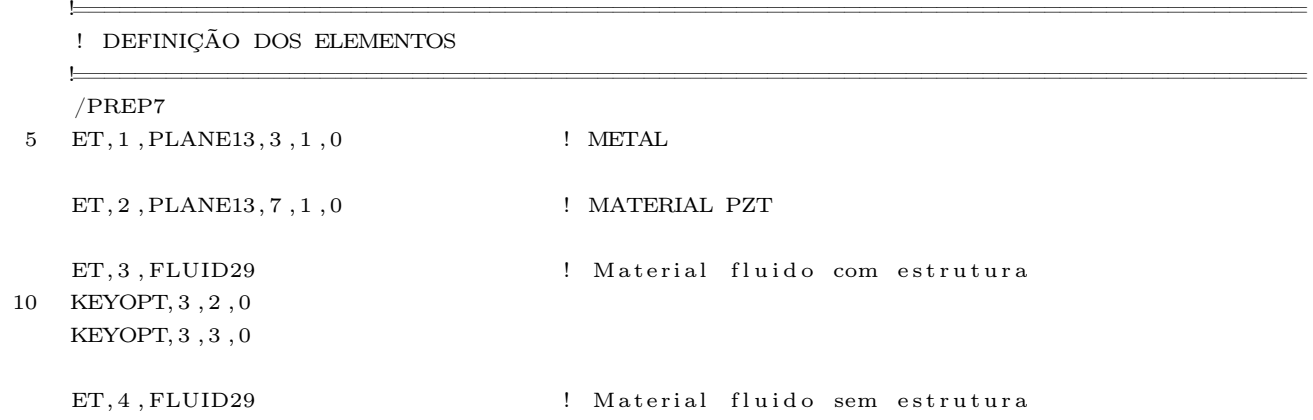


KEYOPT, $4,2,1$

15 KEYOPT, $4,3,0$

0

! PROPRIEDADES DOS MATERIAIS

! Cobre - Material 1

UIMP , 1, EX, , , 11 e10 ,

25 UIMP, 1 , DENS, , ,8970,

UIMP , 1 , PRXY, , , 0.34 ,

! PZT-5A grupo de simetria $6 \mathrm{~mm}$

30

! Piezo constants

!---ー-ー-ー

e $33=15.8$

35 e $15=12.3$

TB, PIEZ , 2

TBDATA, 1, 0, e 31,0

TBDATA, 4,0, e 33,0

TBDATA, 7,0 , е 31,0

40 TBDATA, $10, \mathrm{e} 15,0,0$

TBDATA, $13,0,0$, e 15

\begin{tabular}{|c|c|c|c|c|c|c|c|}
\hline !* & $\mathrm{PZT}-$ & $-5 \mathrm{~A}-$ & class & e de & simetria & $6 \mathrm{~mm}$ & \\
\hline$! *$ & 10 & -5.4 & 0 & I & | 0 & e 31 & 0 \\
\hline$! *$ & | 0 & 15.8 & 0 & I & | 0 & e 33 & 0 \\
\hline !* & 10 & -5.4 & 0 & I & | 0 & e 31 & 0 \\
\hline !* & | 12.3 & 0 & 0 & $=$ & | e 15 & 0 & 0 \\
\hline & 10 & 0 & 12.3 & I & | 0 & 0 & e 15 \\
\hline & | 0 & 0 & 0 & I & | 0 & 0 & 0 \\
\hline
\end{tabular}

! Elastic constants at E cst

!-- $11=12 .------10$

c $12=7.54 \mathrm{E} 10$

$\mathrm{c} 13=7.52 \mathrm{E} 10$

$\mathrm{c} 33=11.1 \mathrm{E} 10$

$\mathrm{c} 44=2.11 \mathrm{E} 10$

$50 \quad \mathrm{c} 66=.5 *(\mathrm{c} 11-\mathrm{c} 12)$

TB, ANEL, $2 \quad$ * PZT $-5 \mathrm{~A}-\mathrm{classe}$ de simetria $6 \mathrm{~mm}\left(* 10^{-10}\right)$

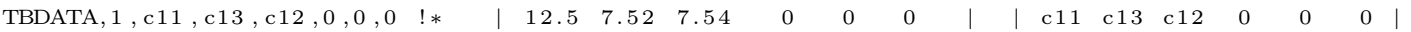

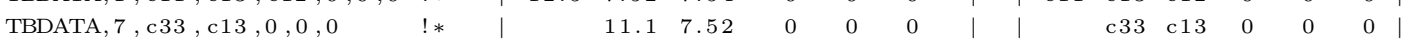

TBDATA, $12, \mathrm{c} 11,0,0,0$

TBDATA, $16, \mathrm{c} 44,0,0$

TBDATA, $19, \mathrm{c} 44,0$

\begin{tabular}{lllll|}
12.5 & 0 & 0 & 0 & $\mid$
\end{tabular}

$\begin{array}{llll}2.11 & 0 & 0 & \mid=1\end{array}$

TBDATA, 21, с 66

$2.1100 \quad|\quad|$

$\begin{array}{llll}\mathrm{c} 11 & 0 & 0 & 0\end{array}$

c $44 \quad 0 \quad 0 \quad$

c44 0

! Constantes dieletricas a strain (S) constante

60

$\mathrm{e} 00=8.85 \mathrm{E}-12$

eps $1=916 * 8.85 \mathrm{E}-12$

eps $3=830 * 8.85 \mathrm{E}-12$

MP, PERX, 2 , eps 1

$65 \mathrm{MP}, \mathrm{PERY}, 2$, eps 3

MP, PERZ, 2 , eps 1

!* PZT-5A - classe de simetria 6mm (*10^-9)

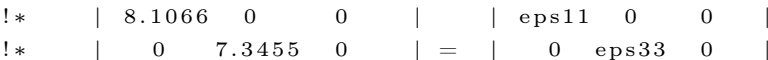

\begin{tabular}{l|lll|l|lll|}
$*$ & 0 & 0 & 8.1066 & 0 & 0 & $\operatorname{eps} 11$
\end{tabular}

! Densidade e amortecimento

MP, DENS, 2,7650

$\mathrm{QM}=75$

$\mathrm{FR}=47000$

OMEGA $=2 * 3.1416 * \mathrm{FR}$

$\mathrm{BETA}=1 /(\mathrm{OMEGA} * \mathrm{QM})$

! Meio fluídico: Agua

UIMP , 4 , DENS, , , 4000 ,

80 UIMP, $4, \quad \mathrm{MU}, \quad, \quad, 1.0$,

UIMP , 4 , SONC, , , 1500 , 
PARÂMETROS DA SIMULAÇÃO

\begin{tabular}{llll}
\hline \hline tensao & $=30$ & & ! Voltagem aplicada nos PZTs \\
Lmetal & $=0.040$ & & ! Comprimento do metal \\
Lpzt & $=0.035$ & & ! Comprimento do PZT \\
Lfix & $=0.004$ & & ! Comprimento do engaste \\
Hmetal & $=0.0002$ & & ! Espessura do metal \\
Hpzt & $=0.0002$ & & ! Espessura do PZT \\
Hcanal & $=0.015$ & & ! Altura do canal \\
Hgap & $=0.002$ & & ! Distancia entre os atuadores \\
Lentrada & $=0.005$ & & ! Comprimento da entrada do canal \\
Lsaida & $=0.010$ & & ! Comprimento da saida do canal \\
Hengast & $=0.002$ & & ! Altura do engaste \\
Lengast & $=0.010$ & & ! Comprimento do engaste \\
elemento & $=0.0002$ & & ! Dimensão do elemento \\
flstr & $=0.0002$ & & ! Espessura do fluido com estrutura \\
Hentrada & $=$ Hcanal $-2 *$ Hengast-Hgap) $/ 2$
\end{tabular}

! Geometria

105

BLC4, 0, Hentrada + Hengast $/ 2-$ Hmetal $/ 2$, Lmetal-Lfix , Hmetal

BLC4, Lmetal-Lpzt-Lfix, Hentrada+Hengast/2-Hmetal/2-Hpzt, Lpzt, Hpzt

BLC4, Lmetal-Lpzt-Lfix, Hentrada+Hengast $/ 2+$ Hmetal $/ 2$, Lpzt, Hpzt

110 BLC4, - Lengast $-\mathrm{flstr}$, Hentrada $-\mathrm{flstr}$, Lengast $+2 * \mathrm{flstr}$, Hengast $+2 * \mathrm{flstr}$ BLC4, 0 , Hentrada+Hengast $/ 2-\mathrm{Hmetal} / 2-\mathrm{flstr}$, Lmetal-Lpzt-Lfix, Hmetal $+2 * \mathrm{fl} \mathrm{st} \mathrm{r}$ BLC4, Lmetal-Lpzt-Lfix-flstr, Hentrada+Hengast $/ 2-\mathrm{Hmetal} / 2-\mathrm{Hpzt}-\mathrm{flstr}, \mathrm{Lpzt}+2 * \mathrm{flstr}, \mathrm{Hmetal}+2 * \mathrm{Hpzt}+2 * \mathrm{flstr}$ BLC4,-Lengast, Hentrada, Lengast, Hengast

115 AADD, $4,5,6$

ASBA, 8 , all, , delete, keep

ADELE, 7

AGLUE, a 11

NUMCMP, a 11

120

BLC4, 0, Hentrada + Hgap + Hengast + Hengast $/ 2-$ Hmetal $/ 2$, Lmetal - Lfix, Hmetal

BLC4, Lmetal-Lpzt-Lfix, Hentrada+Hgap+Hengast+Hengast $/ 2-$ Hmetal $/ 2-$ Hpzt, Lpzt, Hpzt

BLC4, Lmetal-Lpzt-Lfix, Hentrada+Hgap+Hengast+Hengast $/ 2+$ Hmetal $/ 2$, Lpzt , Hpzt

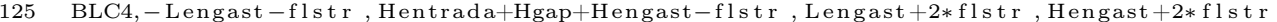
BLC4, 0, Hentrada + Hgap + Hengast + Hengast $/ 2-$ Hmetal $/ 2-\mathrm{flstr}$, Lmetal $-\mathrm{Lpzt}-\mathrm{Lfix}, \mathrm{Hmetal}+2 * \mathrm{flstr}$ BLC4, Lmetal-Lpzt-Lfix $-\mathrm{flstr}$, Hentrada + Hgap + Hengast + Hengast $/ 2-$ Hmetal $/ 2-\mathrm{Hpzt}-\mathrm{flstr}, \mathrm{Lpzt}+2 * \mathrm{flstr}, \mathrm{Hmetal}+2 * \mathrm{Hpzt}+2 * \mathrm{flstr}$ BLC4, - Lengast , Hentrada + Hgap + Hengast, Lengast , Hengast

130 AADD, $8,9,10$

ASBA, 12 , all, , delete, keep

ADELE, 11

AGLUE, a 11

NUMCMP, a 11

135

BLC4, - Lengast -Lentrada, flstr , Lentrada+Lengast + Lmetal - Lfix + Lsaida, Hcanal $-2 * f 1 s t r$ ASBA, 9 , a 11 , , DELETE, KEEP

ADELE, 10,11

BLC4, - Lengast -Lentrada , 0, Lentrada + Lengast + Lmetal - L fix + Lsaida, flstr

140 BLC4, - Lengast-Lentrada, Hcanal-flstr, Lentrada+Lengast + Lmetal - Lfix + Lsaida, flstr AGLUE, a 11

NUMCMP, a 11

LDELE, $20,50,30$

145

! Atribuição dos elementos e materiai

ASEL $, \mathrm{S}, \mathrm{,}, 4,8,4 \quad$ ! Propriedades do metal

AATT, $1,, 1$

150

ASEL $, \mathrm{S},,, 2,3$

ASEL, A , , , 6,7

AATT, $2,, 2$

a $11 \mathrm{~s}$ 
ASEL , S , , , 1, 5,4

! Propriedades do Fluido com estrutura

ASEL , A , , , 9,10

AATT, $3,, 3$

ASEL , S , , , 11

! Propriedades do Fluido sem estrutura

AATT, $3,, 4$

ALLS

GERAÇÃO DA MALHA

LSEL, S , LOC, Y, $2 * \mathrm{flstr}$, Hcanal $-2 * \mathrm{flstr}$

LSEL , R, LOC, X, - Lengast $-2 * \mathrm{f} 1 \mathrm{st} \mathrm{r}$, Lmetal

170 LESIZE, all, elemento, , , 1

ALLS

LSEL, U, LOC, Y, $2 * \mathrm{fl}$ s t r , Hcanal $-2 * \mathrm{fl}$ str

LSEL, A, LOC, X, $-1,-$ Lengast $-2 * \mathrm{fl} \mathrm{s} \mathrm{t} \mathrm{r}$

175 LSEL, A, LOC, X, Lmetal, 1

LESIZE, all, elemento, , , , 1

ALLS

AMESH, a 11

! APLICAÇÃO DE FSI (Fluid-Solid Interface)

185 LSEL, S , , , 1

LSEL , A , , , 3,6

LSEL , A , , , 8

LSEL , A , , , 11,14

LSEL , A, , , 18,19

190 LSEL, A, , , 21,22

NSLL,, 1

SFL, all, FSI

a $11 \mathrm{~s}$

195 LSEL, S , , , 31

LSEL , A , , , 33,36

LSEL, A, , , 38

LSEL , A , , , 41,44

LSEL , A, , , 48,49

200 LSEL, A, , , 51,52

NSLL, $S, 1$

SFL, all, FSI

a $11 \mathrm{~s}$

205

! DEFINIÇÃO DE IMPEDÂNCIA UNITÁRIA NOS CONTORNOS DO MODELO

! (impede que a onda reflita)

210 LSEL, S , , , 61,62

LSEL, A, , , 64

LSEL , A , , , 66,70

NSLL ,, 1

SFL , ALL , IMPD , 1

215 ALLS

! ACOPLAMENTO DOS NÓS DAS SUPERFÍCIES DOS PZTs

220 LSEL, S , , , 29, 30

NSLL , S , 1

$\mathrm{CP}, 1, \mathrm{VOLT}$, a 11

a $11 \mathrm{~s}$

LSEL , S , , , 59,60

NSLL , S , 1 
CP, 1 , VOLT, a 11

alls

230

! CONDIÇÕES DE CONTORNO

LSEL , S , , 2, 11,9 ! Engaste

LSEL, A, , , 18,22

235 LSEL, A, , , 32, 41,9

LSEL , A , , , 48,52

LSEL , A , , , $61,67,6$

NSLL , S , 1

$\mathrm{D}$, all , UX, 0

240 D, all, UY, 0

a $11 \mathrm{~s}$

LSEL , S , , , $3,5,2$

NSLL , S , 1

245 D, all, VOLT, tensao

a $11 \mathrm{~s}$

LSEL , S , , , $33,35,2$

NSLL ,, 1

250 D, all, VOLT, - tensao

a $11 \mathrm{~s}$

LSEL , S , , , 29,30

! Aplicação da tensão nula

255 NSLL, S , 1

D, all , VOLT, 0

a $11 \mathrm{~s}$

LSEL , S , , , $62,70,2$

! Aplicação da tensão

60 LSEL , A, , , 69

NSLL,, , 1

D, all, PRES, 0

a $11 \mathrm{~s}$

265

FINISH

! SOLUÇÃO

/SOLU

ANTYPE, HARMIC

$\mathrm{KBC}, 1$

275 HARFRQ, 200,400

NSUBST, 40

SOLVE

SAVE

\title{
A.3 Simulação acústica de dois atuadores em série
}

\author{
! DEFINIÇÃO DOS ELEMENTOS \\ /PREP7 \\ 5 ET, 1, PLANE13, $3,1,0$ \\ ! METAL \\ ET, 2 , PLANE13, $7,1,0$ \\ ! MATERIAL PZT \\ ET, 3 , FLUID29 \\ ! Material fluido com estrutura \\ 10 KEYOPT, $3,2,0$ \\ KEYOPT, 3,3 , 0 \\ ET, 4, FLUID29 \\ ! Material fluido sem estrutura
}


KEYOPT, 4 , 2 , 1

KEYOPT, 4,3 , 0

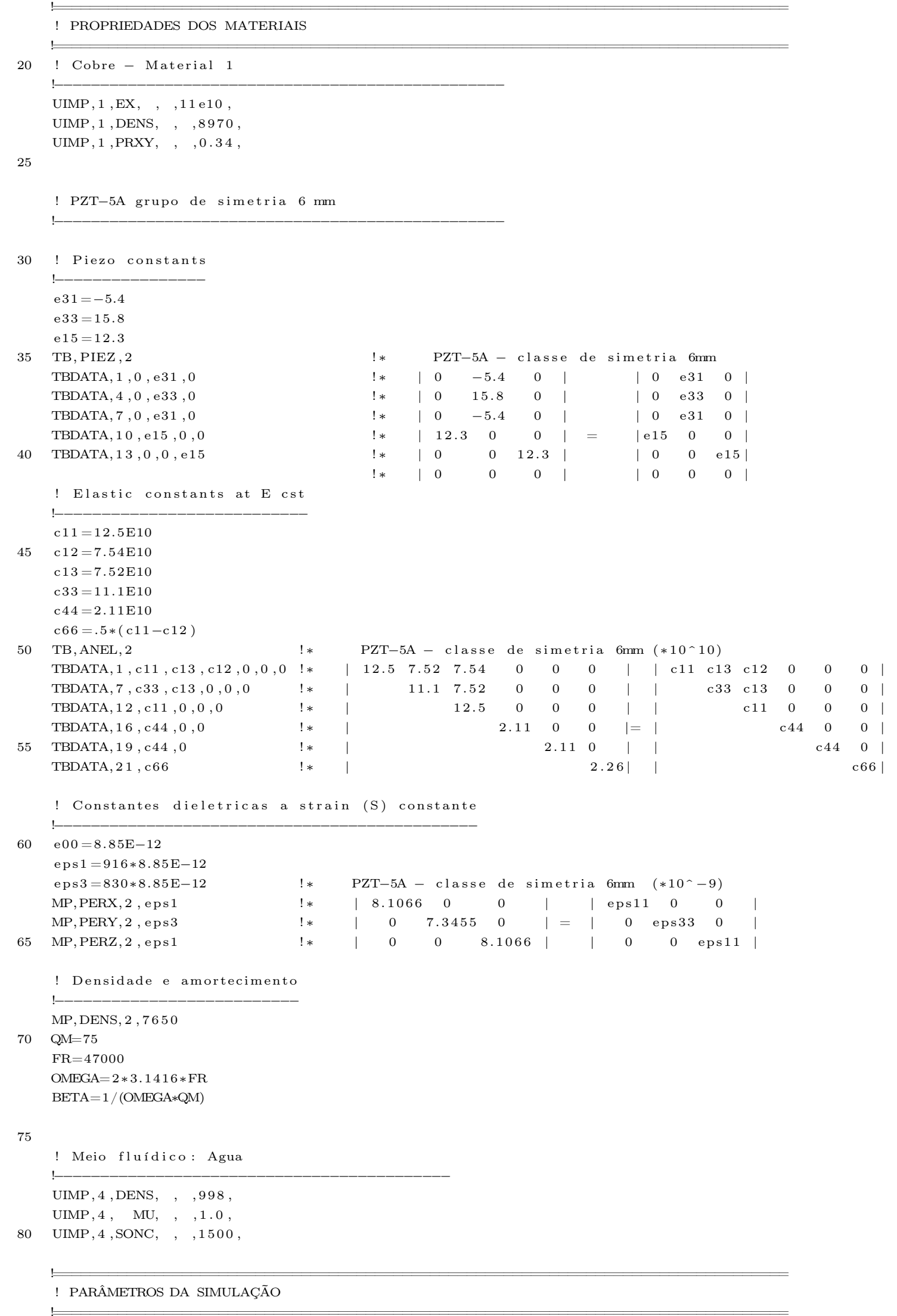




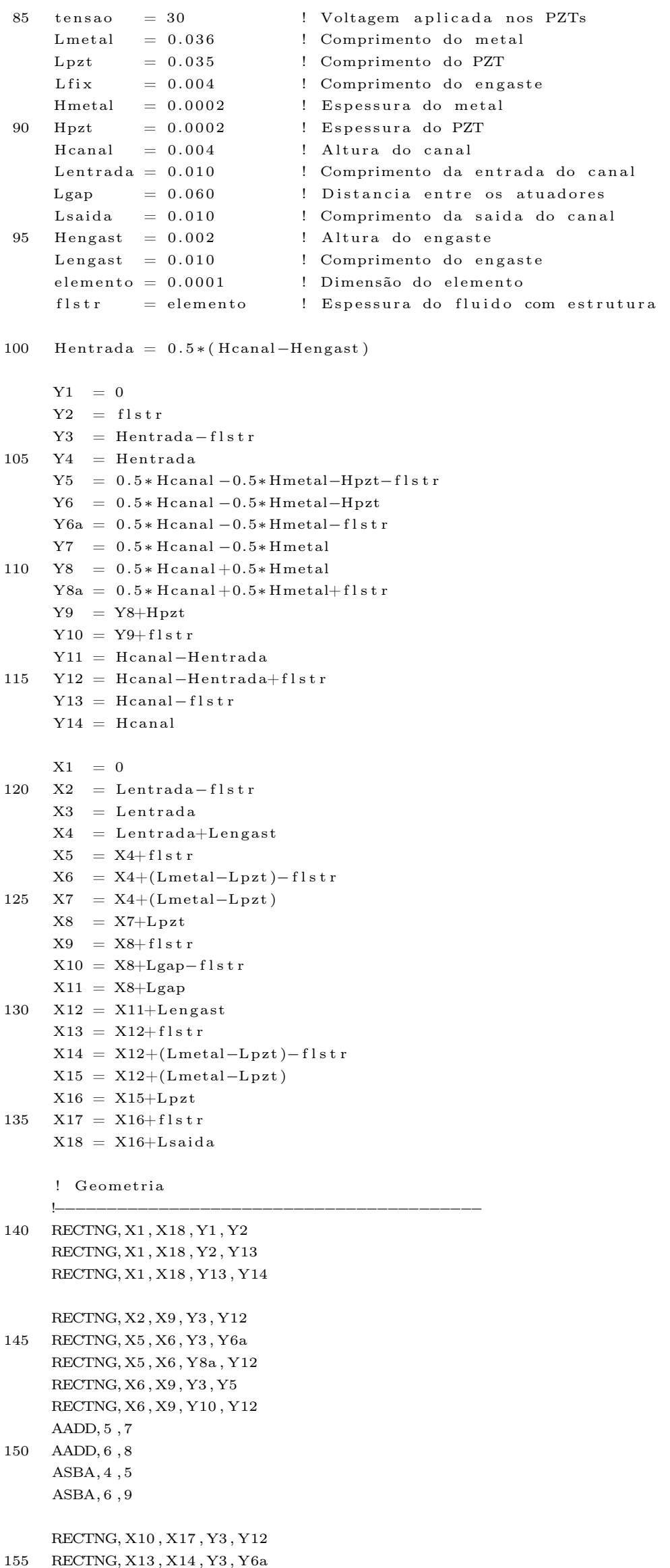


RECTNG, X13, X14, Y8a, Y12

RECTNG, X14, X17, Y3, Y5

RECTNG, X14, X17, Y10, Y12

$\mathrm{AADD}, 6,8$

160 AADD, 7,9

ASBA, 5,6

ASBA, 7,10

ASBA , $2,4,,$, KEEP

ASBA, 6,5, , , KEEP

RECTNG, X3 , X4 , Y4, Y11

RECTNG, X4, X8, Y7, Y8

RECTNG, X7, X8, Y6, Y7

170 RECTNG, X7, X8, Y8, Y9

ASBA, 4,6

ASBA, 10,7, , , KEEP

ASBA, $4,8,,$, , KEEP

ASBA, 6,9 , , , KEEP

175 NUMCMP, a 11

RECTNG, X11, X12, Y4, Y11

RECTNG, X12, X16, Y7, Y8

RECTNG, X15, X16, Y6, Y7

180 RECTNG, X15, X16, Y8, Y9

ASBA, 5,9

ASBA, $13,10,$, , KEEP

ASBA , 5,11, , , KEEP

ASBA, 9,12, , , KEEP

185 NUMCMP, a 11

AGLUE, a 11

NUMCMP, a 11

190

! Atribuição dos elementos e materiais

ASEL , S , , , 9,10

! Propriedades do metal

AATT $, 1,, 1$

195

ASEL $, \mathrm{S},,, 5,8 \quad$ ! Propriedades do PZT

AATT, 2,2

a $11 \mathrm{~s}$

200 ASEL, S , , , 1,4

AATT $, 3,, 3$

ASEL $, S,,, 11$

AATT $, 4,, 4$

205 ALLS

! GERAÇÃO DA MALHA

210

ESIZE, elemento

AMESH, a 11

215

! ACOPLAMENTO DOS NÓS DAS SUPERFÍCIES DOS PZTs

LSEL , S , , , 63,64

NSLL , S , 1

$220 \mathrm{CP}, 1, \mathrm{VOLT}$, a 11

a $11 \mathrm{~s}$

LSEL , S , , , 65,66

NSLL , S , 1

225

CP, 2 , VOLT, a 11

a $11 \mathrm{~s}$ 
230

! CONDIÇÕES DE CONTORNO

LSEL , S , , , ! Engaste

LSEL , A , , , 35

LSEL , A , , , 41,42

LSEL, A , , , $27,29,2$

235 LSEL, A, , , 1, 6, 5

LSEL, A , , , 46

LSEL , A , , , 48,49

LSEL , A , , , 51

LSEL , A , , , 56,57

240 NSLL, S , 1

$\mathrm{D}$, a $11, \mathrm{UX}, 0$

$\mathrm{D}$, all, UY, 0

a $11 \mathrm{~s}$

245 LSEL, S , , , 36, 39,3

! Aplicação da tensão

LSEL , A , , , $52,54,2$

NSLL , S , 1

D, all, VOLT, tensao

a $11 \mathrm{~s}$

250

LSEL , S , , , 63,66

NSLL, S , 1

D, all, VOLT, 0

a $11 \mathrm{~s}$

255

LSEL $, \mathrm{S},,, 2,4,2 \quad$ ! Aplicação de pressão nula

LSEL, A, , , 61,62

LSEL , A, , , 67,68

NSLL , S , 1

260 D, all, PRES, 0

alls

FINISH

265

! SOLUÇÃO

/SOLU

270 ANTYPE, HARMIC

KBC, 1

HARFRQ, 200,400

NSUBST, 40

SOLVE

275 SAVE 